Maurer School of Law: Indiana University

Digital Repository@Maurer Law

Indiana Law Journal

Volume 97 | Issue 1

Article 6

Winter 2022

\title{
Delusions, Moral Incapacity, and the Case for Moral Wrongfulness
}

Lea Johnston

University of Florida Levin College of Law, johnstonl@law.ufl.edu

Follow this and additional works at: https://www.repository.law.indiana.edu/ilj

Part of the Courts Commons, Health Law and Policy Commons, and the Legal Ethics and Professional Responsibility Commons

\section{Recommended Citation}

Johnston, Lea (2022) "Delusions, Moral Incapacity, and the Case for Moral Wrongfulness," Indiana Law Journal: Vol. 97 : Iss. 1 , Article 6.

Available at: https://www.repository.law.indiana.edu/ilj/vol97/iss1/6

This Article is brought to you for free and open access by the Maurer Law Journals at Digital Repository @ Maurer Law. It has been accepted for inclusion in Indiana Law Journal by an authorized editor of Digital Repository @ Maurer Law. For more information, please contact rvaughan@indiana.edu.

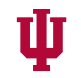

JEROME HALL LAW LIBRARY

INDIANA UNIVERSITY

Maurer School of Law
Bloomington 


\title{
Delusions, Moral Incapacity, and the Case for Moral Wrongfulness
}

\author{
E. LEA JOHNSTON*
}

\begin{abstract}
Responsibility is a legal-not medical-construct. However, science can be useful in exposing faulty assumptions underlying current doctrine or practice, illuminating changes in practice or evidentiary standards to better effectuate the law's animating purpose, and even suggesting updates to legal standards to account for modern understandings of functionalities of concern. This Article uses the science of delusions to assess the law regarding, and practice of establishing, criminal irresponsibility for defendants with psychosis. Over the last two decades, researchers from the cognitive sciences have compiled strong evidence that a host of cognitive and emotional impairments contribute to the origin and maintenance of delusions by impairing decision-making. This Article uses insights from those literatures to make three contributions. First, it analyzes current insanity standards and demonstrates their intimate relationship with rationality. It then argues that courts should consider evidence of any significant reasoning impairment, whether cognitive or emotional, as probative to sanity. Second, the Article explains how the reasoning impairments associated with delusions should bear upon assessments of a defendant's incapacity to know, or ignorance of, the wrongfulness of her criminal act. In assessing the latter, the Article argues that scientific research exposes as misguided the traditional rule expressed in M'Naghten's Case-which is currently followed to varying extents by nine jurisdictions - that a delusional defendant lacked knowledge of her act's wrongfulness only if her delusion, if true, would have justified or excused her act. Instead, the science exposes the strict legal wrongfulness standard as inappropriate for populations with delusions and suggests that courts should consider excusing defendants whose delusions cohere with the general thrust or gist of a legal defense.
\end{abstract}

* Professor of Law, University of Florida Research Foundation Professor, University of Florida Levin College of Law. J.D., Harvard Law School; A.B., Princeton University. I am grateful for the summer grant provided by the Levin College of Law. I appreciate the thoughtful feedback offered by Christopher Slobogin, Susan McMahon, Christina Gliser, Deborah Denno and her students at Fordham College of Law, and the anonymous reviewer of the New Criminal Law Review. I am also grateful for comments on an early draft by Jamelia Morgan, Eve Hanan, and Kathryn Miller. Finally, I thank Sara Bensley, Crystal Ellison, Lucas Goda, Mikaela Guido, Jonathon Haney, Elta Johnston, Vince Leahey, Joshua McCroskey, Jonathan Nickas, Lindsey O’Brien, Melissa Petersen, and Nadia Rossbach for their outstanding research assistance. 


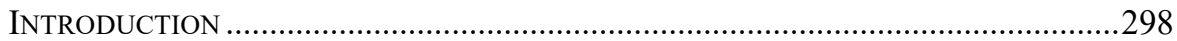

I. MODERN INSANITY STANDARDS AND THEIR ORIGINS ...........................................305

B. MEANING OF “APPRECIATE” AND “KNOW” ................................................... 310

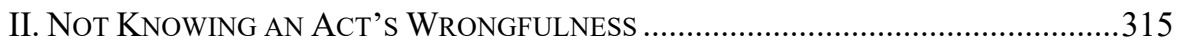

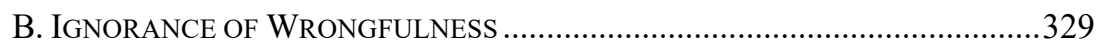

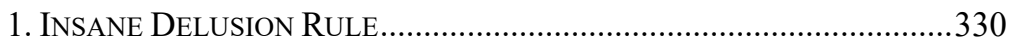

2. The Special Case of Persecutory Delusions .............................332

B. ANGER AND EMOTION REGULATION IMPAIRMENT ............................338

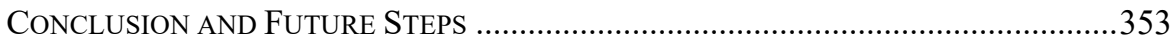

APPENDIX: INSANITY STANDARDS IN THE UNITED STATES .....................................357

\section{INTRODUCTION}

Frank Rowl, age thirty-seven, moved to the basement of his parents' home upon release from his third civil commitment. ${ }^{1}$ Over the past five years, his schizophrenia has been characterized by paranoid delusions involving an attempt by the John Birch Society to take his life. Once home, Rowl began to suspect his parents were part of the plot. Rowl refused to take vitamins supplied by his mother for fear they contained poison, and he believed his parents spied on him with electronic devices.

One evening, when Rowl decided to go for a walk, he opened his closet door and discovered his shotgun was missing. Rowl suspected his father had taken his gun, as he had two other guns before Rowl's latest civil commitment. Rowl believed his father's act was a deliberate attempt to render him defenseless against those plotting to take his life. While rushing up the stairs to confront his father, Rowl overheard his father state over the telephone, "He will have to be stopped." (His father, a professor, was discussing a campus event with a colleague.) Rowl mistakenly believed this statement referred to him. When he reached the top of the stairway, Rowl stepped into the kitchen, grabbed a butcher knife, and plunged it into his father's back, causing injuries that resulted in death the following day. Rowl was charged with intentional murder and entered a plea of not guilty by reason of insanity.

The facts above would not support an insanity acquittal in some jurisdictions. ${ }^{2}$ Factoring the reasoning impairments associated with Rowl's delusions into the test for insanity, however, may justify a finding of irresponsibility. In some jurisdictions, this would require departing from current practice, which subjects the content of delusions to a strict legal wrongfulness standard.

Depending on the jurisdiction, to qualify for insanity, Rowl must prove that, ${ }^{3}$ because of a mental disease or defect, he lacked a substantial capacity to "appreciate," was unable to "know," or was ignorant of the wrongfulness of killing

1. These facts are closely modeled on those in State v. Rawland, 199 N.W.2d 774, 77677 (Minn. 1972).

2. See infra Part III.B.1; E. Lea Johnston \& Vincent T. Leahey, The Status and Legitimacy of M'Naghten's Insane Delusion Rule, 54 U.C. DAVIS L. Rev. 1777, 1795-98, 1813-19 (2021).

3. Most jurisdictions place the burden of proof upon the defendant. 1 WAYNE R. LaFave, Substantive Criminal LaW $\S 8.3$ (a) (3d ed. 2018). 
his father at the time of the stabbing ("moral incapacity"). ${ }^{4}$ This Article considers how Rowl's delusions of a murderous plot may factor into his insanity defense under the various moral incapacity tests currently employed in the United States. It also gleans insights from behavioral and brain research to address the normative question of how Rowl's delusions should factor into his sanity evaluation and ultimate defense. In so doing, this Article joins the call for a broader conception of insanity, argues for a new understanding and expanded use of delusions in insanity cases, and urges the adoption of a broader standard of wrongfulness for delusional defendants.

A substantial minority of insanity pleas involve psychosis. ${ }^{5}$ Thus, updating the law's understanding of delusions could affect the dispositions of a significant percentage of those pleading the defense. ${ }^{6}$ Moreover, since courtroom actors and the public tend to equate insanity with psychosis, ${ }^{7}$ expanding the accepted relevance of cognitive and emotional impairments in psychosis holds the potential of shifting the law toward a broader, more scientifically defensible model of culpability. ${ }^{8}$

4. See infra Part II.A (analyzing current insanity standards); Appendix (presenting key portions of the insanity standards used in the United States). This Article focuses on the moral incapacity prongs of jurisdictions' standards. Most insanity cases turn on moral incapacity. Robert Lloyd Goldstein, The Psychiatrist's Guide to Right and Wrong: Part III: Postpartum Depression and the "Appreciation" of Wrongfulness, 17 Bull. AM. ACAD. PSYCHIATRY \& L. 121, 121 (1989) ("In cognitive tests, a determination of insanity almost never deals with the first prong of the legal test (i.e., whether the defendant knew or appreciated the 'nature and quality' of his act), but decisively turns on the second prong (i.e., whether he knew or appreciated that what he was doing was wrong)."); Richard Rogers, An Introduction to Insanity Evaluations, in Learning Forensic Assessment: Research and PRACTICE 97, 99 (Rebecca Jackson \& Ronald Roesch eds. 2015). The Article, therefore, does not allocate significant attention to cognitive incapacity (an inability to know the nature or quality of the criminal act), see infra note 80 , or volitional incapacity (an inability to conform one's conduct to the requirements of law), see infra note 81 .

5. See Lisa A. Callahan, Henry J. Steadman, Margaret A. McGreevy \& Pamela Clark Robbins, The Volume and Characteristics of Insanity Defense Pleas: An Eight-State Study, 19 Bull. Am. ACAD. Psychiatry \& L. 331, 336 tbl.2 (1991) (examining 8979 insanity pleas in eight states and finding that $43 \%$ of insanity pleas $(2869 / 8979)$ and $67.9 \%$ of insanity acquittals (1592/2565) involved diagnosis of schizophrenia). According to Gary Melton and colleagues, "virtually all studies of the subject indicate that the majority (60-90\%) of defendants acquitted by reason of insanity are diagnosed as psychotic." GARY B. MELTON, John Petrila, Norman G. Poythress, Christopher Slobogin, Randy K. Otto, Douglas Mossman \& Lois O. Condie, Psychological Evaluations for the Courts: A Handbook FOr Mental Health Professionals and Lawyers $§ 8.02$, at 206 (4th ed. 2018). "Psychosis" is not a specific mental disorder but rather is a constellation of symptoms including hallucinations, delusions, and illogical thinking. This term is often used as a synonym for “"madness' and 'craziness." Michael S. Moore, The Quest for a Responsible Responsibility Test: Norwegian Insanity Law After Breivik, 9 CRIM. L. \& PHIL. 645, 685 (2015). 249.

6. Persecutory delusions are particularly common in insanity cases. See infra notes 245

7. Abraham S. Goldstein, The Insanity Defense 59 (1967); Moore, supra note 5, at 685.

8. See Federica Coppola, The Emotional Brain and the Guilty Mind Ch. 5, Pt V. (2021). 
Appreciating the significance of the aims of this Article requires understanding how insanity cases are litigated, how delusions currently factor into sanity assessments, and why the role of delusions may be limited. In a typical case, before raising an insanity defense, the defendant will be evaluated by a forensic psychiatrist. ${ }^{9}$ If the forensic opinion supports an insanity verdict, which is rare, ${ }^{10}$ the defense attorney will file a notice to plead the defense. ${ }^{11}$ At that point, the state will have the opportunity to examine the defendant with a forensic examiner. ${ }^{12}$ The vast majority of insanity acquittals are reached through plea agreement. ${ }^{13}$ However, if sanity is contested, the defendant may proceed to trial. Expert mental health testimony will be crucial to each side's case. ${ }^{14}$ Studies suggest this testimony may be minimal and conclusory ${ }^{15}$ : after qualification, a defense attorney may simply ask the

9. Most states permit psychologists or other mental health professionals to serve this function. See GoldsteIn, supra note 7, at 133; FlA. R. CRIM. P. 3.216(d) (providing for a court-ordered examination by a "mental health expert").

10. See Melton et Al., supra note 5, at 200 (observing that forensic evaluators conclude the defendant is insane less than fifteen percent of the time).

11. See, e.g., Fed. R. Crim. P. 12.2; Ga. Unif. SuPer. Ct. R. 31.1

12. See, e.g., Fla. R. Crim. P. 3.216(d); Ga. Unif. Super. Ct. R. 31.5; Haw. Rev. Stat. $\S 704-404(2)(\mathrm{c})(2020)$.

13. Melton ET AL., supra note 5, at 200 (discussing research finding "in most jurisdictions well over $70 \%$ of . . insanity acquittals resulted from a plea-bargaining or quasiplea-bargaining arrangement rather than a full-fledged jury trial"); see Janet I. Warren, Lawrence Fitch, Park Elliott Dietz \& Barry D. Rosenfeld, Criminal Offense, Psychiatric Diagnosis, and Psycholegal Opinion: An Analysis of 894 Pretrial Referrals, 19 Bull. AM. ACAD. PSYCHIATRY \& L. 63, 67 (1991) ("It is widely acknowledged that evaluation reports supporting insanity routinely are used in plea bargaining and that, faced with the prospect of a contested insanity trial, prosecutors often prefer to reduce the charge or perhaps recommend a desirable treatment disposition in exchange for a plea of guilty.").

14. See infra notes 402-405.

15. "[Psychologist] testimony on direct examination will ordinarily be based on their written report . . . " Irving B. Weiner \& Allen K. Hess, The HandbooK of Forensic PsYCHOLOGY 639 (2006). Experts in the field largely agree on the way that evaluations should be conducted, including the types of information that should be considered in forming an opinion regarding the defendant's sanity. See Melton ET AL., supra note 5, at 240-49; IRA K. Packer, Evaluation Of Criminal ResPonsibility 95-126 (2009); Jeffrey S. Janofsky, Anne Hanson, Philip J. Candilis, Wade C. Myers \& Howard Zonana, AAPL Practice Guideline for Forensic Psychiatric Evaluation of Defendant's Raising the Insanity Defense, $42 \mathrm{~J}$. AM. ACAD. PSYCHIATRY \& L. S3, S21-S26 (2014). However, in practice, adherence to standards is often poor; other than the forensic interview of the defendant, forensic clinicians demonstrate a startling lack of uniformity in consulting other sources of information. See Janet I. Warren, Daniel C. Murrie, Preeti Chauhan, Park E. Dietz \& James Morris, Opinion Formation in Evaluating Sanity at the Time of the Offense: An Examination of 5175 Pretrial Evaluations, 22 Behav. Sci. \& L. 171, 181 tbl.3 (2004); Tess M.S. Neal, Discerning Bias in Forensic Psychological Reports in Insanity Cases, 36 BeHAV. ScI. \& L. 325, 332-33 (2018); PACKER, supra, at 61-63 (reviewing studies highlighting issues with adequacy of information). Studies demonstrate that failures to address psycholegal components of criminal responsibility or provide underlying rationale for opinions are not uncommon. See Kristen D. Fuger, Marvin W. Acklin, Annie H. Nguyen, Lawrie A. Ignacio \& W. Neil Gowensmith, Quality of Criminal Responsibility Reports Submitted to the Hawaii Judiciary, 37 InT'L J.L. \& PSYCHIATRY 272, 
expert for her conclusion on the defendant's sanity, which the expert may then supply without providing much of the underlying evidentiary basis. ${ }^{16}$ Training materials suggest (and experts urge) that much more context should be given: a testifying forensic expert should recount what methods she employed to evaluate the defendant and why, what data she reviewed and what they showed, her diagnosis of the defendant and its identifying characteristics, how those characteristics manifested in the defendant's thoughts and behavior around the time of the criminal act, and, if permitted, the jurisdiction's legal standard for insanity and the expert's opinion on the penultimate and ultimate issues. ${ }^{17}$ Indeed, some appellate opinions reflect this more robust approach. ${ }^{18}$

While the latter approach is certainly more useful to a jury than the former, both may suffer from a fundamental flaw: the discounting - or even overlooking - of evidence of certain reasoning impairments that may be crucial to responsibility assessment. Two phenomena account for this tendency in the context of crimes driven by delusions: (1) an unduly narrow understanding of the capacities relevant to a defendant's ability to "know" the wrongfulness of her criminal act, and (2) a tendency to treat the content of the delusion that allegedly drove a criminal act as dispositive of the holder's ability to "know" the act's wrongfulness.

First, evidence suggests that some defense attorneys ${ }^{19}$ and forensic experts uncritically accept that a defendant's ability to "know" a criminal act's wrongfulness

273 (2014); Thomas Grisso, Guidance for Improving Forensic Reports: A Review of Common Errors, 2 Open ACCESS J. Forensic PSYCH. 102, 104, 110, 112 (2010). Further, although studies suggest recent improvement in reporting, it is unclear whether testimony has been similarly improved. See Fuger et al., supra, at 273, 277. Differences in assessment methodology may contribute to the relatively low rates of agreement between examiners of a defendant's mental state at the time of the offense. See, e.g., id. at 276 (assessing a sample of fifty cases-yielding 150 examiner reports - between 2006-2010 and finding unanimous agreement between three examiners in only $46 \%$ of cases and agreement between two of three examiners in 52\% of cases); W. Neil Gowensmith, Daniel C. Murrie \& Marcus T. Boccaccini, How Reliable Are Forensic Evaluations of Legal Sanity?, 37 L. \& Hum. BeHAv. 98, 101 tbl.1 (2013) (considering a sample of 165 defendants, which included a total of 483 reports submitted by a total of thirty-six examiners and finding that only $55.1 \%$ of cases reached a unanimous agreement between three evaluators, while there was disagreement between evaluators (i.e., at least one evaluator finding sanity and another finding insanity) in $35.2 \%$ of cases).

16. See Goldstein, supra note 7 , at 94 .

17. See 41 Am. Jur. Proof of FACTS 2D 615, §§ 37-51 (June 2019 Update) (providing model direct examination and testimony of a psychiatrist); RICHARD ROGERS \& DANIEL W. Shuman, Fundamentals of Forensic Practice: Mental Health and Criminal Law 7380 (2005) (providing tips and different organizational structures for direct testimony).

18. See People v. Romero, 105 N.E.3d 1048, 1058-60, 1061-62 (Ill. App. Ct. 2018), cert. denied, 139 S. Ct. 1557 (2019); People v. Hardig, No. 3-15-0292, 2017 WL 4251486, at *24 (Ill. App. Ct. Sept. 22, 2017).

19. See Goldstein, supra note 7, at 63-64 (arguing that the narrow view of the M'Naghten standard results from its uncritical acceptance and presentation by counsel and forensic psychiatrists who have "allow[ed] an unwarranted assumption of what the rule 'must' mean to govern their conception of the defense"); Cal. State Bd. of Corr., Special Commissions on Insanity and CRiminal OfFenders First Report, First Report of the Special Study Commissions on Problems of Insanity Relating to Criminal Offenders 23 
is determined only by her cognitive abilities such as perception and understanding. ${ }^{20}$ This perceived scope of knowing wrongfulness - the key functionality in about half of existing insanity standards ${ }^{21}$ - conflicts with the origins of this term and with the current medical understanding of knowledge, which includes both the cognitive and affective components of decision-making. ${ }^{22}$ Under legal actors' cramped understanding, capacities requisite to moral decision-making, such as emotion regulation and appreciation of the interpersonal implications of a criminal act, are irrelevant to sanity determination and, therefore, presumably inadmissible at trial. Although "appreciate" - the term used in a slight majority of jurisdictions' insanity tests $^{23}$ - is typically recognized as permitting consideration of both cognitive and affective impairments, ${ }^{24}$ evidence suggests the narrow understanding of "know" may impact courtroom actors' conception of "appreciate" as well. ${ }^{25}$

Second, court opinions and forensic publications suggest that, when a defendant's criminal act stemmed from a delusion, insanity may turn on the specific content of that delusion, not the underlying disruption of reality testing indicated by its manifestation or the reasoning impairments integral to its creation and

(1962), available at $\mathrm{https} / /$ babel.hathitrust.org/cgi/pt?id=mdp.39015016186085\&view=1up \&seq=5 [https://perma.cc/RWA7-HT8M] (opining that "the ordinary jury," "many psychiatrists and many lawyers," and "perhaps many judges" erroneously assume the term "knowledge" only requires the defendant grasp an abstract proposition that the charged conduct is wrongful).

20. See, e.g., Randy Borum, Not Guilty by Reason of Insanity, in Evaluating COMPETENCIES: FORENSIC ASSESSMENTS AND InSTRUMENTS 193, 204 (2d ed. 2003) ("'Knowledge of criminality' of one's act seems to require only that one has stored in memory, and can retrieve, the fact that the act is prohibited by law."); Goldstein, supra note 4, at 122 ("The fact that a defendant may be "able to verbalize [mechanically] the right answer to a question' e.g., to respond that murder is wrong ... 'is often taken as conclusive evidence that he knew the nature and wrongfulness' of his conduct.”). However, other forensic professionals recognize that "know" may assume a broader meaning in insanity cases. See Michael P. Maloney, Standards for Legal Insanity, in A CLINICIAN's GUIDE TO FoRENSIC PsYCHOLOGICAL Assessment 16, 20 (1985); Richard Rogers \& DANiel W. SHuman, Conducting InSANity EVALUATIONS 67 (2d ed. 2000) ("Much controversy persists on whether the word know refers only to a cognitive or intellectual apprehension of the nature and quality of the act or its wrongfulness, or to a more encompassing affective understanding as well.") (emphasis in original).

21. See infra Part II.A; see infra notes $74,75,83$.

22. See infra Part II.A.1-2; GolDSTEIN, supra note 7, at 49-50; Goldstein, supra note 4, at 123; R. J. Gerber, Is the Insanity Test Insane?, 20 AM. J. JuRIs. 111, 120 \& n.43 (1975).

23. See infra Part II.A; see infra note 73.

24. See Goldstein, supra note 4 , at $123-24$.

25. See Janofsky et al., supra note 15, at S.3, S.31, S.38 \& tbl.1 (identifying jurisdictions' insanity standards as M'Naghten or ALI "variants" and asserting that, when a M'Naghten jurisdiction chooses to replace "know" with "appreciate," the latter may be interpreted as narrowly as the former); see also Federica Coppola, Motus Animi in Mente Insana: An Emotion-Oriented Paradigm of Legal Insanity Informed by the Neuroscience of Moral Judgments and Decision-Making, 109 J. CRIM. L. \& CRIMINOLOGY 1, 17 (2019) (discussing the "interpretive confusion" around the meaning of, and abilities to be considered under, the term "appreciate"). 
maintenance. ${ }^{26}$ The stated justification for telescoping delusional evidence in this way is a rule in M'Naghten's Case called the "insane delusion rule." ${ }^{27}$ This rule holds that if a delusional defendant believed she faced a situation that would have qualified her for a legal defense (such as self-defense) then the delusion demonstrates her ignorance of the wrongfulness of the act. ${ }^{28}$ However, if the delusional content would not provide a legal justification or excuse then the delusional defendant - without additional evidence of cognitive dysfunction — should be liable for the crime. ${ }^{29}$ The modern use of this rule contradicts the express limitations in M'Naghten: the rule applied only to individuals with "partial delusion only, [who are] not in other respects insane," 30 but today is applied to those with major mental illnesses carrying numerous significant impairments, such as schizophrenia. ${ }^{31}$

Cases such as Rowl's exemplify how the combination of a narrow, cognitive understanding of "knowledge" and an exclusion of the reasoning impairments associated with delusions may contribute to the conviction of a nonculpable defendant. Rowl apparently understood the nature and quality of his act: he knew he was stabbing a human being with a butcher knife and intended to inflict serious bodily injury, if not death. The more difficult determination is whether Rowl appreciated his action's wrongfulness. Merely focusing on the content of his delusions would lead to an affirmative answer: Rowl was motivated by paranoid delusions, but had the situation been as he believed his act would not have been justified in self-defense. The missing gun and ambiguous statement, if evaluated by a typical person without a serious mental disorder, would not have suggested that Rowl's father posed an imminent, deadly threat at the moment of the stabbing. Moreover, unless Rowl manifested evidence of formal thought disorder, forensic experts would likely find his cognitive abilities intact enough to support a sanity determination. On this basis, Rowl's defense attorney - perhaps with the assistance of a forensic evaluation - might deem Rowl a poor candidate for an insanity defense and urge him to plead guilty to a lesser charge or favorable sentencing recommendation. Or, if an insanity defense were pursued at trial, Rowl's defense

26. See Brandon A. Yakush \& Melinda Wolbransky, Insanity and the Definition of Wrongfulness in California, 13 J. Forensic PsYCH. PRAC. 355, 360, 366-67 (2013); Robert L. Goldstein, The Psychiatrist's Guide to Right and Wrong: Part II. A Systematic Analysis of Exculpatory Delusions, 17 BULL. AM. ACAD. PSYCHIATRY \& L. 61, 66-67 (1989) (representing that the law largely neglects the defective reasoning process underlying delusions and instead determines culpability assessments by "the specific content of . . . delusions and how it comports with [a legal justification or excuse]"); see infra notes 213-219, 235. But see MELTON ET AL., supra note 5, at 240 (asserting that, because "the governing legal doctrine is amorphous ... virtually any aspect of an individual's personality may assume legal relevance").

27. See Regina v. M'Naghten (M'Nahgten's Case), 8 Eng. Rep. 718, 10 Cl. \& Fin. 200, 211 (1843); see infra Part III.B.1.

28. M'Naghten's Case, $10 \mathrm{Cl}$. \& Fin. at 211; cf. Rogers \& ShUman, supra note 17, at 200-01 (discussing delusional beliefs that may justify a defendant's criminal conduct, including self-defense or defense of others, officially sanctioned duties, misconstrued exigencies that would qualify for the necessity defense, and command by a divine authority).

29. M'Naghten's Case, $10 \mathrm{Cl}$. \& Fin. at 211.

30. Id.

31. See infra note 233. 
attorney and expert witnesses may hamper its success by trying to fit the facts of Rowl's case into what they perceive as the strictures of the law. ${ }^{32}$

But these strategies could result in the conviction of a man undeserving of punishment. A growing body of empirical research in cognitive and social psychology as well as moral and social neuroscience suggests that acting within the throes of a delusion - when the delusion provides the primary reason for that act and particularly under conditions of stress - may itself indicate an inability to engage in sound moral decision-making. If this is the case, Rowl's conviction may be unjust.

This Article draws upon the history of the insanity defense and insights from the psychological, psychiatric, and neuroscientific literatures to argue for jettisoning rigid rules regarding delusional content and to propose a new way of assessing moral incapacity in cases involving delusion-driven crime. The Article consists of three Parts. Part I lays necessary legal groundwork. It examines existing affirmative insanity defenses, their moral incapacity components, and their relationship to the original M'Naghten standard. It highlights the "defect of reason" element in the M'Naghten standard - and the implicit continuation of this rationality element into modern incarnations of this test-which suggests the significance of reasoning impairments (whether cognitive, emotional, or otherwise) to sanity assessment.

Part II details the range of cognitive and emotional impairments associated with delusions and explores how these might contribute to a defendant's inability to know, or ignorance of, the wrongfulness of her criminal act. ${ }^{33}$ This examination demonstrates the incoherence and fundamental unfairness of the current treatment of delusions in moral incapacity assessments. This Part suggests three modifications of current doctrine. First, it argues that the constellation of reasoning impairments associated with delusions should factor into the assessment of a defendant's inability to know or appreciate wrongfulness. Second, it suggests that, when evaluating the moral significance of a delusional defendant's objectives, the defendant's cognitive and emotional impairments must factor into that assessment - not simply the warped content of her delusions. Third, and most controversially, the Article suggests recognizing a broader spectrum of potentially exculpatory delusional content. This would equate to freeing delusional defendants from a rigid legal wrong standard and moving to a standard recognizing the "gist" of perceived justifications and excuses. Case law suggests this standard may be more consistent with societal morality and notions of community justice, as well as more compatible with the scientific understanding of delusions. Finally, in the conclusion, the Article addresses the reforms needed in defense attitudes and practice to implement these proposals.

32. See ABA Criminal Justice Mental Health Standards, 7-6.1, 307 (1989) (detailing the "constellation of decision points" through which the terms used in an insanity test (and their express interpretation) may impact the justice process).

33. Other scholars have also advanced the general argument that delusions' primary significance for responsibility lies more in their defective reasoning process than in their content. See 2 Sir James Fitzjames Stephen, A History of the Criminal Law of England 160-62 (1883); Carl Cohen, Criminal Responsibility and the Knowledge of Right and Wrong, 14 U. MiAmi L. REV. 30, 39-40 (1959); Goldstein, supra note 26, at 66. 


\section{MODERN INSANITY STANDARDS AND THEIR ORIGINS}

The origins and current usage of jurisdictions' insanity tests demonstrate their amenability to consideration of the reasoning impairments associated with delusions. Modern insanity tests derive from those articulated in 1843 in M'Naghten's Case and in 1962 by the American Law Institute (ALI). In 1843, Daniel M'Naghten shot and killed the private secretary to Prime Minister Sir Robert Peel, believing him to be Sir Robert. ${ }^{34}$ M'Naghten was under the delusion that killing Sir Robert would stop his harassment and persecution by the Tories. ${ }^{35}$ When M'Naghten was acquitted on grounds of insanity, outrage ensued. ${ }^{36}$ The House of Lords issued four questions to the fifteen common law judges of England in an attempt to understand "the nature and extent of the unsoundness of mind which would excuse the commission of a felony of this sort." ${ }^{37}$ In response, Chief Justice Tindal pronounced this standard for criminal insanity:

[I]n all cases ... to establish a defence on the ground of insanity, it must be clearly proved that, at the time of the committing of the act, the party accused was labouring under such a defect of reason, from disease of the mind, as not to know the nature and quality of the act he was doing; or, if he did know it, that he did not know he was doing what was wrong. ${ }^{38}$

Until the mid-twentieth century, a substantial majority of states employed the M'Naghten test, adopting it either by statute or recognizing its common law force. ${ }^{39}$

Over time, the narrowness of the M'Naghten standard drew criticism from courts, legal academics, and psychiatrists. ${ }^{40}$ Critics argued three aspects of the test unduly limited criminal irresponsibility: the singular focus on the cognitive capacity of "knowledge," ${ }^{41}$ the apparent requirement that impairment be total, ${ }^{42}$ and the neglect

34. M'Naghten's Case, $10 \mathrm{Cl}$. \& Fin. at 201. For a book-length treatment of M'Naghten's Case, see Richard Moran, Knowing Right from Wrong: The Insanity Defense of Daniel MCNAUGhtan (1981). Controversy surrounds the spelling of Daniel M'Naghten's name. $I d$. at xi-xiii. This article uses "M'Naghten," as his name was spelled in his English legal case.

35. Moran, supra note 34 , at 10 ; see Henry Weihofen, Mental Disorder as a CRiminal DefEnse 64 (1954).

36. Richard Moran, The Modern Foundation for the Insanity Defense: The Cases of James Hadfield (1800) and Daniel McNaughtan (1843), in 477 AnNAls AM. ACAD. Pol. \& Soc. SCI. 31, 39-40 (Richard D. Lambert et al. eds., 1985).

37. M'Naghten's Case, $10 \mathrm{Cl}$. \& Fin. at 202.

38. Id. at 210 .

39. Model Penal Code $\S 4.01 \mathrm{cmt} .2$, at 165 (Am. L. Inst. 1985).

40. For a collection of critiques of M'Naghten's Case and its right-and-wrong test, see Weitofen, supra note 35, at 63-68; United States v. Freeman, 357 F.2d 606, 616-20 (2d Cir. 1966).

41. See Simon E. Sobeloff, Insanity and the Criminal Law: From McNaghten to Durham, and Beyond, 41 A.B.A. J. 793, 794 (1955); Durham v. United States, 214 F.2d 862, 870-72 (D.C. Cir. 1954), abrogated by United States v. Brawner, 471 F.2d 969 (D.C. Cir. 1972).

42. See infra note 93 and accompanying text; Francis A. Allen, The Borderland of CRiminal Justice 112 (1964). 
of volition. ${ }^{43}$ Some contended the narrow scope placed "unrealistically tight shackles" upon expert psychiatric testimony, ${ }^{44}$ while others observed that, even if courts gave testifying experts wide latitude, jurors would naturally construe "knowledge" "as referring to a simple awareness by the actor of his wrongdoing such as would be manifested by a verbal acknowledgement on his part of the forbidden nature of his conduct." 45 Thus, the common meaning of "knowledge" would lead jurors, and ultimately forensic experts, to believe that only cognitive impairment was relevant to the legal test. ${ }^{46}$

In response, the ALI approved a new test in $1962 .{ }^{47}$ Model Penal Code section 4.01 provides: "A person is not responsible for criminal conduct if at the time of such conduct as a result of mental disease or defect he lacks substantial capacity either to appreciate the criminality [wrongfulness] of his conduct or to conform his conduct to the requirements of law." 48 This test retained the structure and overall thrust of the M'Naghten test but broadened that standard by substituting "appreciate" for "know" and specifying that impairment need only be "substantial." 49 In addition, the ALI added a volitional component that permits acquittal for substantial inability to conform one's conduct to the law's requirements. ${ }^{50}$

Several less substantive changes were intended to clarify and simplify the insanity test. The ALI eliminated M'Naghten's "nature and quality of the act" prong, while retaining its wrongfulness aspect. This absorption made sense: a person who lacks the ability to comprehend the nature of her act cannot understand its wrongfulness. ${ }^{51}$ The ALI also replaced M'Naghten's "was labouring under such a defect of reason, from disease of the mind" with "as a result of mental disease or defect." No evidence suggests the ALI eliminated the "defect of reason" component in response to criticism that it inappropriately restricted the defense. Instead, it appears the phrase was dropped as redundant. ${ }^{52}$ In essence, a "defect of reason" must be the mechanism by which a "disease of the mind" could result in a person's inability "to know." 53

43. See Shelton Glueck, Crime and Correction: Selected Papers 153 (1952); Richard H. Kuh, The Insanity Defense-An Effort to Combine Law and Reason, 110 U. PA. L. REV. 771, 783 (1962). For a pithy summary of these and additional sources of psychiatric dissatisfaction with the M'Naghten rule, see ALLEN, supra note 42, at 109-13.

44. Freeman, 357 F.2d at 619.

45. Model Penal Code $\S 4.01 \mathrm{cmt} .2$, at 166 (Am. L. Inst. 1985).

46. Id. at 167 .

47. Model Penal Code $\S 4.01$ hist. n., at 163 (Am. L. Inst. 1985).

48. Model Penal Code $\S 4.01$ (Am. L. Inst. 1985).

49. Id. "Substantial" means "a capacity of some appreciable magnitude when measured by the standard of humanity in general, as opposed to the reduction of capacity to the vagrant and trivial dimensions characteristic of the most severe afflictions of the mind." MODEL PENAL CODE $§ 4.01 \mathrm{cmt}$. 3, at 172 (AM. L. INST. 1985).

50. Model Penal Code $\S 4.01 \mathrm{cmt} .3$, at 172 (Am. L. Inst. 1985).

51. See Clark v. Arizona, 548 U.S. 735, 753-54 (2006).

52. Herbert Fingarette, The Meaning of Criminal Insanity 178 (1972); see also Stephen P. Garvey, Agency and Insanity, 66 Buff. L. Rev. 123, 129 n.26 (2018).

53. The validity of this argument is reflected in the Commentary to the Model Penal Code $\S 4.01$, which construed "[t]he determination of responsibility under the M'Naghten test [to] turn[] on whether the actor by reason of mental disease or defect did not know ...." MODEL Penal Code $\S 4.01 \mathrm{cmt} .2$, at 165-66 (Am. L. InST. 1985). 
Finally, the ALI test recognized only incapacity-not actual lack of understanding - as providing a basis for insanity. ${ }^{54}$ Under the traditional M'Naghten test, a defendant could demonstrate she "did not know" the wrongfulness of her act in two ways. She could establish that a mental disease caused her to lack the cognitive (and perhaps other) ${ }^{55}$ abilities necessary for acquiring knowledge that her act was wrongful. ${ }^{56}$ Alternatively, she could establish that, at the moment of the offense, she was ignorant of the wrongfulness of her act because of a mental disease. ${ }^{57}$ Under this latter prong, a defendant could have the capacity to understand wrongfulness but momentarily lack the intellectual awareness of the factual predicate necessary for her act to be wrongful. ${ }^{58}$ The ALI test eliminated this second basis for insanity. ${ }^{59}$ The ALI's formulation in section 4.01 of the Model Penal Code was highly influential and inspired legislative action in a majority of states across the country. ${ }^{60}$

After the acquittal of John Hinckley in 1982, however, the tide shifted again toward a narrower definition of irresponsibility. ${ }^{61}$ Thirty-six states reformed their insanity defenses, with four abolishing the defense completely. ${ }^{62}$ A number of jurisdictions eliminated the volitional prong and required that impairment be total, not substantial. ${ }^{63}$ In 1984, Congress passed the Insanity Defense Reform Act, which limited irresponsibility to an inability to appreciate the nature and quality or wrongfulness of one's acts due to a "severe mental disease or defect." Report suggests that restricting mental diseases to those that are "severe" was intended to disqualify "mere emotional processes" that could impair appreciation. ${ }^{65}$ The American Bar Association endorsed a similar standard in 1989 but specified that an inability to appreciate wrongfulness must stem from a "mental disease or defect . . that substantially affected the mental or emotional processes of the defendant at the time of the alleged offense." ${ }^{\prime 66}$ As discussed below, jurisdictions' current insanity standards reflect aspects of the M'Naghten, ALI, and ABA approaches.

54. See Paul H. Robinson, Insanity, in 2 Crim. L. Def. § 173 (2009).

55. See infra note 96.

56. See M'Naghten's Case, 8 Eng. Rep. 718, 722, 10 Cl. \& Fin. 200, 210 (1843).

57. See Walter Sinnott-Armstrong \& Ken Levy, Insanity Defenses, in OXFORD Handbook on the Philosophy of the Criminal Law 299, 311 (John Deigh \& David Dolinko eds., 2011) (“Although the M'Naghten rule hinged on actual knowledge rather than ability to know, the criminal law clearly should not excuse agents who do not happen to know that their acts are wrong if those agents could be reasonably expected to know that their acts are wrong.").

58. See id.

59. This linguistic shift has largely escaped attention. See Garvey, supra note 52, at 130 n.27.

60. Model Penal Code $\S 4.01 \mathrm{cmt}$. 5, at 175-76 (Am. L. Inst. 1985).

61. See Janofsky et al., supra note 15, at S6-S8.

62. See id. at S7; see infra note 67.

63. See Janofsky et al., supra note 15 , at S6-S7, S66.

64. See 18 U.S.C. $\S 17(a)$.

65. See S. Rep. No. 98-225, at 229 (1983).

66. AM. BAR Ass'N, supra note 32, at 330 (Standard 7-6.1). 


\section{A. Analysis of Current Insanity Standards}

As set forth in Appendix A, forty-eight jurisdictions currently provide an affirmative defense of insanity. ${ }^{67}$ All but three of these jurisdictions recognize "moral incapacity," that is, they designate as insane a defendant who did not understand the wrongfulness of her criminal act due to mental disease or defect. ${ }^{68}$ Moral incapacity appears in two formulations. Thirty-four jurisdictions hold insane a person who was "unable" or substantially "lacked the capacity" to appreciate (or know or recognize) the wrongfulness of her act. ${ }^{69}$ Eleven additional jurisdictions excuse for ignorance of wrongfulness (e.g., the defendant "did not know what he was doing was wrong"). ${ }^{70}$ This Article assesses how the science of delusions should factor into both lack-ofcapacity and ignorance-of-wrongfulness tests. Importantly, these two forms of moral incapacity matter little in practice: sanity inquiries are typically resolved by demonstrating the defendant knew her act was wrong. ${ }^{71}$ For organizational purposes,

67. See Appendix. In addition to those defenses included in the table, New Hampshire, North Dakota, and Alaska have unique formulations. See Appendix note 1. Four statesIdaho, Kansas, Montana, and Utah - abolished their affirmative insanity defenses but permit mental health evidence to rebut the mens rea of charged offenses. See Appendix n.1. In addition, Alaska limits its affirmative defense of insanity to cognitive incapacity, see ALASKA STAT. § 12.47.010(a) (2018), and permits mental health evidence to rebut the state of mind element of the offense, see id. § 12.47.020. In Kahler v. Kansas, the U.S. Supreme Court found these practices (which it equated) consistent with due process. 140 S. Ct. 1021, 1037 (2020).

68. See Kahler, 140 S. Ct. at 1022 (defining "moral incapacity test"). A total of forty-six jurisdictions provide for acquittal whenever the defendant can establish her moral incapacity at the moment of the offense. See Appendix n.1. Forty-three states, plus the federal government and the District of Columbia, explicitly recognize moral incapacity in their insanity tests. See Appendix. To capture the appropriate degree of understanding, jurisdictions use terms such as "appreciate," "know," and "recognize," among others. See Appendix. In addition, New Hampshire's "product test" is broad enough to encompass moral incapacity. See State v. Fichera, 903 A.2d 1030, 1034 (N.H. 2006) ("A defendant asserting an insanity defense must prove two elements: first, that at the time he acted, he was suffering from a mental disease or defect; and, second, that a mental disease or defect caused his actions.").

69. See Appendix (see "Incapacity" column of "Moral Incapacity" set of columns).

70. These jurisdictions include Arizona, Florida, Minnesota, Mississippi, Nebraska, New Jersey, New Mexico, Ohio, Pennsylvania, Texas, and Virginia. See Appendix. These states incorporate incapacity by implication, i.e., if a person was unable to know the wrongfulness of her act (incapacity), she would necessarily not know it (actual ignorance) at a particular moment in time. In contrast, one state recognizes actual ignorance and an inability to understand wrongfulness. See Cheney v. State, 909 P.2d 74, 90 (Okla. Crim. App. 1995).

71. See Rogers, supra note 4, at 109 ("In the majority of insanity referrals, the defendant's objectives include a clear recognition of wrongfulness. In the remaining cases, the forensic practitioner must evaluate closely the defendant's awareness of wrongfulness and its role in conducting the acts in question."). Some commentators have argued that ignorance of the law is an implicit requirement for irresponsibility under incapacity statutes. See Garvey, supra note 52 , at 130 ("What defeats liability ... is an actor's ignorance of the law, provided it resulted from a mental disease or defect, and provided he was powerless to be anything but ignorant.") (emphasis in original). Others disagree. See Paul H. Robinson, Insanity, in 2 Crim. L. Def. § 173 (July 2021 update) (observing "there is no reason to believe that whenever a dysfunction is sufficient to cause a loss of 'substantial capacity to appreciate' that it necessarily will in fact 
however, this Article will treat assessments of lack of capacity and of ignorance of wrongfulness as distinct. ${ }^{72}$

Standards diverge beyond these primary means of determining moral blamelessness. Jurisdictions differ in their key functionality: nearly two dozen jurisdictions pin insanity on incapacity to "appreciate" wrongfulness ${ }^{73}$ slightly more than a dozen states premise insanity on a defendant's inability to "know" her act was wrong $;{ }^{74}$ and nine states frame their test as inability to "distinguish" right from wrong, ${ }^{75}$ with one state focusing on incapacity to "recognize" the wrongfulness of her conduct. ${ }^{76}$ Twenty-nine jurisdictions suggest incapacity must be total (or at least include no descriptor to indicate otherwise), ${ }^{77}$ while fifteen specify it need only be substantial. ${ }^{78}$ Seven states dictate the relevant impairment must derive from a "defect of reason." $"$ In addition to moral incapacity, twenty jurisdictions include a "cognitive incapacity" component, which assesses the defendant's ability to understand the nature and quality of her act, ${ }^{80}$ and sixteen include a volitional prong,

cause a sufficient lack of appreciation to satisfy the excusing condition;" thus "[t]he A.L.I. test is deficient in its failure to recognize this distinction").

72. See infra Sections A and B.

73. These jurisdictions include Alabama, Arkansas, Connecticut, Delaware, Hawaii, Illinois, Indiana, Kentucky, Maine, Maryland, Massachusetts, Michigan, Missouri ("knowing and appreciating"), Nevada, New York ("know or appreciate"), Oregon, Rhode Island, Tennessee, Vermont, West Virginia, Wisconsin, Wyoming, and the federal system. See Appendix.

74. These jurisdictions include Arizona, Florida, Minnesota, Mississippi, Nebraska, New Jersey, New Mexico, Ohio, Oklahoma ("he does not know his acts are wrong and he is unable to distinguish right from wrong with respect to his acts"), Pennsylvania, South Dakota, Texas, and Virginia. See Appendix.

75. These jurisdictions include California, Colorado, Georgia, Iowa, Louisiana, North Carolina, Oklahoma, South Carolina, and Washington ("unable to tell right from wrong"). See Appendix.

76. See Bethea v. United States, 365 A.2d 64, 79 n.30 (D.C. 1976).

77. These include all "know" and "distinguishing" states, see supra notes 74 ("know"), 75 ("distinguish"), as well as a few states employing the term "appreciate," see Appendix (Alabama, Arkansas, Indiana, Missouri, Nevada, Tennessee, West Virginia, and the federal system).

78. Jurisdictions requiring only substantial incapacity to appreciate wrongfulness include Connecticut, Delaware, Hawaii, Illinois, Kentucky, Maine, Maryland, Massachusetts, Michigan, New York, Oregon, Rhode Island, Wisconsin, Wyoming, and the District of Columbia. See Appendix. Rhode Island asks the trier of fact to assess whether "capacity ... [was] so substantially impaired that [the defendant] cannot justly be held responsible." State v. Carpio, 43 A.3d 1, 12 n.10 (R.I. 2012). In addition to these jurisdictions, Vermont specifies that the defendant must lack "adequate capacity." VT. STAT. ANN. tit. 13, § 4801(a) (2019).

79. These jurisdictions include Minnesota, Mississippi, New Jersey, North Carolina, Oklahoma, Pennsylvania, and South Dakota. See Appendix. All "defect of reason" states condition insanity on ignorance of knowledge of wrongfulness or inability to distinguish right from wrong. See id.

80. Jurisdictions recognizing cognitive incapacity include Alabama, California, Florida, Iowa, Michigan, Minnesota, Mississippi, Missouri, Nebraska, Nevada, New Jersey, New Mexico, New York, North Carolina, Oklahoma, Pennsylvania, Tennessee, Virginia, Washington, and the federal system. See Appendix. Cognitive incapacity adds nothing to 
providing for acquittal on the basis of an inability to conform one's conduct to the requirements of law. ${ }^{81}$

\section{B. Meaning of "Appreciate" and "Know"}

Which impairments factor into a sanity evaluation largely depends upon the meaning ascribed to "appreciate" and "know," the terms generally chosen to convey the necessary measure of a defendant's understanding of a criminal act's wrongfulness. ${ }^{82}$ Roughly an equal number of jurisdictions employ each term in practice, if not in the express language of their statutes. ${ }^{83}$

Twenty-three jurisdictions currently condition sanity on the ability to "appreciate" the wrongfulness of a criminal act. ${ }^{84}$ The ALI chose the word "appreciate" to convey the relevance of the gamut of capacities inherent in reasoning, including both affective and cognitive abilities. ${ }^{85}$ Section 4.01 explains, "An individual's failure to

moral incapacity. See supra note 51 and accompanying text.

81. These jurisdictions include Arkansas, Connecticut, Hawaii, Kentucky, Maryland, Massachusetts, Michigan, New Mexico, Oregon, Rhode Island, Vermont, Virginia, West Virginia, Wisconsin, Wyoming, and the District of Columbia. See Appendix. In addition, Georgia's delusional compulsion statute provides: "A person shall not be found guilty of a crime when, at the time of the act, omission, or negligence constituting the crime, the person, because of mental disease, injury, or congenital deficiency, acted as he did because of a delusional compulsion as to such act which overmastered his will to resist committing the crime." GA. CODE ANN. § 16-3-3 (2020). Georgia courts have limited the application of this test to delusions that, if true, would have legally justified or excused the defendant's actions. See Lawrence v. State, 454 S.E.2d 446, 450 (Ga. 1995); Johnston \& Leahey, supra note 2, at Part II.B.1 (discussing how Georgia's statute has been utilized over time). As the focus of this Article is delusions' effect on moral incapacity, it does not separately address their effect on volition. Numerous scholars have argued that impairments in cognition cannot easily be separated from volition, however, and, for that reason, some have argued that volition is inherently part of M'Naghten's moral incapacity test. See STEPHEN, supra note 33, at 170-71. Regardless, impairments associated with delusions are clearly relevant to volitional insanity. See id. at 167-68. Indeed, studies show that psychosis and delusions often contribute to findings of volitional impairment in insanity assessments. See Andrew Donohue, Vinay Arya, Lawrence Fitch \& Debra Hammen, Legal Insanity: Assessment of the Inability to Refrain, 5(3) PSYCHIATRY 58, 63 (2008) (finding that psychotic disorders were the most common diagnoses in forty-four defendants found volitionally, but not cognitively, impaired and that delusional beliefs were the most commonly cited factor connecting the defendant's mental illness to the offense in these forensic evaluations).

82. See Appendix. Psychosis could also affect a defendant's understanding of the nature and quality of her act, but, in doing so, would also affect her comprehension of its wrongfulness. See supra note 51.

83. While the insanity tests of only thirteen jurisdictions include the term "know," supra note 74, states conditioning insanity on an inability to distinguish or tell right from wrong typically interpret this language in accordance with the M'Naghten standard. See supra note 75; People v. Leeds, 192 Cal. Rptr. 3d 906, 913 (Ct. App. 2015), as modified on denial of reh'g (Oct. 27, 2015); Roberts v. State, 3 Ga. 310, 326-27 (1847); State v. Nicholson, 466 P.2d 181, 182-83 (Wash. Ct. App. 1970).

84. See Appendix.

85. See Model Penal Code $\S 4.01$ app. C, at 212 (Am. L. Inst. 1985) (discussing the 
appreciate the criminality of his conduct may consist in a lack of awareness of what he is doing or a misapprehension of material circumstances, or a failure to apprehend the significance of his actions in some deeper sense." ${ }^{86}$ Herbert Wechsler, chief reporter for the Model Penal Code, described the standard this way in his model jury charge: "To appreciate the wrongfulness of conduct is, in short, to realize that it is wrong; to understand the idea as a matter of importance and reality; to grasp it in a way that makes it meaningful in the life of the individual, not as a bare abstraction put in words." 87 Jurisdictions following the ALI's example give "appreciate" wide breadth and tend to permit consideration of any cognitive or emotional impairment relevant to reasoning, judgment, and evaluation of the moral nature of one's act. ${ }^{88}$ Consistent with this practice, forensic experts tend to recognize that "appreciate ... encompass[es] affective dimensions of major mental illness" and "take[s] into account all aspects of the defendant's mental and emotional functioning relating to an ability to recognize and understand the significance of personal actions." 89

The meaning of "know" is more contested than "appreciate" and over time has been a source of fervent disagreement. ${ }^{90}$ Many commentators have asserted that "know" must refer only to cognitive abilities, ${ }^{91}$ given contemporary understandings of rationalism at the time M'Naghten was decided..$^{92}$ Moreover, some have argued that "inability to know" can only be satisfied by total impairment of cognitive processes, or by “totally deteriorated, drooling, hopeless psychotics of long standing,

importance of reason to justness of blame); id. $\S 4.01 \mathrm{cmt} .3$, at $169 ;$ id. $\S 4.01 \mathrm{cmt} .2$, at 166 .

86. Id. $\S 4.01$, explanatory n., at 164 .

87. Id. $\S 4.01$, app. C, at 215 .

88. See, e.g., State v. White, 456 P.2d 797, 803 (Idaho 1969) (holding that "appreciate" allows for consideration of emotional and cognitive knowledge); State v. Dyer, 518 P.2d 184, 186 (Or. Ct. App. 1974) (noting that 'the word 'appreciate' allows psychiatric testimony regarding emotional as well as intellectual cognition of the criminality of the conduct"); People v. Engram, 549 N.E.2d 1333, 1336 (Ill. App. Ct. 1990) (noting expert testimony concerning the "marked separation of the act from the emotions and from logical thinking," the defendant's "emotional blunting," and her "inability to conduct her behavior in a way that would be appropriate," to "recognize cause and effect," to use "appropriate judgment," and to "understand the consequences of her behavior"); People v. Hernandez-Beltre, 69 N.Y.S.3d 336, 338 (App. Div. 2018) (considering expert testimony that "in the context of his delusional beliefs, disorganized thinking, religious preoccupation, and his hallucinatory state . . . the thought resulted in no more than a surface awareness, without depth or emotional significance").

89. Janofsky et al., supra note 15 , at S7.

90. For a lucid and pithy presentation of the variance in meanings, see RICHARD J. BONNIE, John C. Jeffries, Jr. \& Peter W. Low, A Case Study in the Insanity Defense: The Trial OF JOHN W. HiNCKLEY, JR. 12 (3d ed. 2008). For an overview of disagreement among scholars, see COPPOLA, supra note 8, at 22-24.

91. See Arval A. Morris, Criminal Insanity, 43 WASH. L. REV. 583, 605 (1968) (assessing the term "know" and concluding: "[T]he test is heavily intellectualistic, and from a psychological point of view, narrow because the cognitive becomes the single, important criterion of criminal responsibility."); Gerber, supra note 22, at 120-22; CoPPOLA, supra note 25, at 14-15, 26 (concluding "standards such as the M'Naghten rule do not consider emotional capacity at all"').

92. See Gerber, supra note 22, at 121. 
and congenital idiots." 93 Under this interpretation, an act motivated by pathological reasoning or impulses would be deemed sane so long as the defendant understood in an intellectual sense that her action was wrong. ${ }^{94}$ Disordered reasoning is the predominant form of irrationality of those with severe mental illness, so the majority of the most seriously ill whose criminal acts stem from irrationality would not qualify for the insanity defense under this conception of "know."

However, properly understood, "know" and "appreciate" should carry similar meanings and encompass the same abilities. ${ }^{96}$ Crucially, M'Naghten made clear that "knowledge" must be the product of rational thinking. ${ }^{97}$ The opinion dictates that, to qualify for insanity, a defendant must prove that a "disease of the mind" produced "such a defect of reason" that she did not "know" the act's wrongfulness. ${ }^{98}$ The opinion also conditions criminal responsibility on sufficiency of reason. ${ }^{99}$ Therefore, although scholars have contended to the contrary, ${ }^{100}$ consideration of "knowledge" should extend beyond cognition to include any ability requisite to rational decisionmaking, including affective capacities. ${ }^{101}$

It appears that modern courts largely agree. ${ }^{102}$ Courts that define "know" or explore its meaning in case law typically, though not always, ${ }^{103}$ give the term broad

93. Gregory Zilboorg, Mind, Medicine and Man 273 (1943).

94. Morris, supra note 91, at $606 \mathrm{n} .113$.

95. See Stephen J. Morse, Excusing the Crazy: The Insanity Defense Reconsidered, $58 \mathrm{~S}$. CAL. L. Rev. 777, 810 (1985).

96. See Commonwealth v. McHoul, 226 N.E.2d 556, 561 (Mass. 1967) ("We think that the use of 'appreciate' rather than 'know' expresses what the word 'know' in the classical statement of the rule means in the light of modern knowledge. Many psychiatrists, as indicated in the records in recent cases, appear to have recognized this."). A number of scholars have advocated for a broad conception of "knowledge." See Johnston \& Leahey, supra note 2, at 1791 n.66 (listing some of these scholars).

97. FINGARETTE, supra note 52, at 198.

98. M'Naghten's Case, 8 Eng. Rep. 718, 722, 10 Cl. \& Fin. 200, 210 (1843); see FingARETTE, supra note 52, at 198, 210-11.

99. M'Naghten's Case, $10 \mathrm{Cl}$. \& Fin. at 210.

100. See supra note 91.

101. See supra note 96. "Reasoning" and "rationality" are normative concepts best left to the common sense of the jury. See FingARETTE, supra note 52, at 203. However, some scholars have attempted to provide working definitions. See Stephen J. Morse, Rationality and Responsibility, 74 S. CAL. L. Rev. 251, 255 (2000) (defining rationality as "the general ability to recognize and be responsive to the good reasons that should guide action"); FINGARETTE, supra note 52, at 186-94 (defining rationality as the ability to respond relevantly to anything essentially relevant to one's action, including its physical and moral aspects).

102. See infra notes 104-116. Some evidence suggests that forensic evaluators share this perspective. See Robert M. Wettstein, Edward P. Mulvey \& Richard Rogers, A Prospective Comparison of Four Insanity Defense Standards, 148 Am. J. Psychiatry 21, 21-27 (1991) (finding that forensic psychiatrists' assessments did not vary when using the ALI and M'Naghten).

103. See Commonwealth v. Banks, 521 A.2d 1, 14-15 (Pa. 1987) (holding that to construe "knowledge" as including an appreciation of the social and emotional implications of an act "either misperceives the nature of the M'Naghten test or seeks to fundamentally alter it"); State v. Everett, 520 P.2d 301, 305 (Ariz. 1974) (en banc). 
meaning. ${ }^{104}$ Some courts have held that knowledge requires an ability to "understand," 105 a term that at least one court has held allows "a full range of testimony as to emotional as well as intellectual cognition of the act." 106 Others have interpreted knowing wrongfulness as requiring an ability to "appreciate" the character and consequences of one's act. ${ }^{107}$ While many courts stress that the "appreciation" intended by "knowledge" includes a range of cognitive capacities, ${ }^{108}$ some expressly consider emotional appreciation. For instance, the Supreme Court of Minnesota endorsed this language of the American Law Report when construing its traditional M'Naghten insanity standard:

It seems clear . . . in the light of current medical and psychiatric information, that the ability to 'know' right from wrong should no longer be presented to jury or witness in the exclusively intellectual sense ... but that the test should be the accused's ability to emotionally and intellectually realize and appreciate, as an integrated personality, the nature and consequences of the moral choice presented, and that the mere ability to verbalize a correct answer to questions about the distinction should not be accepted as conclusive on the issue of criminal responsibility. ${ }^{109}$

104. See People v. Horn, 205 Cal. Rptr. 119, 132 (Ct. App. 1984) ("In sum, what the [right from wrong] clause requires is incapacity, due to serious mental disease, to make the relevant valuations of a normal adult - to realize, for instance, that it is wrong to kill a human being or take his property. ... It expresses in plain words an abiding insight into what is paramount in human nature.").

105. See Clark v. Arizona, 548 U.S. 735, 747 (2006); Barrett v. State, 772 P.2d 559, 571 (Alaska Ct. App. 1989); State v. Singleton, 48 A.3d 285, 293 (N.J. 2012); see infra note 106 (providing additional examples).

106. State v. Dyer, 518 P.2d 184, 186 (Or. Ct. App. 1974); see also People v. Wolff, 394 P.2d 959, 962-63 (Cal. 1964) (recognizing "the California courts have attempted to give a psychologically sound recognition to the depth and insight required of a defendant's knowledge" and approving an instruction that asks if the defendant had sufficient mental capacity to "understand that [his act] was wrong and a violation of the rights of another") (emphasis in original).

107. Moore, supra note 5, at 680. According to Abraham Goldstein, trial courts in eleven states instruct juries that knowledge means understanding that enables a person to judge "the nature, character, and consequences of the act charged against him" or the "capacity to appreciate the character and to comprehend the probable or possible consequences of his act." GoldSTEIN, supra note 7, at 49-50; see, e.g., State v. Esser, 115 N.W.2d 505, 521-22 (Wis. 1962) (recognizing that "distinguishing between right and wrong" requires "real insight" to "be able to make a normal moral judgement" and "appreciate and evaluate" an act at the time committed); People v. Skinner, 704 P.2d 752, 761 (Cal. 1985) (explaining that " knowing' in the sense of being able to verbalize the concepts of right and wrong [is] insufficient to establish legal sanity[;] [r]ather, the defendant must 'know' in a broader sense - he must appreciate or understand these concepts").

108. See supra note 107.

109. State v. Rawland, 199 N.W.2d 774, 790 (Minn. 1972) (quoting with approval 45 A.L.R.2d 1447, 1450). 
Reflecting M'Naghten's emphasis on reasoning, ${ }^{110}$ courts have also recognized that knowledge requires rationality and a sufficient capacity to reason. ${ }^{111}$ Some courts have even recognized the relevance of volitional impairments to a defendant's ability to know the wrongfulness of her acts. ${ }^{112}$ Given how broadly courts have interpreted "know" in practice, some have observed that the ALI test "is essentially the M'Naghten rule with respect to the actor's knowledge of his acts." 113 Many states prefer to leave the interpretation of "know" to jurors' common sense. ${ }^{114}$ However, courts overwhelmingly give forensic witnesses broad latitude to testify to the defendant's mental condition (including cognitive, affective, and volitional impairments $)^{115}$ and have indicated their appreciation for detailed testimony about defendants' capabilities. ${ }^{116}$ Thus, courts permit jurors in "know" jurisdictions - as in "appreciate" jurisdictions ${ }^{117}$ - to learn of, and consider, the full panoply of a defendant's reasoning impairments. Yet, hampered by misconceptions of the breadth

110. See M'Naghten's Case, 8 Eng. Rep. 718, 722-23, 10 Cl. \& Fin. 200, 210 (1843).

111. See, e.g., Skinner, 704 P.2d at 762-63 ("If he has reasoning capacity sufficient to distinguish between right and wrong as to the particular act he is doing, knowledge and consciousness that what he is doing is wrong and criminal and will subject him to punishment, he must be held responsible for his conduct."); Davis v. State, 28 S.W.2d 993, 996 (Tenn. 1930) ("The general rule is that if a defendant has capacity and reason to enable him to distinguish the difference between right and wrong as to the particular act he is then doing, he is criminally responsible for such act."); State v. Davies, 148 A.2d 251, 255 (Conn. 1959) ("To be the subject of punishment, an individual must have mind and capacity, reason and understanding enough to enable him to judge of the nature, character and consequence of the act charged against him, that the act is wrong and criminal, and that the commission of it will justly and properly expose him to penalty."); Rawland, 199 N.W.2d at 785 ("The defendant will be excused if at the time of the criminal act he had a mental disease or defect which included among its symptoms or consequences an impairment in one or more of the psychological functions requisite for reasoning (i.e., cognitive ego functions [perceiving, remembering, classifying, judging, etc.]) which, in turn, reduced the strength of his disposition to token 'this is wrong' to a negligibly low value ...." (quoting Joseph M. Livermore \& Paul E. Meehl, The Virtues of M'Naghten, 51 MinN. L. REV. 789, 808 (1966)). Indeed, the examples provided in M'Naghten - when differentiating between motivations that would inculpate and those that would exculpate under the insane delusion rule - demonstrate the importance of intact reasoning abilities. See M'Naghten's Case, $10 \mathrm{Cl}$. \& Fin. at 211 (distinguishing between killing for self-defense and for revenge).

112. See Rawland, 199 N.W.2d at 785; State v. Putzell, 242 P.2d 180, 184 (Wash. 1952) (en banc); Arridy v. People, 82 P.2d 757, 761 (Colo. 1938).

113. State v. Dyer, 518 P.2d 184, 186 (Or. Ct. App. 1974).

114. See GoldSTEIN, supra note 7, at 50 (noting that, in nineteen jurisdictions, "the jury is simply given the words of the rule, without explanation, and left to find the 'common sense' meaning from their own backgrounds or from the materials presented to them at trial").

115. See id. at 53-54 ("There is virtually no support in law for the view that M'Naghten is responsible for inhibiting the flow of testimony on the insanity issue... The almost unvarying policy of the courts has been to admit any evidence of aberrational behavior so long as it is probative of the defendant's mental condition, without regard to the supposed restrictions of the test used to define insanity for the jury.") (emphasis in original).

116. See State v. Shoffner, 143 N.W.2d 458, 463-64 (Wis. 1966); Pope v. United States, 372 F.2d 710, 736-37 (8th Cir. 1967), vacated, 392 U.S. 651 (1968) (per curiam).

117. See supra note 88 . 
of these terms, legal and forensic professionals may not bring reasoning impairments associated with delusions to jurors' attention.

\section{NOT KNOWING AN ACT’S WRONGFULNESS}

Determinations of moral incapacity often turn on the effects of psychosis, including delusions, and a defendant's ability to understand the wrongfulness of her criminal act. Herbert Fingarette observed, "Paranoid delusion is a classic paradigm of insanity, both historically, as the occasion for historic and leading legal rulings, and practically, as representing a sizable proportion of the symptoms of mental disorder at issue when the insanity plea is raised." 118 Indeed, the most impactful cases in insanity jurisprudence have involved paranoia or schizophrenia-related disorders characterized by delusions. ${ }^{119}$ Today, lawyers, psychiatrists, and the public recognize psychosis as the quintessential embodiment of insanity. ${ }^{120}$ Thus, understanding the range of impairments associated with delusions - and their relevance to the criteria of insanity - is central both to the conception of insanity and the operation of the defense.

Forensic experts tend to adopt one of two perspectives regarding the use of delusions in insanity cases. In most jurisdictions, they will factor delusions into the moral incapacity test, ${ }^{121}$ stressing how delusions impair the defendant's ability to distinguish subjective experience from the reality of the external world. ${ }^{122}$ Although infrequently reflected in appellate opinions, testimony may include discussion of delusions' effects on attention, perception, reflective awareness, reasoning, and judgment. ${ }^{123}$ In essence, if a defendant is incapable of accurately perceiving and rationally responding to the physical and morally relevant aspects of her action, ${ }^{124}$

118. FingARETTE, supra note 52, at 137-38.

119. See WeIHOFEn, supra note 35, at 105; GLUECK, supra note 43, at 156 n.38.

120. See Moore, supra note 5, at 689 ("The most familiar forms of mental disease that are so seriously deranging of the qualities of personhood that they render those who suffer them non-responsible, are, as it happens, those psychiatrists for over 150 years have called psychoses."); Borum, supra note 20, at 206 ("Typically, courts have determined that the condition must be characterized by a severe disorder of thought or mood and, typically, must interfere with one's capacity accurately to perceive reality."); $c f$. MELTON ET AL., supra note 5, at 227, 228 tbl.8.1 (displaying characteristics of individuals found not guilty by reason of insanity (NGRI) in eight studies and concluding that "these data . . suggest that suffering from a psychosis is usually required for the insanity defense to succeed").

121. See Johnston \& Leahey, supra note 2, at 1795 n. 80.

122. The effect of delusions on defendants' sense of reality is a frequent topic of expert testimony. See State v. Currie, 812 So. 2d 128, 134 (La. Ct. App. 2002); People v. Demagall, 978 N.Y.S.2d 416, 421 (App. Div. 2014); People v. Plackowska, No. 2-17-1015, 2020 WL 4463108, *20-27 (Ill. App. Ct. Aug. 3, 2020).

123. See infra notes 139-145 (discussing types of disordered reasoning associated with schizophrenia); State v. Dye, 776 N.W.2d 302, *4-5 (Iowa Ct. App. 2009); State v. Gerone, 435 So. 2d 1132, 1134, 1137 (La. Ct. App. 1983); People v. Young, 479 N.E.2d 815, 817 (N.Y. 1985); People v. Serravo, 823 P.2d 128, 132 (Colo. 1992) (en banc); People v. Moore, Nos.1-16-1117 \& 1-16-2850, 2019 WL 3779772, at*5 (Ill. App. Ct. Aug. 9, 2019).

124. FINGARETTE, supra note 52, at 186-94 (defining rationality as the ability to respond relevantly (even if foolishly) to anything essentially relevant to one's action, including its 
she cannot fairly be expected to comport with the requirements of law. ${ }^{125}$ In a minority of states, delusional content has less relevance and may only support a defendant's insanity defense if it would have justified or excused the defendant's act had it been true. ${ }^{126}$

However, a growing body of research in the cognitive sciences suggests that delusions hold additional import. Notably, the very existence of delusions could signal a disordered process of rational thinking capable of impairing moral decisionmaking. ${ }^{127}$ Exaggerated cognitive biases and emotional impairments appear across delusion subtypes, ${ }^{128}$ so they may provide additional grist (beyond warped content) for moral incapacity in a broad range of cases. Moreover, an additional set of attentional and attributional biases relevant to paranoid psychosis suggests the legal system should pay increased attention to delusions of impending harm, including those that would not constitute a legal justification or excuse. The Sections below detail how the cognitive and emotional aberrations associated with delusions may bear on a defendant's inability to understand - and her actual ignorance of - the wrongfulness of her criminal act. They also explore the implications of this science for the evolution of the law and the practice of defense attorneys and forensic mental health professionals.

\section{A. Incapacity to Know or Appreciate Wrongfulness}

Most insanity standards assess the capacity of a defendant to "appreciate" or "know" the wrongfulness of her criminal act. ${ }^{129}$ As Part I established, the origin and modern judicial interpretation of these terms demonstrate the centrality of reasoning abilities to sanity. ${ }^{130}$ Often, an individual with psychosis will exhibit a range of significant cognitive impairments that affect reasoning. ${ }^{131}$

physical and moral aspects).

125. See id. at 230.

126. See Johnston \& Leahey, supra note 2, at 1795-98, 1813-17 (discussing the treatment of delusions in Nevada and California); see infra notes 227-240 and accompanying text (discussing the insane delusion rule).

127. For a review of these impairments, see Part III of Johnston \& Leahey, supra note 2.

128. See Philippa A. Garety, Matthew Gittins, Suzanne Jolley, Paul Bebbington, Graham Dunn, Elizabeth Kuipers, David Fowler \& Daniel Freeman, Differences in Cognitive and Emotional Processes Between Persecutory and Grandiose Delusions, 39 SCHIzOPHRENIA BuLl. 629, 635-37 (2012). Researchers note that "surprisingly few studies have examined whether biased reasoning generalises across delusion sub-types (e.g., grandiose, ideas of reference) or if some types are more highly associated than others." George Savulich, Sukhwinder Shergill \& Jenny Yiend, Biased Cognition in Psychosis, 3 J. ExPERIMENTAL Psychopathology 514, 521 (2012).

129. To be more precise, thirty-four jurisdictions assess the ability or capacity of the defendant to appreciate, know, or recognize the wrongfulness of her act, or to distinguish right from wrong with reference to the particular act charged. See Appendix.

130. See supra Part I.B.

131. See Savulich et al., supra note 128, at 516 (collecting studies). 
Schizophrenia, the best known and most researched form of psychotic disorder, ${ }^{132}$ offers a prime example. ${ }^{133}$ This severe and debilitating mental illness is characterized by delusions, ${ }^{134}$ hallucinations, disorganized speech, grossly disorganized or catatonic behavior, and negative symptoms such as diminished emotional expression. ${ }^{135}$ The vast majority of individuals with schizophrenia exhibit an array of cognitive dysfunctions, including impaired processing speed, attention, executive ability, verbal fluency, and working memory. ${ }^{136}$ These impairments, assessed using traditional neuropsychological and IQ measures, are generally at or above one standard deviation relative to community comparison groups. ${ }^{137}$ However, twenty to twenty-five percent of individuals with schizophrenia do not display global cognitive impairments. ${ }^{138}$

Robert Schopp has detailed four types of disordered cognitive processes associated with schizophrenia that can lead to distorted understanding and decisionmaking. ${ }^{139}$ First, schizophrenia manifests in impaired reality relatedness, which includes "the capacity to accurately perceive the external world (reality testing) and

132. See Suzanne Ho-wai So, Nicolson Yat-fan Siu, Hau-lam Wong, Wai Chan \& Philippa Anne Garety, 'Jumping to Conclusions' Data-Gathering Bias in Psychosis and Other Psychiatric Disorders - Two Meta-Analyses of Comparisons Between Patients and Healthy Individuals, 46 Clinical Psych. Rev. 151, 161 app. A (2016); P. A. Garety \& D. Freeman, The Past and Future of Delusions Research: From the Inexplicable to the Treatable, 203 BRIT. J. PSYCHIATRY 327, 331 (2013).

133. See Christopher R. Bowie \& Philip D. Harvey, Cognitive Deficits and Functional Outcome in Schizophrenia, 2 Neuropsychiatric DisEaSe \& TrEatMENT 531, 531-36 (2006) (reviewing cognitive deficits in schizophrenia).

134. A large majority of individuals with schizophrenia experience delusions over the course of their illness. See Michael V. Bronstein, Gordon Pennycook, Jutta Joormann, Philip R. Corlett \& Tyrone D. Cannon, Dual-Process Theory, Conflict Processing, and Delusional Belief, 72 Clinical Psych. Rev. 1, 1 (2019); Benjamin F. McLean, Julie K. Mattiske \& Ryan P. Balzan, Association of the Jumping to Conclusions and Evidence Integration Biases with Delusions in Psychosis: A Detailed Meta-Analysis, 43 Schizophrenia Bull. 344, 346 (2016).

135. See Am. Psychiatric Ass'n, Diagnostic and Statistical Manual of Mental DisORDERS 99-100 (5th ed. 2013).

136. See Dwight Dickinson, Jonathan Schaefer \& Daniel R. Weinberger, The MultiFaceted, "Global" Cognitive Impairment Profile in Schizophrenia, in CogNitive IMPAIRMENT IN SChizophrenia 24, 29 (Philip D. Harvey ed., 2013); Ronan O'Carroll, Cognitive Impairment in Schizophrenia, 6 AdVANCEs Psychiatric TREATMENT 161, 162 (2000). For example, a 2000 literature review concluded that up to seventy-five percent of patients with schizophrenia suffer significant cognitive impairment, including impaired function in "memory, attention, motor skills, executive function [including such cognitive abilities as attentional control, cognitive inhibition, inhibitory control, working memory, and cognitive flexibility] and intelligence." O'Carroll, supra note 136, at 162.

137. R. Walter Heinrichs, Ashley A. Miles, Narmeen Ammari \& Eva Muharib, Cognition as a Central Illness Feature in Schizophrenia, in Cognitive Impairment IN SCHIzOPHRENIA 1, 4-5 (Philip D. Harvey ed., 2013); see Dickinson et al., supra note 136, at 25.

138. See Heinrichs et al., supra note 137, at 5-6. It is possible, of course, that these individuals display subtle deficits and lie near the bottom of normality for measures of cognitive function, but they are not grossly impaired.

139. Robert F. Schopp, Automatism, Insanity, And the Psychology of Criminal RESPONSIBILITY 176-88 (1991). 
the individual's relationship to it (reality sense)." ${ }^{140}$ Disordered reality testing results in inaccurate perception and evaluation of external events, poor judgment, and inappropriate responses. ${ }^{141}$ Second, schizophrenia correlates with various forms of disordered reasoning, including thinking that is overgeneralized (drawing conclusions without sufficient evidence) or combinative (generating impossible beliefs from impressions or ideas). ${ }^{142}$ Third, schizophrenia results in impaired cognitive focus, or the ability to select and attend to relevant aspects of a situation. ${ }^{143}$ Finally, schizophrenia is associated with disordered concept formation, which presents as misinterpreting aspects of reality and imbuing facts with larger, inappropriate significance. ${ }^{144}$ As a result of these distorted processes, the "understanding, reasoning, judgment, and actions" of an individual with schizophrenia "tend to be idiosyncratic and often maladaptive."145

Accumulating knowledge in delusion research enriches understanding of the complex of disordered cognitive processes associated with psychosis and could be useful in deciphering a defendant's choices and behavior in an insanity case. Recent research in cognitive and social psychology, as well as cognitive and affective neuroscience, has revealed an interlocking series of cognitive biases and emotional impairments believed to contribute to the origin, maintenance, and increasing severity of delusions. ${ }^{146}$ Whereas cognitive deficits involve impairment at the global level, cognitive biases involve the selective processing of information. ${ }^{147}$ Particularly important to psychosis are pathology-congruent biases that work to cement and reinforce a pathological belief. ${ }^{148}$

\section{Cognitive Biases}

Comprehending the relationship of delusions to reasoning requires familiarity with the leading framework of decision-making. ${ }^{149}$ In his groundbreaking book,

140. Id. at 187 .

141. $I d$.

142. Id. at 186 .

143. See Am. PsychiAtric Ass'N, supra note 135, at 101.

144. SCHOPP, supra note 139, at 187.

145. Id. at 188 .

146. See, e.g., Thomas Ward \& Philippa A. Garety, Fast and Slow Thinking in Distressing Delusions: A Review of the Literature and Implications for Targeted Therapy, 203 SCHIZOPHRENIA RsCH. 80, 82-83 (2019) (suggesting an integrated cognitive-based model for development and maintenance of delusional ideation); Garety \& Freeman, supra note 132, at 329-31 (discussing hypotheses relating to the role of emotion in the genesis and maintenance of delusions); McLean et al., supra note 134, at 350 (concluding that the cognitive biases assessed "are not simply stable features of schizophrenia . . . [but rather] appear elevated during times of worse delusions, and appear lower ... or comparable to normal levels ... as delusions abate").

147. See Savulich et al., supra note 128, at 516.

148. See id.

149. See Ward \& Garety, supra note 146 , at $82-83$ (proposing a hypothetical model that integrates exaggerated reasoning biases in psychosis to the dual-process model of decisionmaking but noting that studies providing supporting evidence are "few in number and at an early stage of methodological development"). The relationship of reasoning biases to the dual- 
Thinking Fast and Slow, ${ }^{150}$ psychologist Daniel Kahneman drew upon decades of research to propose a model of decision-making that involves the interaction of intuitive and analytical processes. ${ }^{151}$ This dual-process model posits the interplay of "System 1" processing, which "operates automatically and quickly, with little or no effort and no sense of voluntary control," and "System 2" processing, which involves conscious, analytic reasoning. ${ }^{152}$ The dual-process framework is sometimes referred to as having a "default-interventionalist" structure, by which System 1 produces intuition-based responses and System 2 reviews and, if necessary, modifies those responses. ${ }^{153}$ Accordingly, System 1 regulates most everyday behaviors, while System 2 has the option to effortlessly endorse those behaviors or intervene when it disagrees or to suggest a course of action in the first instance. ${ }^{154}$

Cognitive neuroscientist Joshua Greene and colleagues have applied Kahneman's dual-process model to moral decision-making. ${ }^{155}$ Greene's moral decision-making model centers around the competition between a "social-emotional" pathway, which mirrors System 1, and a "cognitive" pathway, which mirrors System 2. ${ }^{156}$ Others refined this model to emphasize the dynamic nature of the interactions between the two pathways. ${ }^{157}$ Researchers have tested Greene's model using moral probes, which involve analyzing a lethal scenario to decide whether to commit a harmful act in order to maximize the possible number of lives saved. ${ }^{158}$ Moral probes elicit an

process model of decision-making is hypothetical and contested. See Fiery Cushman, Action, Outcome, and Value: A Dual-System Framework for Morality, 17 Personality \& Soc. Psych. Rev. 273 (2013) (suggesting shifting away from a dual-process model in favor of reinforcement-learning model, which includes more complex interactions between Systems 1 and 2); Oriel FeldmanHall, Dean Mobbs, Davy Evans, Lucy Hiscox, Lauren Navrady \& Tim Dalgleish, What We Say and What We Do: The Relationship Between Real and Hypothetical Moral Choices, 123 Cognition 434, 440 (2012) (“[O]ur moral beliefs may have a much weaker impact on our decision-making if the context is enriched with other compelling motivational forces, such as the presence of a significant self-gain.”).

150. Daniel Kahneman, Thinking, Fast And Slow 19-30 (2011).

151. Id.

152. Id. at 20-21. But see Jonathan St. B. T. Evans \& Keith E. Stanovich, Dual-Process Theories of Higher Cognition: Advancing the Debate, 8 PERSPS. ON PsYCH. SCI. 223, 227-35 (2013) (considering and responding to various criticisms of dual-process theories).

153. Evans \& Stanovich, supra note 152, at 227.

154. See KaHNEMAN, supra note 150, at 39-49.

155. See Joshua D. Greene, Leigh E. Nystrom, Andrew D. Engell, John M. Darley \& Jonathan D. Cohen, The Neural Bases of Cognitive Conflict and Control in Moral Judgment, 44 Neuron 389, 389 (2004). The dual-process model finds support in brain imaging studies investigating the neural physiology of moral decision-making. See generally Beverley Garrigan, Anna L.R. Adlam \& Peter E. Langdon, The Neural Correlates of Moral DecisionMaking: A Systematic Review and Meta-Analysis of Moral Evaluations and Response Decision Judgments, 108 BRAIN \& COGNITION 88 (2016) (reviewing data from brain imaging studies). Further discussion of the physiological underpinnings of the dual-process model is beyond the scope of this Article, which instead focuses on behavioral outputs as they relate to the capacity to form rational and reasoned moral judgments.

156. Greene et al., supra note 155, at 389, 393; see Cushman, supra note 149, at 285.

157. See, e.g., Cushman, supra note 149, at 277-78.

158. See, e.g., Marc Hauser, Fiery Cushman, Liane Young, R. Kang-Xing Jin \& John Mikhail, A Dissociation Between Moral Judgments and Justifications, 22 MIND AND 
intuitive resistance to commit harm (via System 1), which can be overcome by consciously focusing on reaching a utilitarian outcome (via System 2)-that is, saving the greatest number of lives possible. ${ }^{159}$

Research in cognitive psychiatry and neuroscience suggests that populations with delusions may have difficulties modulating System 1 and System 2 processes. ${ }^{160}$ In particular, delusional individuals may engage in more intuitive and automatic processing and less conscious and deliberative decision-making relative to healthy individuals. ${ }^{161}$ Researchers speculate that this disordered reasoning process may be related to the host of systematic errors in thinking - or cognitive biases - associated with delusions. ${ }^{162}$ These cognitive biases include a bias against disconfirmatory evidence, a bias against confirmatory evidence, liberal acceptance, and a bias to "jump to conclusions." 163

Meta-analyses and literature reviews reveal that a common trait among populations with delusions is belief inflexibility, or a diminished tendency to engage analytic reasoning to review beliefs or initial interpretations of events according to available evidence. Belief flexibility is a meta-cognitive (higher order) reasoning construct. ${ }^{164}$ Delusional individuals often exhibit an impaired ability to examine their inaccurate beliefs, to alter them in response to reflection or new evidence, and to generate and assess alternatives - a fact which, if explained to the jury, helps corroborate beliefs about impending harm that most would consider unreasonable. ${ }^{165}$

LANGUAGE 1, 3-4, 7 (2007). The paradigmatic moral dilemma is the "trolley" dilemma, where an out-of-control train is rapidly approaching five people standing on the tracks in its path. Participants must decide whether to push a large man in front of the train, thus killing the man but saving the five people on the track, or refrain from taking any action, which dooms the five people in the train's path but saves the large man. See Joshua Greene \& Jonathan Haidt, How (and Where) Does Moral Judgment Work?, 6 Trends Cognitive SCI. 517, 519 (2002).

159. Id.; see Cushman, supra note 149, at 285.

160. See Ward \& Garety, supra note 146, at 82-83; William J. Speechley \& Elton T.C. Ngan, Dual-Stream Modulation Failure: A Novel Hypothesis for the Formation and Maintenance of Delusions in Schizophrenia, 70 MED. HyPOTHESES 1210, 1211-13 (2008).

161. See Michael V. Bronstein, Jonas Everaert, Ariana Castro, Jutta Joormann \& Tyrone D. Cannon, Pathways to Paranoia: Analytic Thinking and Belief Flexibility, 113 Benav. RSCH. \& THERAPY 18, 18 (2019) (summarizing existing research and noting its tentative nature); Ward \& Garety, supra note 146 , at 83.

162. See Bronstein et al., supra note 161, at 22.

163. See McLean et al., supra note 134, at 344-45 (providing an overview of each of these cognitive biases).

164. Ward \& Garety, supra note 146 , at 81 .

165. Chen Zhu, Xiaoqi Sun \& Suzanne Ho-wai So, Associations Between Belief Inflexibility and Dimensions of Delusions: A Meta-Analytic Review of Two Approaches to Assessing Belief Flexibility, 57 BRIT. J. Clinical Psych. 59, 60 (2017) (collecting studies finding that $43-76 \%$ of individuals with non-affective psychosis were unable to consider the possibility of having been mistaken about their delusions, reduce their delusional conviction in face of hypothetical contradiction, and generate alternative explanations); Ward \& Garety, supra note 146, at 82 (reporting that studies have typically found around $50 \%$ of people with delusions are unable to accept the possibility of being mistaken). 
A recent meta-analysis found a significant association between belief inflexibility and global severity of delusions. ${ }^{166}$

Moreover, populations with delusions tend to show evidence-integration errors unrelated to delusional content. Studies have found that populations with delusions tend to exhibit a general bias against disconfirmatory evidence, or a bias against revising an initial interpretation of an event when confronted with evidence contrary to that interpretation. ${ }^{167}$ This bias, typically absent from the general population, is associated with delusions regardless of diagnosis ${ }^{168}$ and tends to increase with delusional severity. ${ }^{169}$ Two additional evidence-integration biases are associated with delusions ${ }^{170}$ : a bias against confirmatory evidence, in which individuals tend not to acknowledge the increasing plausibility of a true interpretation despite additional supporting evidence, ${ }^{171}$ and liberal acceptance, involving individuals' overrating the plausibility of absurd interpretations. ${ }^{172}$ Research suggests these three cognitive biases are related parts of a single evidence-integration cognitive process. ${ }^{173}$ Taken together, these cognitive biases reflect an impairment of a System 2 process - that is, they impair an individual's ability to consciously reflect on new information in order to modify beliefs or behavior - that increases as delusion severity worsens. ${ }^{174}$

Finally, delusions are associated with the jumping-to-conclusions bias, ${ }^{175}$ a hasty decision-making style in which a person makes "fully convinced decisions with little

166. Zhu et al., supra note 165 , at 75 .

167. McLean et al., supra note 134, at 349 (finding a greater association of bias against disconfirmatory evidence (BADE) in groups with current delusions relative to groups without current delusions, with a small effect size); Bronstein et al., supra note 134, at 5.

168. McLean et al., supra note 134, at 349. But see Jonas Everaert, Michael V. Bronstein, Tyrone D. Cannon \& Jutta Joormann, Looking Through Tinted Glasses: Depression and Social Anxiety Are Related to Both Interpretation Biases and Inflexible Negative Interpretations, 6 ClinICAL Psych. SCI. 517, 517 (2018) (finding that depression and social anxiety were associated with reduced revision of negative interpretations by disconfirmatory positive information).

169. McLean et al., supra note 134 , at 350.

170. In a 2016 meta-analysis and systemic review, Benjamin McLean found that the jumping-to-conclusions bias (JTC), BADE, bias against confirmatory evidence (BACE), and liberal acceptance (LA) "appear elevated during times of worse delusions, and appear lower (BADE, BACE, LA) or comparable to normal levels (JTC) as delusions abate." Id.

171. Id. at 345 (describing BACE as the failure to "adequately up-rate the plausibility of the true interpretation despite additional supporting evidence").

172. Id.; see also Steffen Moritz, Gerit Pfuhl, Thies Lüdtke, Mahesh Menon, Ryan P. Balzan \& Christina Andreou, A Two-Stage Cognitive Theory of the Positive Symptoms of Psychosis: Highlighting the Role of Lowered Decision Thresholds, 56 J. BEHAV. THERAPY \& EXPERIMENTAL PSYCHIATRY 12, 13-17 (2017) (providing a narrative review of studies investigating liberal acceptance, which the authors describe as "reason[ing] like "bad statisticians,' that is, ... assign[ing] meaning and momentum to weakly supported evidence").

173. McLean et al., supra note 134 , at 345,352 .

174. See Ward \& Garety, supra note 146 , at 82 .

175. See, e.g., Robert Dudley, Peter Taylor, Sophie Wickham \& Paul Hutton, Psychosis, Delusions, and the "Jumping to Conclusions" Reasoning Bias: A Systematic Review and Meta-Analysis, 42 SchizoPHRENIA BulL. 652, 656-63 (2016); So et al., supra note 132, at 160 (performing meta-analysis and finding robust evidence for JTC in individuals with psychosis compared to healthy individuals); Ward \& Garety, supra note 146, at 80 ("Systematic reviews 
contextual evidence." ${ }^{176}$ Some evidence suggests that this bias results from a failure to shift toward analytic reasoning when a conflict arises between intuitive and analytic reasoning. ${ }^{177} \mathrm{~A}$ large body of research suggests this tendency to gather scant data before reaching a conclusion may "lead to the premature acceptance of implausible ideas" and thus contribute to persistence, and perhaps formation, of delusional beliefs. ${ }^{178}$ Importantly, the presence of this bias is not associated with any particular mental illness, but rather is elevated in delusional groups across various diagnoses. ${ }^{179}$ The jumping-to-conclusions bias represents overuse of a System 1 process as it reflects reaching a conclusion without gathering and reflecting upon sufficient evidence. ${ }^{180}$

Research "strongly suggests" that these reasoning biases play a causal role in the genesis and maintenance of delusions. ${ }^{181}$ All of these biases are associated with delusions across multiple diagnoses, not merely with having schizophrenia or a psychiatric illness generally. ${ }^{182}$ Research also shows that each of the evidenceintegration biases correlates positively with delusional severity. ${ }^{183}$ Together, these systematic distortions in thinking reflect decreased engagement in analytic reasoning processes. They render populations with delusions more likely to make hasty decisions consistent with existing delusional beliefs and less likely to revise their initial interpretation of events in response to contrary evidence. In the context of emotion-laden decisions - such as those involving anger or fear-these cognitive biases may be particularly likely to result in inaccurate judgments. ${ }^{184}$

and meta-analyses demonstrate a large and consistent evidence base in over 50 studies, in which the clear majority show that individuals with delusions and psychosis make decisions on the basis of limited evidence in probabilistic reasoning tasks; the so-called 'jump-toconclusions' (JTC) data-gathering bias.").

176. Estrella Serrano-Guerrero, Miguel Ruiz-Veguilla, Agustín Martín-Rodríguez \& Juan F. Rodríguez-Testal, Inflexibility of Beliefs and Jumping to Conclusions in Active Schizophrenia, PSYCHIATRY RsCH. 1 (2020).

177. See W. J. Speechley, C.B. Murray, R.M. McKay, M.T. Munz \& E.T.C. Ngan, $A$ Failure of Conflict to Modulate Dual-Stream Processing May Underlie the Formation and Maintenance of Delusions, 25 EUR. PSYCHIATRY 80, 81, 84-85 (2010).

178. Dudley et al., supra note 175, at 652; see Savulich et al., supra note 128, at 520.

179. See McLean et al., supra note 134, at 351 (concluding that delusional status is a good predictor of JTC bias, whereas a diagnosis of mental illness, e.g., schizophrenia, is not).

180. Ward \& Garety, supra note 146, at 82 ("It is apparent that JTC may reflect the operation of [System] 1 fast processes ....").

181. Bronstein et al., supra note 134, at 1; see McLean et al., supra note 134, at 352. It is important to emphasize that psychosis is complex and multicausal, likely arising from a number of interacting genetic, biological, psychological, and social factors. See, e.g., Jim van Os \& Uli Reininghaus, Psychosis as a Transdiagnostic and Extended Phenotype in the General Population, 15 WORLD PSYCHIATRY 118, 120-21 (2016) (discussing various factors that contribute to symptoms of psychosis).

182. McLean et al., supra note 134, at 352.

183. Id. at 350 .

184. See Ward \& Garety, supra note 146 , at 82-83; KAHNEMAN, supra note 150 , at 234 44 (discussing the relative likelihood of inaccurate predictions when relying on intuition). Kahneman suggests that the reliability of intuitions reflects two basic conditions - that is, an 


\section{Emotional Dysfunction}

Delusions are also associated with emotional dysfunctions that make engagement in deliberate, analytic System 2 processing more difficult and less likely. Decades of research demonstrate that emotion plays an important (and complex) role in reason ${ }^{185}$ and moral judgment. ${ }^{186}$ Researchers have theorized that emotion is pertinent in both the automatic "social-emotional" pathway and the deliberate "cognitive" pathway processes of Greene's dual process model of moral reasoning ${ }^{187}$ : emotions can be generated intuitively; emotion regulation involves cognitive processes which can upor down-regulate emotions upon reflection; and emotion regulation can become habitual. ${ }^{188}$ Numerous studies, using various research designs, suggest that negative affect - "an umbrella term used for affective states and discrete emotions such as fear, shame, guilt, and anger"-plays a significant role in the formation, maintenance, and exacerbation of delusions, ${ }^{189}$ especially those involving persecution. ${ }^{190}$ The key role of negative affect in persecutory delusion formation and delusional interpretation suggests a link between psychosis and deficiencies in emotion regulation. ${ }^{191}$

"environment that is sufficiently regular to be predictable" and "an opportunity to learn these regularities through prolonged practice." KAHNEMAN, supra note 150, at 240.

185. A number of scholars have examined the importance of emotion for reasoning in the context of the criminal justice system. See, e.g., Laura Reider, Toward a New Test for the Insanity Defense: Incorporating the Discoveries of Neuroscience into Moral and Legal Theories, 46 UCLA L. REV. 289, 313-27, 328-29, 341 (1998); Theodore Y. Blumoff, Rationality, Insanity, and the Insanity Defense: Reflections on the Limits of Reason, 39 LAW \& Psych. Rev. 161, 167-68, 187-93 (2014-2015); Coppola, supra note 25, at 6-7, 30-49; Terry A. Maroney, Emotional Competence, "Rational Understanding," and the Criminal Defendant, 43 Am. Crim. L. Rev. 1375, 1399-1409 (2006).

186. See infra notes 188, 198-200; Yana R. Avramova \& Yoel Inbar, Emotion and Moral Judgment, 4 WIREs CoGNITIVE SCI. 169, 170-75 (2013) (assessing the evidentiary basis for three claims regarding the role of emotion in moral judgment).

187. See supra notes $155-159$ (discussing Greene's model).

188. See Chelsea Helion \& Kevin N. Ochsner, The Role of Emotion Regulation in Moral Judgment, 11 NeUROETHICS 297, 299-300 (2018).

189. Lea Ludwig, Dirk Werner \& Tania M. Lincoln, The Relevance of Cognitive Emotion Regulation to Psychotic Symptoms - A Systematic Review and Meta-Analysis, ClinICAL Psych. Rev. 1, 1 (2019).

190. See Antonio Preti \& Matteo Cella, Paranoid Thinking as a Heuristic, 4 Early INTERVENTION PSYCHIATRY 263, 263 (2010). In fact, emotion may play a role in contributing to formation of many discrete delusion subtypes. For example, clinical psychologists Daniel Freeman and Philippa Garety observed that "all the major emotions have delusions with related themes, which is consistent with a direct role for emotion in delusion formation." Daniel Freeman \& Philippa A. Garety, Connecting Neurosis and Psychosis: The Direct Influence of Emotion on Delusions and Hallucinations, 41 BEHAV. RsCH. \& THERAPY 923, 933 (2003); see id. at 933 tbl.2 (providing common themes of emotions and corresponding delusion subtypes).

191. See Anett Gyurak, James J. Gross \& Amit Etkin, Explicit and Implicit Emotion Regulation: A Dual-Process Framework, 25 Cognition \& EMOTION 400, 401 (2011) (defining emotion regulation as "goal directed processes functioning to influence the intensity, duration, and type of emotion experienced") (emphasis in original). Considerable definitional ambiguity 
A 2019 systematic review and meta-analysis concluded that emotion regulation is "markedly impaired in patients with psychotic disorders." 192 The meta-analysis found that individuals with psychosis habitually use more maladaptive emotion regulation strategies, such as rumination and suppression, ${ }^{193}$ and fewer adaptive strategies, such as cognitive reappraisal, ${ }^{194}$ compared to healthy controls. ${ }^{195}$ Further, correlative data indicated a positive association between maladaptive emotion regulation strategies and positive symptoms of psychosis such as delusions. ${ }^{196}$ An earlier review and meta-analysis found similar results concerning habitual use of emotion-regulation strategies. ${ }^{197}$

The marked impairment of emotion regulation in populations with psychosis holds important implications for moral reasoning. "Wrongfulness" is a moral judgment, and moral dilemmas (which involve an evaluation of the moral acceptability of one's or another's actions) induce negative emotions such as anger or fear in decision-makers. ${ }^{198}$ Increasing evidence shows that regulating negative emotions through cognitive reappraisal-a System 2 process - impacts moral decision-making by leading to more reason-based judgments. ${ }^{199}$ Other studies have

attends the term "emotional regulation." Ludwig et al., supra note 189, at 2 (discussing the distinction between "emotion regulation" and "coping").

192. Ludwig et al., supra note 189 , at 1 .

193. Rumination refers to "passive and repetitive focus on negative emotions or symptoms of distress." Clara Marie Nittel, Tania Marie Lincoln, Fabian Lamster, Dirk Leube, Winfried Rief, Tilo Kircher \& Stephanie Mehl, Expressive Suppression is Associated with State Paranoia in Psychosis: An Experience Sampling Study on the Association Between Adaptive and Maladaptive Emotion Regulation Strategies and Paranoia, 57 Brit. J. Clinical Psych. 291, 295 tbl.1 (2018). Suppression refers to "conscious inhibition of expressive or behavioural components of an emotion." Id.

194. Cognitive reappraisal is defined as a "cognitive change that involves changing the subjective interpretation of an emotion-eliciting event in a way that alters its emotional impact." Id. at 294.

195. Ludwig et al., supra note 189 , at 6 . "Adaptive" emotion regulation strategies are associated with better mental health outcomes, while "maladaptive" strategies are associated with poorer mental health outcomes. Nittel et al., supra note 193, at 293, 296. In particular, the meta-analysis found that individuals with psychosis were significantly more likely to habitually manage emotions through the maladaptive strategies of rumination, self-blaming, distraction, and suppression. Ludwig et al., supra note 189, at 6, 8. The effect sizes for rumination, self-blaming, and distraction were in the moderate to large range. $I d$. at 6 .

196. Ludwig et al., supra note 189, at 7-8 (including self-blaming, suppression, rumination, and maladaptive coping).

197. See Ciarán O’Driscoll, Jennifer Laing \& Oliver Mason, Cognitive Emotion Regulation Strategies, Alexithymia and Dissociation in Schizophrenia, a Review and MetaAnalysis, 34 Clinical Psych. Rev. 482, 489-92 (2014).

198. Avramova \& Inbar, supra note 186, at 172.

199. See Zhongquan Li, Shiyu Xia, Xiaoyuan Wu \& Zhaoyu Chen, Analytical Thinking Style Leads to More Utilitarian Moral Judgments: An Exploration with a ProcessDissociation Approach, 131 Personality \& Individual Differences 180, 183 (2018) (comparing an "intuitive" and "analytical" group on moral dilemma tasks); Raluca D. Szekely \& Andrei C. Miu, Incidental Emotions in Moral Dilemmas: The Influence of Emotion Regulation, 29 Cognition \& EMotion 64, 71 (2015); Matthew Feinberg, Robb Willer, Olga 
found that individuals with relatively high emotion-regulation difficulties are more likely to make intuitive, emotion-driven moral judgements. ${ }^{200}$ Since use of adaptive emotion regulation in moral probes helps to overcome intuitively generated emotions to reach a more deliberate judgment, it logically follows that populations with psychosis tend to reach less-reasoned judgments in scenarios involving intense negative emotion.

Stress makes intuitive decision-making particularly likely. Experimentally, individuals with psychosis demonstrate a stronger reaction to stressors compared to healthy controls. ${ }^{201}$ Stemming from the observation that individuals make more intuitive responses when under stress, the "stress induced deliberation-to-intuition" (SIDI) model theorizes how stress affects moral decision-making. ${ }^{202}$ The model suggests that, under stressful conditions, "intuitive responses may bypass the examination of reasoning and reach the threshold to become final decisions."203 Research has found that stress induces fewer reasoned decisions on a moral decisionmaking task using moral dilemmas, ${ }^{204}$ although results are inconsistent with everyday moral decision tasks. ${ }^{205}$ The majority of studies point to "convergent

Antonenko \& Oliver P. John, Liberating Reason from the Passions: Overriding Intuitionist Moral Judgments Through Emotional Reappraisal, 23 Psych. SCI. 788, 790-93 (2012).

200. See Lisong Zhang, Ming Kong \& Zhongquan Li, Emotion Regulation Difficulties and Moral Judgment in Different Domains: The Mediation of Emotional Valence and Arousal, 109 Personality \& Individual DifFEREnCES 56, 58 (2017) (using a set of standardized immoral scenarios and finding that emotion regulation difficulties positively predicted immorality ratings in the five moral domains of Sanctity, Harm, Fairness, Loyalty, and Authority); Lisong Zhang, Zhongquan Li, Xiaoyuan Wu \& Ziyuan Zhang, Why People with More Emotion Regulation Difficulties Made a More Deontological Judgment: The Role of Deontological Inclinations, Frontiers Psych., Nov. 2017, 1, at 5. Notably, however, although the participants in these studies were classified as having emotion regulation difficulties, they did not have psychiatric illnesses; additionally, the subjects were Chinese students so generalizability to Western culture should be made with caution.

201. Tania M. Lincoln, Maike Hartmann, Ulf Köther \& Steffen Moritz, Dealing with Feeling: Specific Emotion Regulation Skills Predict Responses to Stress in Psychosis, 228 PSYCHIATRY RsCH. 216, 219-21 (2015) (using noise stressors to show that individuals with psychotic illnesses - specifically schizophrenia and schizoaffective disorder-demonstrated more reactivity to stress both through self-report (i.e., subjective) and physiological (i.e., objective) measures).

202. See Rongjun Yu, Stress Potentiates Decision Biases: A Stress Induced Deliberationto-Intuition (SIDI) Model, 3 Neurobiology Stress 83, 83 (2016).

203. Id. at 84 ("[S]tressed individuals may fall back on more intuition and involve less amounts of conscious reasoning.").

204. See Farid F. Youssef et al., Stress Alters Personal Moral Decision Making, 37 PSYCHONEUROENDOCRINOLOGY 491, 494-95 (2012) (demonstrating a moderate negative correlation between stress and utilitarian decisions during personal moral dilemma tasks and noting that the results are in line with Greene's dual-process model).

205. While everyday moral decision tasks may be ecologically valid, they are less emotionally evocative than moral dilemma tasks and therefore are less effective at highlighting competing deontological and utilitarian processes. Compare Katrin Starcke, Christin Polzer, Oliver T. Wolf \& Matthias Brand, Does Stress Alter Everyday Moral Decision-Making?, 36 PSYCHONEUROENDOCRINOLOGY 210, 214-16 (2011) (finding no difference between groups on everyday moral decision-making tasks, although there was an association between increased 
evidence that stressed individuals are . . . less likely to exert cognitive control to examine their responses [to moral dilemmas]. ${ }^{, 206}$ Importantly, the SIDI model does not necessarily indicate that stress is detrimental to decision-making, as some situations (i.e., where fight-or-flight response is appropriate) call for an intuitive response without the need for cognitive control. ${ }^{207}$ However, in an individual with persecutory delusions, where stress has been inappropriately generated and maintained, the likelihood of a contextually inappropriate response intuitively driven by stress is high.

In sum, a host of cognitive biases and emotional impairments combine to implicate an overreliance on System 1 intuitive processing and failed engagement of System 2 analytical processing. This tendency may be particularly pronounced in situations related to delusional beliefs. Stress exacerbates the tendency to reach intuitive decisions that bypass analytic scrutiny. Forensic psychiatrists should consider these disordered patterns of reasoning and emotion regulation, along with other forms of cognitive and emotional impairment, when assessing a defendant's capacity to understand the wrongfulness of her criminal act.

\section{Implications for Sanity Evaluations}

Research suggests that deluded individuals may have a diminished tendency to accurately evaluate external events, generate options for actions, engage in reflective decision-making, and reach reasoned decisions, especially when under stress and confronted by evidence that challenges preexisting beliefs. Each of these forms of disorder may be relevant to an individual's capacity to reflect upon and appreciate the wrongfulness of her acts and should be considered in sanity evaluation along with other evidence of impairment.

The potential effect of these impairments can be illustrated through the hypothetical in the introduction. Recall that Rowl believed his parents were engaged in a homicidal plot and on the day of the killing discovered his missing gun. Rowl exhibited the jumping-to-conclusions bias by relying on inadequate information to conclude that his father had taken the gun to leave him defenseless against those planning to kill him. Liberal acceptance also helps to explain Rowl's misinterpretation: Rowl's belief in the murderous plot lowered his subjective threshold of significance for evidence in support of this belief. Thus, although a missing gun was weak evidence of his father's murderous intent, it still exceeded Rowl's subjective threshold of significance, leading to his delusional conclusion.

cortisol response and egoistic responses to high-emotional dilemmas, thus concluding that "stress overall does not impair everyday moral decision-making in the current setting, but endocrine stress responses might be related to egoistic decision-making"), with Nina Singer, Monika Sommer, Katrin Döhnel, Sandra Zänkert, Stefan Wüst \& Brigitte M. Kudielka, Acute Psychosocial Stress and Everyday Moral Decision-Making in Young Healthy Men: The Impact of Cortisol, 93 Hormones \& BeHAV. 72, 75-78 (2017) (observing that stress led to more altruistic decisions on everyday moral decision-making tasks and suggesting that the contrasting results are due to less emotionally evocative dilemmas used in the instant study compared to Starcke et al., supra).

206. Yu, supra note 202, at 91.

207. Id. at 92 . 
Additional facts are necessary to illustrate how evidence-integration dysfunction could contribute to Rowl's erroneous conclusions. Imagine that Rowl, upon discovering the missing gun, remembered that his father had lent his own gun to a friend and had an upcoming hunting trip. Imagine Rowl also noticed his hunting cap, which he shared with his father, was absent from the closet. A reasonable person in this situation may conclude his father borrowed his gun to hunt. However, because of his psychosis, Rowl exhibited belief inflexibility by failing to integrate evidence of his father's need for a gun to modify his conclusion that his father wanted to leave him vulnerable to attempted murder. He manifested bias against disconfirmatory evidence when he failed to revise his initial interpretation of the missing gun in light of contrary evidence. He also demonstrated bias against confirmatory evidence by not acknowledging the increasing plausibility of the hunting explanation when he noted the missing hunting cap. The effect of these cognitive biases in solidifying Rowl's conclusion that his father was advancing the murderous plot could have been exaggerated by Rowl's difficulty in regulating his rage and fear-especially in the stress of the moment-leading to an emotion-fueled, intuitive decision with little deliberative reflection.

Recognizing the biases and impairments that contribute to the origin, maintenance, and strengthening of delusions could assist forensic experts when interpreting a defendant's behavior and explaining their conclusions to the trier of fact. A forensic expert's evaluation focuses on a defendant's thinking and behavior at the time of the offense. ${ }^{208}$ As James Ogloff and colleagues explain, "The clinical evaluation of a defendant's mental state at the time of offense is, fundamentally, an investigative endeavor that attempts to retrospectively reconstruct the cognitive, conative, emotional, motivational, and psychopathological concomitants and determinants of the defendant's behavior at the time of the crime."209 This retrospective inquiry "always requires some degree of speculation" and thus requires "placing the data in a psychological conceptual framework that is relevant to the legal issues." ${ }^{210}$ Of course, knowledge of reasoning impairments associated with delusions does not provide direct evidence of the defendant's mental state at the moment of the criminal act, but it may suggest probabilistically how psychopathological elements could have affected the defendant's mental functioning. ${ }^{211}$ Such knowledge could also be used to buttress the expert's conclusions when explaining the relationship

208. Janofsky et al., supra note 15 , at S23.

209. James R.P. Ogloff, Caton F. Roberts \& Ronald Roesch, The Insanity Defense: Legal Standards and Clinical Assessment, 2 ApPlied \& Preventive Psych. 163, 169 (1993).

210. Id. at 168 .

211. Id. at 172; MeLton ET AL., supra note 5, $\S 8.07$, at 251 (observing that a psychiatric diagnosis "may facilitate consideration of the extent to which biological, personality, and/or situational factors influenced legally relevant behavior"); $i d$. at 250 ("With appropriate caution, examiners may even elaborate on behaviors often associated with the syndrome or diagnosis - for example, type and degree of cognitive impairment, perceptual disturbances, range and control of emotional expression, and so on ...."). 
between a defendant's mental disorder, her irrationality, and (if permitted to opine on the subject) the legal criteria of insanity to the jury. ${ }^{212}$

However, some forensic mental health professionals largely confine their consideration of delusions to their disordered content, so recognition of the cognitive and emotional processes implicated by delusions would require updating and expanding their evaluative focus in sanity evaluations. ${ }^{213}$ Brandon A. Yakush (forensic psychologist) and Melinda Wolbransky (professor of psychology) suggest that forensic mental health examiners, when assessing "whether or not the defendant's mental disorder or defect impaired his capacity to reason through the illegality of the act," ${ }^{214}$ largely focus on evidence of thought disorder-or evidence of a disturbance in the organization, processing, and interconnectivity of ideas - and ignore the potential contribution of delusions. ${ }^{215}$ Yakush and Wolbransky justify this position with their belief that delusions do not involve cognitive dysfunctions sufficiently corrosive of appreciation to warrant consideration in the general rightor-wrong test. ${ }^{216}$ They explain:

If the belief that drives the illicit behavior is sourced in mental illness (e.g., delusional ideation) . . . from a clinical perspective, the defendant likely knew the act was illegal in so far as much as he was capable of processing right- and wrong-level cognitions. Due to an absence of mental disorganization, the reasoning skills necessary to reason right and wrong were typically present. Yet, the processing of right and wrong was likely contaminated by delusional content. Thus, the defendant was able to think about right and wrong decisions but came to the wrong conclusion due to false beliefs. ${ }^{217}$

212. Whether the rules of evidence permit a forensic expert to opine on whether the defendant satisfies the legal standard for insanity varies by jurisdiction. See Comment Note: Testimony of Expert Witness as to Ultimate Fact, 78 A.L.R. 755 (Cum. Supp. 2021).

213. See Goldstein, supra note 26 , at 61 ("The criminal law does not recognize a transcendent constancy in the legal insanity status of psychotic individuals whose offense was the result of their delusional ideation. In most such cases, exculpation is based primarily on the specific content of their delusions and how it comports with the law of the jurisdiction in which the act was committed."); infra notes 214-219.

214. Yakush \& Wolbransky, supra note 26, at 360. The authors stated, "While this article focuses primarily on the issue of defining wrongfulness in California, the discussion is relevant for those other states and the federal courts that have adopted similar definitions of insanity." Id. at 357.

215. Id. at 366 ("Thus, the clinical component of insanity evaluations in California should focus primarily on the role of cognitive dysfunctions that could have impaired the defendant's ability to process right versus wrong decisions. Any other symptoms would be important only to the final decision if they somehow impaired the defendant's reasoning abilities (e.g., the auditory hallucinations were so constant and overwhelming that the individual was unable to think clearly).").

216. Id. at 360. This statement is true so long as a defendant maintained the capacity to know that society would view the act as wrong. See id. at 366.

217. Id. at 360 . 
Thus, the typical delusional defendant will be found sane. ${ }^{218}$ Yakush and Wolbransky identify one exception: delusions that involve perceived justification, such as acting in self-defense because of imminent danger, may qualify for insanity without additional signs of cognitive dysfunction. ${ }^{219}$ This position is consistent with an oftneglected rule in M'Naghten's Case called the "insane delusion rule," which is explored in the next Section. ${ }^{220}$

This perspective stands in tension with the growing scientific consensus that delusions are strongly associated with reasoning biases reflecting a diminished engagement with analytical decision-making. Key components of sanity depend on ability to reason. While cognitive biases alone may not impact the accuracy of judgments, ${ }^{221}$ research suggests they can lead to errors when combined with emotionregulation difficulties and evidence-integration dysfunction, particularly in emotionladen situations. ${ }^{22}$ Thus, forensic mental health examiners should consider the systemic, cognitive, and affective distortions associated with delusions, in addition to delusions' faulty content, in sanity evaluations and assess the extent they could have undermined a defendant's ability to understand the wrongfulness of her act.

\section{B. Ignorance of Wrongfulness}

Rather than focusing on ability, a more common way of resolving sanity inquiries involves demonstrating the defendant's actual knowledge that her act was wrong. ${ }^{223}$ In eleven jurisdictions, this inquiry is dictated by the insanity test, which expressly limits moral incapacity to a defendant's ignorance of wrongfulness due to mental disease or defect. ${ }^{224}$ The explicit focus of this inquiry differs from that in tests with a lack-of-capacity component: instead of focusing on the disability (the incapacity to know or appreciate wrongfulness), the inquiry centers on the excusing condition. ${ }^{225}$

218. See id. at 366 ("In essence, delusions or hallucinations in the absence of cognitive impairments would not ordinarily lead to the type of dysfunction necessary for the defendant to have not known his act was wrong, whether illegal or immoral.”).

219. Id. at 366-67. In addition, individuals experiencing delusions that are "so bizarre that [they] fall[] outside of society's moral framework," such as the belief that the victim is a menacing alien, may qualify for insanity. Id. at 367.

220. See infra Part II.B.1.

221. R.E.J. Dudley \& D.E. Over, People with Delusions Jump to Conclusions: A Theoretical Account of Research Findings on the Reasoning of People with Delusions, 10 Clinical Psych. \& Psychotherapy 263, 269 (2003).

222. See id. at 264, 272; supra Part II.A.2 (surveying emotional dysfunctions associated with delusions).

223. See supra note 71 and accompanying text (observing that, when applying incapacity standards, courts concentrate on the actual state of knowledge of the defendant).

224. These states include Arizona, Florida, Minnesota, Mississippi, Nebraska, New Jersey, New Mexico, Ohio, Pennsylvania, Texas, and Virginia. See Appendix.

225. See Paul H. Robinson, Insanity, 2 Crim. L. Def. $§ 173$ (July 2020 update) ("The issues . . . are distinct: the degree of impairment of capacity to know is a disability issue; whether the actor actually knew his particular conduct was wrong is an excusing condition issue. In requiring that the actor not know his conduct is wrong, M'Naghten did not require a complete impairment of capacity to distinguish right and wrong. While there may be good reason to require a substantial impairment in order to satisfy the disability requirement[,] ... 
Because ascertaining the defendant's knowledge of wrongfulness is a common aim of sanity evaluations, however, this section is widely relevant. ${ }^{226}$

\section{Insane Delusion Rule}

The tendency of some forensic psychiatrists to limit delusions' relevance to their content coheres with some jurisdictions' treatment of delusions under the "insane delusion rule," an enigmatic, subsidiary rule in M'Naghten's Case. ${ }^{227}$ This rule holds that when the defendant labored under a "partial delusion only"-meaning that her only symptom of mental illness was her delusional belief on a particular subject ${ }^{228}$ her culpability must be assessed as if the factual content of her delusion were true. ${ }^{229}$ Thus, if a person with delusions killed in self-defense, as she believed, she should be acquitted. ${ }^{230}$ But if she killed anticipating future harm, she may be convicted of intentional murder. ${ }^{231}$ The rule has been employed both in jurisdictions with ignorance-of-wrongfulness tests and in those with lack-of-capacity tests, presumably under the logic that a delusional person who believed she was acting in justified selfdefense necessarily was unable to realize her act was wrong. ${ }^{232}$ Importantly, modern cases typically ignore the "partial delusion" language and apply the rule in cases where other aspects of mental disorder are clearly evident, as with schizophrenia. ${ }^{233}$

there is no reason to believe that whenever a dysfunction is sufficient to cause a loss of 'substantial capacity to appreciate' that it necessarily will in fact cause a sufficient lack of appreciation to satisfy the excusing condition.").

226. See infra note 232 (discussing application of insane delusion rule to incapacity standards).

227. M'Naghten's Case, 8 Eng. Rep. 718, 72310 Cl. \& Fin. 200, 211 (1843). For an investigation into contemporary manifestations of this rule and their soundness, see Johnston \& Leahey, supra note 2, at 1794-1819.

228. Johnston \& Leahey, supra note 2, at 1794.

229. M'Naghten's Case, 10 Cl. \& Fin. at 211 (“'Asssuming] that he labours under ... partial delusion only, and is not in other respects insane, we think he must be considered in the same situation as to responsibility as if the facts with respect to which the delusion exists were real.").

230. Id.

231. See Ryan v. People, 153 P. 756, 758 (Colo. 1915).

232. The insane delusion rule - in carefully and repeatedly cabining its application to a defendant with a "partial delusion only, and is not in other respects insane"-limits itself to ignorance of knowledge and expressly does not extend to incapacity to appreciate wrongfulness. M'Naghten's Case, $10 \mathrm{Cl}$. \& Fin. at 211. However, most of the jurisdictions that employ the insane delusion rule only reference incapacity in their insanity standards. See infra note 237; Appendix (noting statutes for California, Georgia, Nevada, Tennessee, and the federal and military systems of justice). Moreover, although the insane delusion rule was used to interpret ignorance of knowledge, states have applied its principle to insanity standards with "appreciation" in place of knowledge. See Finger v. State, 27 P.3d 66, 84-85 (Nev. 2001) (using the insane delusion rule to exemplify and define the limits of a defendant's inability to "appreciate the wrongfulness of his act").

233. See, e.g., Finger v. State, 27 P.3d 66, 84-85 (Nev. 2001); Diestel v. Hines, 506 F.3d 1249, 1271-74 (10th Cir. 2007); GA. CODE AnN. § 16-3-3 (2018). On the other hand, Tennessee appears to limit the rule to defendants with intact reasoning capabilities. See Overton v. State, 56 S.W.2d 740, 741 (Tenn. 1933). 
Consistent with Yakush and Wolbransky's position ${ }^{234}$-and mirrored in some forensic practice guides ${ }^{235}$ - the insane delusion rule directs courts and forensic evaluators to scrutinize the content of a defendant's delusions and strictly assess whether acting under the perceived circumstances would satisfy the elements of a recognized justification or excuse. ${ }^{236}$ Appellate decisions document that nine jurisdictions employ the affirmative aspect of the rule, meaning they allow a delusion's perceived satisfaction of a legal defense (when that delusion stemmed from a mental disease or defect and motivated the criminal act) to establish a defendant's insanity without further inquiry. ${ }^{237}$ A couple of jurisdictions recognize a negative aspect as well, holding that a delusion's failure to conform to a legal justification or excuse may be fatal to her insanity claim. ${ }^{238}$ In California, for instance, when a delusion (if true) would not justify or excuse, a defendant's moral incapacity may depend on additional evidence of thought disorder and global cognitive dysfunction, such as deficits in attention, working memory, and executive functioning. ${ }^{239}$ Nevada precludes a finding of moral incapacity altogether for a person whose delusions would not justify the criminal act. ${ }^{240}$

234. See supra notes 214-219.

235. See supra note 213; Rogers, supra note 4, at 109 ("The crux of the determination can be stated simply: If the defendant's beliefs and perceptions were accurate, would they justify his or her actions?"). For an interesting and effective illustration of a forensic expert's application of the insane delusion rule, see Kate Bloch \& Jeffery Gould, Legal Indeterminacy in Insanity Cases: Clarifying Wrongfulness and Applying a Triadic Approach to Forensic Evaluations, 67 HASTINGS L.J. 913, 927-28 (2016).

236. See, e.g., Miller v. State, 940 S.W.2d 810, 813-14 (Tex. App. 1997) (describing proper and improper jury instructions in insane delusion cases); CAL. JURY INSTR. - CRIM. 4.06 (7th ed. 2016) ("A defendant who commits an act that would otherwise be criminal is not guilty by reason of insanity if the defendant was suffering from an insane delusion, and the facts perceived as real as a product of the delusion would have caused the act to be lawful."); Ga. Suggested Pattern Jury InStR. - Crim. 3.80 .30 (4th ed. 2019) ("In order for mental delusion or delusional compulsion to constitute a defense, it must appear not only that the accused was actually laboring under a delusion at the time of the commission of the alleged criminal act but that the alleged criminal act itself was connected with the particular delusion under which the accused was then laboring and that the delusion was as to a fact that, if true, would have justified the alleged act by the accused.").

237. See, e.g., Ga. Code AnN. § 16-3-3 (2018); United States v. Ewing, 494 F.3d 607, 61213 (7th Cir. 2007); United States v. Mott, 72 M.J. 319, 324-26 (C.A.A.F. 2013); People v. Leeds, 192 Cal. Rptr. 3d 906, 912 (Ct. App. 2015), as modified on denial of reh'g (Oct. 27, 2015); Martin v. State, 110 So. 3d 936, 938 (Fla. Dist. Ct. App. 2013); Finger v. State, 27 P.3d 66, 84-85 (Nev. 2001); Dukes v. State, 499 P.2d 471, 476 (Okla. Crim. App. 1972); Davis v. State, 28 S.W.2d 993, 994 (Tenn. 1930); Miller, 940 S.W.2d at 812.

238. See Leeds, 192 Cal. Rptr. $3 d$ at 912; Finger, 27 P.3d at 84-85.

239. See Johnston \& Leahey, supra note 2, at Part II.B.3 (considering California's use of the rule); see supra notes 136-137 (describing forms of cognitive impairment often associated with schizophrenia).

240. Finger, 27 P.3d at 85 (limiting insanity to delusional defendants whose delusions, "if true, would justify the commission of the criminal act"). Nevada apparently does not recognize other forms of moral incapacity. Id. at 85 ("Unless a defendant presents evidence that complies with this standard, he or she is not entitled to have the jury instructed on the issue of insanity.”). 
Many scholars, including this author, have criticized the reasoning behind - and the application of - the insane delusion rule. ${ }^{241}$ This Article will not repeat those critiques but offers two new arguments as to why and how courts should interpret this rule differently in light of modern science. First, the logic of the insane delusion rule suggests it should factor in all mental-disorder-related impairments of the defendant, not simply the content of her delusions. Second, scientific insights suggest that delusional defendants should be held to a more relaxed standard of wrongfulness than strict illegality. In essence, a jury should be permitted to excuse a deluded individual if, had her delusion been real, her action would have satisfied the basic thrust (not necessarily the particulars) of a legal defense, especially if the individual is able to explain why she thought the act was "necessary" at the time she did it. ${ }^{242}$ This would be akin to adopting a societal morality standard. ${ }^{243}$ Evidence suggests that such treatment would be more consistent with the origins of M'Naghten and would cohere with community notions of insanity and justice. ${ }^{244}$ While the cognitive and emotional impairments detailed in Part II.A lend support to these positions, these arguments can be made most forcefully by examining the science of persecutory delusions.

\section{The Special Case of Persecutory Delusions}

Persecutory delusions - defined as beliefs that others intend current or future harm to oneself $\mathrm{f}^{245}$ - are the most common type of delusion. ${ }^{246}$ Persecutory delusions are associated with violence ${ }^{247}$ and appear to be of particular significance in insanity cases. ${ }^{248}$ As Richard Rogers, a distinguished professor of psychology, reports, "[t]he most common reason why a defendant does not appreciate the wrongfulness of his

241. See, e.g., Johnston \& Leahey, supra note 2; STEPHEN, supra note 33, at 156-64; S. Sheldon Glueck, Mental Disorder and the CRiminal Law 169-71, 183, 249-53 (1925) (noting that at least eight states follow the rule); I. RAY, A TREATISE ON THE MEDICAL JURISPRUDENCE OF INSANITY $§ \S 34-35$ (Boston, Little, Brown \& Co. 4th ed. 1860).

242. See infra notes 320 \& 328 (comparing this proposal to Christopher Slobogin's Integrationist Test).

243. See infra notes 347-348 and accompanying text.

244. See infra notes 378-382.

245. See Daniel Freeman \& Philippa A. Garety, Comments on the Content of Persecutory Delusions: Does the Definition Need Clarification?, 39 BRIT. J. CliniCAL Psych. 407, 409, 412 (2000) (identifying commonalities and differences among common definitions of "persecutory delusions" and suggesting new criteria).

246. Speechley \& Ngan, supra note 160, at 1211; Preti \& Cella, supra note 190, at 263.

247. See, e.g., Jeremy W. Coid, Simone Ullrich, Constantinos Kallis, Robert Keers, Dave Barker, Fiona Cowden \& Rebekah Stamps, The Relationship Between Delusions and Violence: Findings from the East London First Episode Psychosis Study, 70 JAMA PSYCHIATRY 465, 467-70 (2013) (finding a significant association between serious violence and delusions of surveillance, persecution, and conspiracy); infra notes 296-308 (discussing the relationship between persecutory delusions, anger, and violence).

248. See, e.g., George F. Parker, Outcomes of Assertive Community Treatment in an NGRI Conditional Release Program, 32 J. AM. ACAD. Psychiatry \& L. 291, 295 tbl.1 (2004) (examining eighty-three NGRI acquittees and finding that fifty-nine (71\%) had a diagnosis of schizophrenia and fifty-four (65\%) had paranoid schizophrenia specifically). 
or her actions is because of grossly misperceived threats." 249 Research indicates that a number of perceptual and inferential cognitive processes related to information processing contribute to paranoid thinking. ${ }^{250}$ Of particular importance, attentional biases, attributional biases, and reasoning biases associated with persecutory delusions all affect a delusional person's subjective appraisal of perceived threats. ${ }^{251}$ These threats can generate anger, which may impel aggression when not effectively regulated. ${ }^{252}$

\section{a. Threat Appraisal}

A sustained body of studies documents that populations with persecutory delusions are more likely to perceive threats from ambiguous or neutral circumstances and to infer hostile intent than those without such delusions. ${ }^{253}$ Researchers hypothesize that attentional, attributional, and reasoning biases drive these appraisals.

First, investigations of cognitive biases in populations with persecutory delusions have found an attentional bias in relation to threat-related information, ${ }^{254}$ resulting in hypervigilance and excessive sensitivity to possible danger. ${ }^{255}$ Although consensus

249. Rogers, supra note 4, at 109.

250. See Dennis R. Combs, David L. Penn, Christopher O. Michael, Michael R. Basso, Rachel Wiedeman, Marsha Siebenmorgan, Joshua Tiegreen \& Dustin Chapman, Perceptions of Hostility by Persons with and Without Persecutory Delusions, 14 Cognitive NEUROPSYCHIATRY 30, 31 (2009) (observing that "[i]ncreased attention to threatening stimuli, jumping to conclusions, a failure to generate alternatives, theory of mind deficits, problems in emotion perception, and the presence of differences in attributional style have all been associated with persecutory delusions" and listing relevant reviews of these areas). The discussion in this Section - which involves how individuals with persecutory delusions tend to reason under stress and when experiencing anger-is conceptually better treated as a lack of capacity issue and may be useful for that purpose. However, to the extent that forensic examiners tend to limit conception of incapacity to formal thought disorder, the impairments discussed in this section (especially when appearing in a person not evidencing other manifestations of cognitive dysfunction) may be more fruitfully applied within the ignorance of knowledge category of insanity.

251. "“Threat appraisal' . . refers to classifying a stimulus based on its capacity for harming the organism." Raphael Underwood, Veena Kumari \& Emmanuelle Peters, Cognitive and Neural Models of Threat Appraisal in Psychosis: A Theoretical Integration, 239 PSYCHIATRY RES. 131, 133 (2016).

252. See infra Part II.B.2.a.

253. R.P. Bentall, R. Corcoran, R. Howard, N. Blackwood \& P. Kinderman, Persecutory Delusions: A Review and Theoretical Integration, 21 CuInICAL Psych. Rev. 1143, 1154-55 (2001).

254. See Antonella Trotta, Jungwoo Kang, Daniel Stahl \& Jenny Yiend, Interpretation Bias in Paranoia: A Systematic Review and Meta-Analysis, Clinical Psych. Sci. 3, 4 (2021) ("Attentional bias is thought of as the preferential selection, for further processing, of one stimulus from among multiple competing stimuli. A bias occurs when the selected stimulus is consistently of one particular type, such as threat in the case of anxiety or paranoid in the case of paranoia.").

255. Underwood et al., supra note 251, at 134. 
has not yet been reached on the precise profile of the bias, ${ }^{256}$ accumulated evidence supports a two-stage "vigilance-avoidance" model, whereby populations with persecutory delusions exhibit "an initial automatic attentional bias towards threatening material, but a subsequent controlled attentional bias away from threat." ${ }^{257}$ Researchers theorize that the first automatic attentional bias may contribute to misperceiving threat in ambiguous situations, while the second controlled bias may prevent corrective re-evaluation of information. ${ }^{258}$ This theory substantially overlaps with the dual-process model, where misperception of threat mirrors the jumping-to-conclusions bias and overuse of System 1, and the disinclination to re-evaluate information reflects a bias against disconfirmatory evidence and impaired engagement of System 2. ${ }^{259}$

Each of the biases in the vigilance-avoidance model finds support from empirical data. Consistent with an excessive initial sensitivity to and tendency to dwell on threatening stimuli, ${ }^{260}$ memory studies have found that patients with persecutory delusions show better memory for threat-related words than those without delusions and a significant tendency to repeat these words during recall. ${ }^{261}$ Patients with persecutory delusions also estimate that negative events happen more often to themselves and others, "indicating a paranoid world view in which everyone is seen as vulnerable to threat." ${ }^{262}$ A large collection of eye movement studies supports the

256. Savulich et al., supra note 128, at 517-19 (analyzing evidence in psychosis research supporting selective attention to negative information, delay in attentional disengagement from a threatening stimulus, and the vigilance-avoidance strategy).

257. Melissa J. Green \& Mary L. Phillips, Social Threat Perception and the Evolution of Paranoia, 28 Neuroscience \& Biobehavior Rev. 333, 339 (2004); see K. Prochwicz \& J. Klosowska, Attentional Focus Moderates the Relationship Between Attention to Threat Bias and Delusion-like Experiences in Healthy Adults, 39 Eur. Psychiatry 27, 31 (2017).

258. Green \& Phillips, supra note 257, at 339; Savulich et al., supra note 128, at 519.

259. See supra notes $167-80$ and accompanying text (discussing evidence integration impairment and jumping-to-conclusions bias).

260. Support for a heightened pre-attentive process of threatening information comes from investigations of pre-attentive processing of words referring to delusional themes, which found that patients with persecutory delusions were slower in naming the ink-color of threat-related words, suggesting selective attention to those words. See Richard P. Bentall \& Sue Kaney, Content Specific Information Processing and Persecutory Delusions: An Investigation Using the Emotional Stroop Test, 62 Brit. J. MeD. Psych. 355, 355-64 (1989); Nathalie Besnier, Arthur Kaladjian, Pascale Mazzola-Pomietto, Marc Adida, Eric Fakra, Régine Jeanningros \& Jean-Michel Azorin, Differential Responses to Emotional Interference in Paranoid Schizophrenia and Bipolar Mania, 44 Psychopathology 1, 7-8 (2011) (finding an emotional bias towards threatening words related to paranoia in group with schizophrenia and that paranoid interference increased with positive symptoms).

261. See Richard P. Bentall, Sue Kaney \& Kim Bowen-Jones, Persecutory Delusions and Recall of Threat-Related, Depression-Related, and Neutral Words, 19 COGNITIVE TherAPY \& Rsch. 445, 453 (1995); Sue Kaney, Melanie Wolfenden, Michael E. Dewey \& Richard P. Bentall, Persecutory Delusions and Recall of Threatening Propositions, 31 BRIT. J. CLINICAL PsYCH. 85, 85-87 (1992).

262. See Bentall et al., supra note 253, at 1154 (discussing Sue Kaney, Kim Bowen-Jones, Michael E. Dewey \& Richard P. Bentall, Two Predictions about Paranoid Ideation: Deluded, Depressed and Normal Participants' Subjective Frequency and Consensus Judgments for Positive, Neutral and Negative Events, 36 BRit. J. Clinical Psych. 349, 349-64 (1997)). 
existence of the second stage of attentional bias by showing that delusion-prone populations pay less attention than healthy controls to the salient features of threatrelated facial expressions of anger and fear and to the threatening areas of social scenes. ${ }^{263}$ These results may suggest hasty decision-making and reduced datagathering, ${ }^{264}$ in addition to hyper-vigilance. ${ }^{265}$ Interestingly, evidence suggests that, while populations with persecutory delusions tend to misidentify neutral faces as angry, ${ }^{266}$ these populations are accurate (and particularly sensitive) in gauging others' expressions of negative emotions. ${ }^{267}$

Second, studies show that populations with persecutory delusions demonstrate a hostile intent attribution bias. ${ }^{268}$ Hostile intent attribution bias refers generally to responding in a hostile manner to ambiguous $\operatorname{cues}^{269}$ and is associated with resulting anger. ${ }^{270}$ Research has consistently demonstrated that populations with persecutory

263. See Tobias E. Hillmann, Jürgen Kempkensteffen \& Tania M. Lincoln, Visual Attention to Threat-Related Faces and Delusion-Proneness: An Eye Tracking Study Using Dynamic Stimuli, 39 Cognitive THERAPY Rsch. 808, 808-09 (2015) (reviewing visual scanpath studies of facial expressions); see also Green \& Phillips, supra note 257, at 335-37 (reviewing visual scan-path studies of facial expressions and photographs of social scenes).

264. See Hillmann et al., supra note 263, at 813.

265. Underwood et al., supra note 251, at 134.

266. Amy E. Pinkham, Colleen Brensinger, Christian Kohler, Raquel E. Gur \& Ruben C. Gur, Actively Paranoid Patients with Schizophrenia Over Attribute Anger to Neutral Faces, 125 SCHIZOPHRENIA RsCH. 174, 174 (2011).

267. See Green \& Phillips, supra note 257, at 334 (reporting "robust evidence for superior emotion perception in paranoid schizophrenia patients ... specifically with regard to negative emotions" and suggesting "heightened perception of certain negative emotions may be relevant to the genesis of persecutory delusions"); Penelope J. Davis \& Melissa G. Gibson, Recognition of Posed and Genuine Facial Expressions of Emotion in Paranoid and Nonparanoid Schizophrenia, 109 J. ABNORMal Psych. 445, 448-49 (2000) (finding individuals with paranoid schizophrenia displayed greater accuracy in recognizing genuine facial expression of negative emotions and surprise than individuals with nonparanoid schizophrenia and the control group).

268. See Erin B. Tone \& Jennifer S. Davis, Paranoid Thinking, Suspicion, and Risk for Aggression: A Neurodevelopmental Perspective, 24 Dev. \& Psychopathology 1031, 1039 (2012); Combs et al., supra note 250, at 45-46 (finding the group with persecutory delusions, but not the psychiatric or nonpsychiatric control groups, showed a bias for perceiving hostility in ambiguous situations); Suk Kyoon An, Jee In Kang, Jin Young Park, Kyung Ran Kim, Su Young Lee \& Eun Lee, Attribution Bias in Ultra-High Risk for Psychosis and First-Episode Schizophrenia, 118 SCHIZOPHRENIA RsCH. 54, 54 (2010) (finding an attribution bias for perceiving hostility and blaming others in first-episode patients with schizophrenia, which was associated with persecutory symptoms, as well as participants at ultra-high risk for psychosis).

269. Thomas Suslow et al., Automatic Amygdala Response to Facial Expression in Schizophrenia: Initial Hyperresponsitivity Followed by Hyporesponsitivity, 14 BMC Neuroscience, 2013, at 4 (using neuroimaging to show that schizophrenia patients initially showed greater amygdala activation to neutral face expressions compared to healthy controls, although this was followed by subsequent amygdala hypoactivity in the patient group; the authors interpreted the latter finding as possibly protecting the patient from environmental overstimulation).

270. See Raymond W. Novaco, Cognitive-Behavioral Factors and Anger in the Occurrence of Aggression and Violence, in THE Wiley HANDBOoK OF Violence \& 
delusions tend to blame others rather than situations for negative outcomes. ${ }^{271}$ Experimentally, patients with psychosis have shown difficulties processing negative information, ${ }^{272}$ which researchers have suggested causes misinterpretation of what others intend to communicate. ${ }^{273}$ A hostile attributional bias may contribute to an individual with persecutory delusions perceiving a threat where none is actually present. ${ }^{274}$ For instance, studies have found that populations with persecutory delusions over-attribute anger to neutral faces, ${ }^{275}$ tend to misinterpret fearful faces as angry and threatening, ${ }^{276}$ and are more prone to attribute hostility and aggression to ambiguous social situations. ${ }^{277}$ Importantly, a recent study found that patients with persecutory delusions exhibited a heightened perception of harm in relation to neutral events as compared to individuals with high anxiety and healthy controls. ${ }^{278}$

Third, researchers speculate that myriad reasoning biases reinforce paranoid beliefs and contribute to the formation and maintenance of persecutory delusions. ${ }^{279}$

AgGression, 329, 333 (Peter Sturmey ed., 2017).

271. See Paul Kinderman \& Richard P. Bentall, Causal Attributions in Paranoia and Depression: Internal, Personal, and Situational Attributions for Negative Events, $106 \mathrm{~J}$. ABNORMAL PSYCH. 341, 344 (1997) (demonstrating empirically that patients with paranoia tended to make external, personal attributions for negative events when nonpatients tended to choose situational or circumstantial external attributions).

272. Fumiaki Ito, Kazunori Matsumoto, Tesuo Miyakoshi, Noriyuki Ohmuro, Tomohiro Uchida \& Hiroo Matsuoka, Emotional Processing During Speech Communication and Positive Symptoms in Schizophrenia, 67 Psychiatry \& CliniCAL Neurosciences 526, 52830 (2013) (finding a prominent correlation between positive symptoms and inappropriate responses when processing affectively negative information); Norichika Iwashiro, Yosuke Takano, Tatsunobu Natsubori, Yuta Aoki, Noriaki Yahata, Wataru Gonoi, Akira Kunimatsu, Osamu Abe, Kiyoto Kasai \& Hidenori Yamasue, Aberrant Attentive and Inattentive Brain Activity to Auditory Negative Words, and Its Relation to Persecutory Delusion in Patients with Schizophrenia, 15 Neuropsychiatric Disease \& Treatment 491, 497-98 (2019) (finding decreased brain activity in response to negatively valenced words in schizophrenia patients, which correlated with positive symptoms and delusional behavior).

273. Ito et al., supra note 272, at 529.

274. Tone \& Davis, supra note 268, at 1036 (listing studies suggesting that adults with clinically significant persecutory delusions and normal-range paranoid ideation show a bias to overattend to various kinds of threat cues, "even in the absence of real danger," but noting that other research has failed to detect such biases in these populations).

275. Pinkham et al., supra note 266, at 177.

276. Ivy F. Tso, Anita M. Calwas, Jinsoo Chun, Savanna A. Mueller, Stephan F. Taylor \& Patricia J. Deldin, Altered Attentional and Perceptual Processes as Indexed by N170 During Gaze Perception in Schizophrenia: Relationship with Perceived Threat and Paranoid Delusions, 124 J. ABNORMal PSYCH. 519, 519 (2015).

277. Combs et al., supra note 250, at 31 (finding the group with persecutory delusions, but not the psychiatric or nonpsychiatric control groups, showed a bias for perceiving hostility in ambiguous situations).

278. Suzanne Ho-wai So, Xiaoqi Sun, Gloria Hoi Kei Chan, Iris Hiu Hung Chan, Chui De Chiu, Sherry Kit Wa Chan, Wai Yin Elisabeth Wong, Patrick Wing-leung Leung \& Eric Yu Hai Chen, Risk Perception in Paranoia and Anxiety: Two Investigations Across Clinical and Non-Clinical Populations, 21 Schizophrenia Rsch. 1, 5-6 (2020).

279. Prochwicz \& Klosowska, supra note 257, at 28 ("Delusional ideation may develop since attentional bias along with data gathering bias of JTC favour the development of false 
Early research stressed the key role of the jumping-to-conclusions bias to maladaptive appraisals. ${ }^{280}$ This data-collection bias, perhaps cultivated by a perceived need for closure and discomfort with ambiguity, ${ }^{281}$ could contribute to a tendency to rapidly appraise ambiguous information on the basis of limited evidence without a thorough consideration of alternatives. ${ }^{282}$ In addition, individuals under stress may use the heuristic ${ }^{283}$ of paranoia to "increase the chances of perceiving threatening stimuli or prevent the chance of missing a real menace, eventually creating the preconditions for the development of delusional ideation." 284

In support, consider the observation that populations with psychosis often demonstrate safety-seeking behaviors ${ }^{285}$ in response to situations perceived as threatening. ${ }^{286}$ Safety-seeking behaviors are associated with increased levels of anxiety and depression, suggesting the behaviors are at least partially related to fear and distress. ${ }^{287}$ When faced with an ambiguous situation, an individual with persecutory delusions may jump to the conclusion that there is a risk of harm and engage in safety-seeking, and, since the individual has a diminished capacity to reflect on behaviors associated with the delusion, she may incorrectly conclude that the harm was avoided because of the safety-seeking, thus reinforcing the delusional

interpretations of neutral events, which are then maintained and fixed by other biases, such as confirmation bias, belief inflexibility and external attribution bias.").

280. Helen Startup, Daniel Freeman \& Philippa A. Garety, Jumping to Conclusions and Persecutory Delusions, 23 Eur. Psychiatry 457-59 (2008) (finding evidence of jumping to conclusions in a psychiatric group characterized by persecutory delusions); Underwood et al., supra note 251, at 133; Tone \& Davis, supra note 268, at 1038 (collecting studies finding a significant association between JTC bias and vulnerability to paranoid thoughts).

281. See Ryan McKay, Robyn Langdon \& Max Coltheart, Jumping to Delusions? Paranoia, Probabilistic Reasoning, and Need for Closure, 12 Cognitive NeUROPSYCHIATRY 362,362 (2007) (finding that patients with a history of persecutory delusions scored higher on need for closure than the controls); Richard P. Bentall \& Rebecca Swarbrick, The Best Laid Schemas of Paranoid Patients: Autonomy, Sociotropy, and Need for Closure, 76 PsYch. \& PSYCHOTHERAPY 163, 169 (2003) (finding that currently ill psychotic patients with persecutory delusions and remitted paranoid patients scored higher on the need for closure, indicating a high intolerance for ambiguity). But see Daniel Freeman, Philippa Garety, Elizabeth Kuipers, Susannah Colbert, Suzanne Jolley, David Fowler, Graham Dunn \& Paul Bebbington, Delusions and Decision-Making Style: Use of the Need for Closure Scale, 44 BEHAV. Rsch. $\&$ THERAPY 1147, 1155 (2006) (finding any potential effect of the need for closure on psychotic symptoms was indirect and mediated through affect).

282. Garety \& Freeman, supra note 132 , at 328.

283. See Preti \& Cella, supra note 190, at 263-64 (defining heuristic as "a highly economical method of decision-making that can lead to systematic and predictable errors").

284. Id.

285. Daniel Freeman, Philippa A. Garety, Elizabeth Kuipers, David Fowler, Paul E. Bebbington \& Graham Dunn, Acting on Persecutory Delusions: The Importance of Safety Seeking, 45 BeHAV. RsCH. \& THERAPY 89, 90 (2007) (defining safety-seeking behaviors as "actions designed to prevent [a] feared catastrophe from occurring"); see also id. at 92-93 (enumerating several types of safety-seeking behaviors).

286. Id. at 93 (finding that ninety-six out of 100 participants with persecutory delusions reported using safety-seeking behaviors within the previous month).

287. Id. at 96. 
belief. $^{288}$ Importantly, novel cognitive and meta-cognitive therapies, which rely on forced engagement of System 2 analytical reflection, ${ }^{289}$ demonstrate that encouraging populations with persecutory delusions to consciously avoid use of safety-seeking behaviors in a feared environment can drastically reduce delusional conviction. ${ }^{290}$ This suggests that System 2, while not completely abolished, may be impaired in populations with persecutory delusions, leading to overreliance on faulty System 1.

\section{b. Anger and Emotion Regulation Impairment}

Difficulties in regulating emotions may contribute to the formation and maintenance of persecutory delusions. ${ }^{291}$ Studies show that negative affect often precedes paranoid ideation, which, in turn, leads to presentation of psychotic symptoms. ${ }^{292}$ Negative affect may be, at least in part, the byproduct of an inability to mitigate stress. One study of the effect of stress on populations with psychosis found

288. This feedback loop may continue where the individual continues engaging in safetyseeking behaviors when confronted with situations perceived as stressful or potentially harmful. Since aggression is one of the commonly recognized safety-seeking behaviors, it logically follows that each loop carries the risk of an aggressive reaction, which might lead to violence. See infra notes 296-308.

289. Commonly used therapies include cognitive-based therapy (CBT) and metacognitive training (MCT). See Tania M. Lincoln \& Emmanuelle Peters, A Systematic Review and Discussion of Symptom Specific Cognitive Behavioural Approaches to Delusions and Hallucinations, 203 SCHIZOPHRENIA RSCH. 66, 66 (2017) ("The main instrument of change in $[\mathrm{CBT}]$ involves reframing appraisals and modifying behavior related to psychotic symptoms, to reduce distress and improve functioning and well-being."); Steffen Moritz et al., Complementary Group Metacognitive Training (MCT) Reduces Delusional Ideation in Schizophrenia, 151 SchizophrenIA Rsch. 61 (2013) (discussing MCT). Even beyond the use of these therapies in addressing safety-seeking behaviors, the therapies have shown to be effective in reducing delusional conviction and positive symptoms of psychosis more generally. See, e.g., Lincoln \& Peters, supra note 289, at 75-76; Steffen Moritz, Christina Andreou, Brooke C. Schneider, Charlotte E. Wittekind, Mahesh Menon, Ryan P. Balzan \& Todd S. Woodward, Sowing the Seeds of Doubt: A Narrative Review on Metacognitive Training in Schizophrenia, 34 CliniCAL Psych. Rev. 358, 363-64 (2014).

290. See Daniel Freeman et al., Virtual Reality in the Treatment of Persecutory Delusions: Randomised Controlled Experimental Study Testing How to Reduce Delusional Conviction, 209 BRIT. J. PSYCHIATRY 62 (2016) (using virtual reality environment to expose participants to a feared environment and demonstrating that such exposure in conjunction with dropping safety-seeking behaviors reduced delusional conviction significantly more than exposure alone).

291. See Stefan Westermann \& Tania M. Lincoln, Emotion Regulation Difficulties Are Relevant to Persecutory Ideation, 84 Psych. \& Psychotherapy: TheOry, Rsch., \& Practice 273, 281-83 (2011).

292. See Ingrid Kramer, Claudia J. P. Simons, Johanna T. W. Wigman, Dina Collip, Nele Jacobs, Catherine Derom, Evert Thiery, Jim van Os, Inez Myin-Germeys \& Marieke Wichers, Time-Lagged Moment-to-Moment Interplay Between Negative Affect and Paranoia: New Insights in the Affective Pathway to Psychosis, 40 Schizophrenia Bull. 278, 284 (2014) (using time-lagged analysis to show that negative affect precedes everyday paranoia, which, when accumulated, caused psychotic symptoms). 
that, within the psychosis group, the ability to accept and regulate emotions predicted both the strength of the physiological response as well as the change in level of paranoia. ${ }^{293}$ Research has also demonstrated that anxiety increases paranoid thoughts and the occurrence of certain cognitive biases. ${ }^{294}$ Moreover, since populations with delusions demonstrate impaired emotion regulation, it is plausible that populations with persecutory delusions fail to down-regulate negative affect, which, when accumulated, could lead to psychotic symptoms. ${ }^{295}$

This may lead to violent results, especially in situations involving intense anger. Although most individuals with psychosis will never commit an act of violence, there is a "modest but consistent association" between psychosis, particularly persecutory delusions, ${ }^{296}$ and violent offending. ${ }^{297}$ Research has consistently demonstrated that anger mediates the relationship between delusions and violence. ${ }^{298}$ A longitudinal study of 1136 civil psychiatry inpatients after discharge found "strong associations" between threat-based delusions, anger, and violence. ${ }^{299}$ This study found that anger

293. Lincoln et al., supra note 201, at 219-20; see supra text accompanying note 201.

294. See Steffen Mortiz, Pia Burnette, Sabine Sperber, Ulf Köther, Marion HagemannGoebel, Maike Hartmann \& Tania M. Lincoln, Elucidating the Black Box from Stress to Paranoia, 37 Schizophrenia Bull. 1311, 1311 (2011) (finding that stress increased paranoid symptoms and significantly increased the jumping-to-conclusions bias in schizophrenia patients with acute psychotic symptoms); Tania M. Lincoln, Jennifer Lange, Julia Burau, Cornelia Exner \& Steffen Moritz, The Effect of State Anxiety on Paranoid Ideation and Jumping to Conclusions. An Experimental Investigation, 36 Schizophrenia BULl. 1140, 1145-46 (2009) (finding that induced state anxiety increased paranoid thoughts and jumping to conclusions in healthy participants vulnerable to psychosis symptoms); Steffen Moritz, R. Veckenstedt, S. Randjbar, B. Hottenrott, T.S. Woodward, F.V. v. Eckstaedt, C. Schmidt, L Jelinek \& T. M. Lincoln, Decision Making Under Uncertainty and Mood Induction: Further Evidence for Liberal Acceptance in Schizophrenia, 39 PsYch. MED. 1821, 1827 (2009) (finding that patients with delusions made decisions more quickly than healthy controls when listening to anxiety-evoking music).

295. See Westermann \& Lincoln, supra note 291, at 282 (“[T]he usually functional emotion regulation strategy of reappraising emotional evocative situations in a neutral or nonthreatening manner could be corrupted by hasty decisions due to jumping-to-conclusions ... .”).

296. See Robert Keers, Simone Ullrich, Bianca L. DeStavola \& Jeremy W. Coid, Association of Violence with Emergence of Persecutory Delusions in Untreated Schizophrenia, 171 Am. J. Psychiatry 332, 333, 335 (2014); Simone Ullrich, Robert Keers \& Jeremy W. Coid, Delusions, Anger, and Serious Violence: New Findings from the MacArthur Violence Risk Assessment Study, 40 Schizophrenia Bull. 1174, 1176-77 (2014).

297. Matthew M. Large \& Olav Nielssen, Violence in First-Episode Psychosis: A Systematic Review and Meta-Analysis, 125 SCHIzOPHRENIA RsCH. 209, 209-10 (2011) (noting that the risk of homicide in untreated schizophrenia is one in 630).

298. See Ullrich et al., supra note 296, at 1176-80; Coid et al., supra note 247, at 467-70; Shuja Reagu, Roland Jones, Veena Kumari \& Pamela J. Taylor, Angry Affect and Violence in the Context of a Psychotic Illness: A Systematic Review and Meta-Analysis of the Literature, 146 SCHIZOPHRENIA RsCH. 46, 46-48 (2013) (including eleven studies with a variety of psychiatric diagnoses and finding significantly higher anger scores for violent groups compared to nonviolent groups).

299. See Ullrich et al., supra note 296, at 1178. The effect remained significant after accounting for demographic characteristics, alcohol/drug use disorders and other comorbid 
mediated the pathway between serious violence and five delusion subtypes, including "being spied upon, being followed, being plotted against, having thoughts inserted, and being under external control." ${ }^{300}$ The results of this study mirrored those found in an earlier study, which considered 458 first-episode psychosis patients over the twelve months prior to contact with psychiatric services. ${ }^{301}$ That study found significant association between "serious" violence and delusions of being spied on, persecution, and conspiracy - a pathway also mediated by anger due to delusional beliefs. ${ }^{302}$ The consistency in these results is notable given the large sample sizes of diverse populations at different stages in the course of psychiatric illness. ${ }^{303}$

Importantly, all of the delusional beliefs associated with violence imply threat to the individual, which suggests that anger develops as a response to feelings of being threatened ${ }^{304}$ It is well accepted that "[t]hreat perception is fundamental to anger activation," as anger is viewed as a natural response to survival challenges. ${ }^{305}$ As Raymond Novaco has observed, although "anger is neither necessary nor sufficient for aggression or violence," it does impel aggression, "particularly when its intensity overrides regulatory control mechanisms." 306 These regulatory mechanisms require reappraisal, ${ }^{307}$ which is impaired in populations with delusions, as previously discussed. ${ }^{308}$

Thus, it is possible to construct a pathway leading to development and maintenance of persecutory delusions resulting in acts of serious violence. Aberrant stress response coupled with belief inflexibility and dysfunctional emotionregulation strategies may impede the down-regulation of angry affect and reconsideration of a threat. The more intense the feelings of anger, the less likely the individual will be able to down-regulate the anger, resulting in a higher likelihood of serious violence. Consequently, because of her mental disorder, the deluded individual could commit a serious violent act based on intuitions and without the input of reflective thought.

pathology, substance use, and trait anger. Id.

300. Id. at 1176-79 (classifying violence as "serious" if it involved "(1) batteries that resulted in physical injury or involved the use of a weapon; (2) sexual assaults; or (3) threats made with a weapon in hand," and noting that violent acts "committed in self-defense were not counted as violent behavior").

301. Coid et al., supra note 247, at 467-70.

302. Id. at 467-68 (defining "serious" violence as "assault resulting in injury or involving use of a lethal weapon, threat with a lethal weapon, or sexual assault").

303. Compare id. at 466-70 (assessing ethnically diverse individuals with first-episode psychosis across a range of diagnoses over the twelve months preceding contact with psychiatric services), with Ullrich et al., supra note 296, at 1175-76 (considering a large sample with primarily white ethnic backgrounds and a variety of psychotic diagnoses in a longitudinal study following discharge from acute inpatient facilities).

304. See Ullrich et al., supra note 296, at 1178-80.

305. Novaco, supra note 270, at 333.

306. Id. at 331 .

307. Id. at 335 .

308. See supra Part II.A.2. 


\section{Subjectivizing the Insane Delusion Rule}

M'Naghten's insane delusion rule-and arguably the common stance that "wrong" should be construed as "legal wrong" 309 - trains courtroom actors' attention on the content of a defendant's delusions and whether, had they been real, they would have provided a complete legal defense. ${ }^{310}$ Following courts' lead, forensic examiners scrutinize the delusional defendant's objective in engaging in the criminal act and emphasize that a moral incapacity assessment will typically turn on the delusion's conformance with a legal defense. ${ }^{311}$ As Richard Rogers writes in his introduction to insanity evaluations, "[ $t]$ he crux of the determination can be stated simply: If the defendant's beliefs and perceptions were accurate, would they justify his or her actions?" 312 However, the justness of this approach turns on whether the delusional defendant likely possessed - and could have fairly been expected to exercise - adequate reasoning abilities while in the throes of psychosis. ${ }^{313}$

When drafted in 1843, M'Naghten's insane delusion rule cohered with prevalent theories of phrenology and monomania, ${ }^{314}$ which conceptualized the brain as consisting of separate parts, whereby one area could be diseased while the others remained unaffected. ${ }^{315}$ Under these theories, the insane delusion rule conceivably made sense: if a delusion's effect was confined to the content of that delusion, its holder could be expected to engage in sound moral decision-making around that content. ${ }^{316}$ Commentators have long recognized that the insane delusion rule operates similarly to the mistake-of-fact doctrine, with delusion substituting for the reasonableness of the mistake. ${ }^{317}$ In essence, the rule subjectivizes the mistake-of-

309. More than a dozen states define "wrong” as illegal, Kahler v. Kansas, 140 S. Ct. 1021 , 1035 n.10 (2020) (listing sixteen states), while the majority conceptualize wrongfulness as contrary to public or societal standards of morality, State v. Hamann, 285 N.W.2d 180, 184 (Iowa 1979). Public morality usually equates to legality, however, because insanity cases typically involve serious crimes. GOLDSTEIN, supra note 7, at 52. For a discussion of the interconnectedness of the insane delusion rule and moral incapacity, see infra note 325 .

310. Johnston \& Leahey, supra note 2, at 1842-43.

311. See Rogers, supra note 4, at 109; Yakush \& Wolbransky, supra note 26, at 357.

312. Rogers, supra note 4, at 109.

313. For this reason, a number of courts have declined to follow the insane delusion rule. See Ryan v. People, 153 P. 756, 759 (Colo. 1915) ("It practically holds a man, confessed to be insane, accountable for the exercise of the same reason, judgment, and controlling mental power that is required of a man in perfect mental health."); infra note 371 (listing cases rejecting insane delusion rule).

314. See Glueck, supra note 241, at 169-70; G.W. KeEton, Guilty But Insane 193 (1961).

315. See Weinofen, supra note 35, at 110 (describing "monomania" as "essentially a state of mind characterized by the predominance of one insane idea, while the rest of the mind was normal" and "phrenology" as the "theory that the brain was a bundle of some twenty-seven different organs presiding over the different traits of the individual").

316. Heinrich OpPenheimer, The Criminal Responsibility of LunAtics 215 (1909) ("The theory ... . of the English law then is that an isolated delusion lies imbedded, like a foreign body, in a brain which is and remains normal all around.").

317. Rollin M. Perkins \& Ronald N. Boyce, Criminal Law 965 (3d ed. 1982); Edwin R. Keedy, Ignorance and Mistake in the Criminal Law, 22 HARV. L. REV. 75,87 (1908); 
fact rule - completely. In limiting the rule to defendants who "labour[] under . . . partial delusion only, and [are] not in other respects insane," the justices in M'Naghten expressed their belief that, by treating the defendant "as if the facts with respect to which the delusion exists were real," they were taking into account every aspect of the defendant's mental disorder. ${ }^{318}$ The rule directs the trier of fact to stand in the shoes of the disordered defendant, view circumstances as she perceived them, and then apply the law that applies to everyone else.

Application of the rule's logic in light of modern science requires the trier of fact, when viewing the world from the perspective of the defendant, to take into account every aspect of her mental disorder, including any related cognitive and emotional dysfunction. ${ }^{319}$ In this way, the rule would comport with the modern trend to subjectivize the criminal law, including defenses. ${ }^{320}$ Only by interpreting the situation from the defendant's viewpoint and psychological context can the trier of fact assess the defendant's culpability in responding to that situation. ${ }^{321}$ However, doing so will likely reveal the incoherence and inhumanity of the current formulation of the rule, which only excuses the conduct of delusional defendants whose objectives (within their warped perception of reality and disordered frame of

OPPENHEIMER, supra note 316, at 218.

318. M'Naghten's Case, 8 Eng. Rep. 718, 723, 10 Cl. \& Fin. 200, 211 (1843); supra note 229.

319. Admittedly, although this approach would satisfy the logic of the rule, it apparently would contradict its express language. See supra note 229.

320. See Christopher Slobogin, An End to Insanity: Recasting the Role of Mental Disability in Criminal Cases, 86 VA. L. Rev. 1199, 1217-20 (2000) [hereinafter Slobogin, An End to Insanity]. Christopher Slobogin has proposed something similar with his Integrationist Test. See id. at 1236 (proposing "the insanity defense should be abolished and . . . people with mental disorder should have a complete defensive claim only when they lack mens rea or act for reasons that sound in justification or duress," such that they would satisfy the MPC's justification or duress standard); Christopher Slobogin, A Defense of the Integrationist Test as a Replacement for the Special Defense of Insanity, 42 TEX. TECH L. REv. 523, $541 \mathrm{n} .123$ (2009) [hereinafter Slobogin, A Defense] (noting that M'Naghten's insane delusion test is "very similar" to the Integrationist Test he proposes). The proposal ultimately offered in this Article differs from his in key respects, however. See infra notes 330-331 and accompanying text.

321. See Johnston \& Leahey, supra note 2, at 1851 (proposing a jury instruction that the jury, when assessing a delusional defendant's ignorance of the wrongfulness of her act, "attempt to interpret and experience the delusional facts as the defendant would have in that moment—or ... [stated differently], from the viewpoint of the defendant"). For an example of subjectivation in the context of delusion-driven crime, see United States v. Mott, 72 M.J. 319, 333 (C.A.A.F. 2013) ("Under the defense theory, Appellant's schizophrenia not only made him think that JG was the gang leader who previously raped and tried to kill him and now was back to kill him, but also that he faced imminent death and had no option but to kill JG. Even if a rational person would have understood that he could report JG to the authorities or run away, Appellant asserted that he was unable to process these options like a rational person, and therefore was unable to appreciate that he was not acting in self-defense by attacking JG - that is, Appellant was unable to appreciate that attacking JG was wrongful."); Johnston \& Leahey, supra note 2, at 1808-10 (discussing this case in the context of the insane delusion rule). 
reasoning) happened to accord with the rules of conduct required for individuals with sound decision-making abilities.

Subjecting the Rowl hypothetical to the insane delusion rule under a subjective approach is illustrative. Rowl's disorder likely made him especially attentive to threat-relevant information (the missing gun) consistent with his paranoid delusions. This attentional bias, in concert with cognitive biases to make strong judgments based on little information, distorted his representation of reality with a delusional connotation. The missing gun alerted him to a possible threat, worried him, and directed further attention to that fact as well as to associated paranoia-relevant information in local and temporal proximity. Evidence integration biases may have impaired Rowl's ability to revise his belief in light of contradictory evidence (the planned hunting trip and missing cap), thus cementing his paranoid belief and increasing delusional conviction. Manifesting hostile intent attribution bias, Rowl attributed aggression to his father's taking of the gun, experienced a heightened perception of harm, and responded in a hostile and angry manner. Feelings of stress and anxiety likely stoked his feelings of paranoia, magnified the effect of his jumping-to-conclusions bias, reduced his ability to engage in deliberative processing, and contributed to his interpreting the ambiguous statement- "he will have to be stopped"- as confirmation of impending harm. His distorted perception of reality hindered his ability to generate options for action and colored his evaluation of options generated. ${ }^{322}$ Rowl's mounting fear resulted in overwhelming anger, which ultimately overrode his impaired regulatory control mechanisms, impelling aggression. As an expert witness testified in the trial that inspired these facts, "he was at the mercy of his rage, which effectively prevented him from reflecting on his actions or taking into consideration the consequences of his behavior." 323

Instructing the trier of fact to interpret and experience the delusional facts as Rowl would have in that moment-given the cognitive and emotional impairments associated with his paranoid schizophrenia — and assess whether, had that situation been accurate, his action would have been legally justified, may leave the jury bewildered and disturbed. If the perceived circumstances had been real, then Rowl's parents, with a history of trying to kill him with poisoned vitamins, had removed his sole means of defense and just voiced plans to murder him. Experiencing the delusional facts as Rowl likely did, the jurors would believe Rowl felt overwhelming fear, panic, and rage, rendering him unable to notice evidence that contradicted his persecutory delusion and incapable of generating and evaluating alternative courses of action. In that predicament, would taking his father's life appear necessary to him to prevent death or serious bodily harm? If so, perhaps he should be acquitted on grounds of insanity. If not, he may be guilty of murder.

322. Annemarie Kalis \& Gerben Meynen, Mental Disorder and Legal Responsibility: The Relevance of Stages of Decision Making, 37 InT'L J.L. \& Psychiatry 601, 603-07 (2014) (discussing effect of delusions on generation of options of action and selection among those options); id. at 606 ("In this selection stage, there does not seem to be room for contemplations like: Is it really true that I am being persecuted ... ? The nature of delusions is such that beliefs produced by them are in fact unshakable, and all the alternative options are likely to arise within the constraints of the person's distorted perception.").

323. State v. Rawland, 199 N.W.2d 774, 778 (Minn. 1972). 
As this discussion illustrates, research demonstrates the fallacy of presuming a psychotic defendant can soundly reason about the content of her delusions. ${ }^{324}$ Certainly delusional circumstances that, if true, would have provided a legal defense demonstrate the defendant's ignorance of the wrongfulness of her criminal act. However, given the cognitive and emotional impairments associated with delusions, it is not necessarily the case that a delusion whose perceived circumstances fall just outside the contours of a legal defense signals moral blameworthiness. A different, more just, approach is needed to ensure that the moral quality of the defendant's objective, within her psychological context, is properly reflected in the sanity evaluation.

\section{Broadening the Meaning of "Wrongfulness"}

Subjectivizing the insane delusion rule challenges the logic and fundamental fairness of defining "wrong" as illegal—both within the context of the rule itself and for purposes of moral incapacity. ${ }^{325}$ As Edwin Keedy asserted in 1908:

In order that the defendant may escape criminal liability because he acted under an insane delusion it is clear that the standard of an ordinary, reasonable man cannot be applied, because the definition of delusion indicates that the belief of the defendant is not in accord with the impression which would ordinarily be obtained from the situation by the use of the senses. ${ }^{326}$

324. The central scientific insight offered in this article - that the presence of delusions suggests a disordered reasoning process especially likely to generate irrational and impulsive judgments in the context of those delusions - has been offered many times in the past. See Johnston \& Leahey, supra note 2, at 1788 n.46.

325. Scholars and courts have recognized (and debated) the intimate relationship between the insane delusion rule and the general test for moral incapacity. See WeIHOfEN, supra note 35 , at 107-08 (" $[$ S]ince the judges were not professing to reform or modify the law, but merely to state the law of England as it then was, it seems that this mistake of fact test was not intended by the judges as a distinct test, but as entirely consistent with the right and wrong test they had just set forth."); Dennis R. Klinck, "Specific Delusions" in the Insanity Defence, 25 CRIM. L.Q. 458, 466-70 (1983) (considering and rejecting the view that the insane delusion rule is a separate test from the general rule); Mott, 72 M.J. at 324-26 (stating that "evidence that-if the facts of the accused's delusions were true - then his conduct would not violate the law" would demonstrate he did not appreciate his act's wrongfulness); United States v. Ewing, 494 F.3d 607, 619-20 (7th Cir. 2007) (using the insane delusion rule to inform its definition of "wrong" for purposes of moral incapacity). The tests are clearly synergistic. See Johnston \& Leahey, supra note 2, at 1842-43 (explaining why "the insane delusion rule may reduce the defendant's likelihood of ultimately prevailing" on the moral incapacity test). Case law suggests that, even in jurisdictions that espouse a moral (not legal) wrong standard for purposes of moral incapacity, application of the insane delusion may largely dictate the result of the general wrongfulness inquiry. See People v. Leeds, 192 Cal. Rptr. 3d 906, 914 (Ct. App. 2015), as modified on denial of reh'g (2015); Yakush \& Wolbransky, supra note 26, at 362 (opining that the narrow definition of morality in California basically eliminates the distinction between moral and legal wrongfulness); infra note 366 and accompanying text.

326. Keedy, supra note 317 , at 88. 
Assessing circumstances from the viewpoint of a paranoid defendant with serious mental disorder might lead a trier of fact to conclude that the defendant's ability to deliberate upon her response to a perceived threat was so impaired, and the emotions propelling her to action so great, that she cannot fairly be blamed for acting on her fear; in other words, her response - although disproportionate for a "reasonable" person - was understandable. ${ }^{327}$ Under this logic, the science of delusions suggests the trier of fact should be permitted to consider whether the delusions that propelled a criminal act and generally cohere to the basic thrust of a justification or excuse so affected the defendant's "experience of choosing" and the moral quality of her act that the defendant should not be subject to moral censure. ${ }^{328}$

This proposal appears to differ significantly from that proposed by Christopher Slobogin. Slobogin has argued that "the insanity defense should be abolished and . . . people with mental disorder should have a complete defensive claim only when they lack mens rea or act for reasons that sound in justification or duress" ${ }^{229}$ such that they would satisfy the MPC's justification or duress standard. ${ }^{330}$ Slobogin would recognize as exculpatory, for instance, a delusional belief that "such force is immediately necessary for the purpose of protecting [the defendant] against the use of unlawful force by such other person on the present occasion." 331 Thus, a defendant would have a viable defense if she proved to the trier of fact that her use of force was objectively proportionate to what she believed the victim was threatening and that she believed the force was necessary to prevent the victim's attack. However, the MPC's definition of a justification or excuse may well be more demanding than what a jury would find necessary to satisfy the gist of that justification or excuse in a particular jurisdiction for purpose of the insanity defense. ${ }^{332}$ In this way, the proposal

327. Crucially, this Article does not advocate for a completely subjective moral wrongfulness standard. Persuasive arguments exist for why "wrong" should hew to societal standards of morality. See State v. Crenshaw, 659 P.2d 488, 493 (Wash. 1983) (en banc); People v. Serravo, 823 P.2d 128 (Colo. 1992) (en banc).

328. See Richard J. Bonnie, Presentation at Conference on the Affirmative Defense of Insanity in Texas: Why "Appreciation of Wrongfulness" Is the Morally Preferable Standard for the Insanity Defense 55 (Feb. 7, 2003) (transcript available at https://www.txpsych.org/wpcontent/uploads/2016/02/insanitytranscript.pdf [https://perma.cc/5RVC-5EM3]). Of course, it will be up to the trier of fact to determine whether within the perceived circumstances of the defendant's delusion - with her mentally diseased mindset and emotional composition - she believed her actions cohered with societal morality (and, within the circumstances as she perceived them, would have), such that she was unable to appreciate the fundamental wrongfulness of her act. For issues to consider (and questions to ask) when assessing a delusional defendant's objectives in the context of misperceived threats or responsibilities, see Rogers, supra note 4, at 109.

329. Slobogin, An End to Insanity, supra note 320, at 1246.

330. Id. at $1218-20$.

331. Model Penal Code § 3.04(1) (Am. L. Inst. 1985); see Slobogin, An End to Insanity, supra note 320 , at $1218-20$.

332. Cf. infra notes 373-76 (discussing justificatory content of delusions in jurisdictions not employing a legal wrong standard). The MPC could be useful, though, in supplying an "external, objective standard" by which to measure the defendant's delusional justificatory or excusing belief in those jurisdictions with such a requirement for the insanity defense. See infra notes 363, 365-70 and accompanying text (discussing California case law). 
offered here more forcefully delinks the excuse from the necessity component of the delusional justification.

Expanding the standard of legality used in the insane delusion rule to capture a broader conception of justified or excused action would permit expression of societal notions of morality for delusion-driven behavior. ${ }^{333}$ Scholars often argue that "the distinction between legal and moral wrong is, on the whole, unimportant; for as to most serious antisocial acts, law and morals are indistinguishable." ${ }^{334}$ The most commonly recognized difference between the two standards appears in the context of deific decrees. ${ }^{335}$ Results under the two standards may also differ, however, in cases of perceived justified action. ${ }^{336}$

Indeed, applying an understanding of "wrong" broader than illegal to delusiondriven behavior - at least through the moral incapacity test ${ }^{337}$-appears consistent with M'Naghten's Case. ${ }^{338}$ The English judges defined "wrong" as a moral wrong that is also contrary to law in the context of the general wrongfulness test of insanity. ${ }^{339}$ The judges made clear this standard should apply "in all cases," including "where a person alleged to be afflicted with insane delusion[s] respecting one or more particular subjects or persons, is charged with the commission of a crime." ${ }^{340}$ On the other hand, the judges expressly limited the standard of legal wrongfulness to the context of "those persons who labour under such partial delusions only, and are not in other respects insane," 341 which shows this stricter standard applies only when no

333. Importantly, the components of "know" and "wrong" are reciprocally related, and the meanings of one or both may allow a finding of insanity on the basis of perceived justification. On the one hand, a person who, because of a mental illness-induced delusion, believed her criminal act to be morally justified could be found irresponsible because she did not know her act was morally wrong. On the other hand, she also probably could be found insane on the basis that she lacked a substantial capacity to appreciate the criminal wrongfulness of her act. Model PenAl Code $\S 4.01$ cmt. 3, at 170 (AM. L. InST. 1985); GoldSTEIN, supra note 7, at 52-53.

334. GLUECK, supra note 241, at 220; see GOLDSTEIN, supra note 7, at 52-53.

335. Margaret E. Clark, The Immutable Command Meets the Unknowable Mind: Deific Decree Claims and the Insanity Defense After People v. Serravo, 70 DENV. U. L. REV. 161, 168 (1992) (asserting that "the occurrence of the deific decree is recognized as the only general instance of wrong as purely moral wrong").

336. Model Penal Code $\S 4.01 \mathrm{cmt}$. 3, at 169-70 (Am. L. Inst. 1985) (noting that the difference between legal and moral wrong may "matter significantly . . . where the wrongfulness standard is taken to refer to the actor's own moral perception . . . in a case in which the defendant thinks that an act he knows to be legally prohibited is commanded by God or otherwise morally justified") (emphasis added); see infra notes 367-70 (listing illustrative cases).

337. See supra note 325.

338. See People v. Serravo, 823 P.2d 128, 135-36 (Colo. 1992) (en banc); People v. Schmidt, 110 N.E. 945, 946-48 (N.Y. 1915).

339. M'Naghten's Case, 8 Eng. Rep. 718, 723, 10 Cl. \& Fin. 200, 210 (1843) ("If the accused was conscious that the act was one which he ought not to do, and if that act was at the same time contrary to the law of the land, he is punishable ....").

340. Id. at 209.

341. Id. at 211 ; see supra note 229. 
additional symptoms of mental disorder are present. ${ }^{342}$ Indeed, the court stressed the test must "depend on the nature of the delusion," indicating that delusions not partial should be held to the moral wrong standard applicable to the general test. ${ }^{343}$ Also, the judges might have intended the insane delusion doctrine merely to provide an example of moral incapacity, not to define wrongfulness. ${ }^{344}$ Finally_and perhaps most decisively - the fundamental task of the English judges in M'Naghten was to articulate the governing law of insanity (not to divine a new test), ${ }^{345}$ and English common law had consistently understood wrongfulness to reflect "principles of general morality rather than ... . enactments of positive law." 346

Adopting an expanded understanding of wrongfulness within the insane delusion rule would resemble the moral incapacity tests currently employed by a subset of jurisdictions with a societal morality standard. As legal scholar Kate Bloch and forensic psychiatrist Jeffery Gould explain, under a "hybrid" approach to societal moral wrongfulness,

the trier of fact would ... look through the microscope to see the event through the defendant's delusion, but in evaluating whether the event violated society's morals, the trier of fact would apply society's view of the conduct. . . . . [T] he trier of fact would presumably apply some reasonable person, or more generalized societal vantage point, or the principles of the criminal code itself, to assess whether society would find [the defendant's] conduct morally wrong. ${ }^{347}$

Thus, in these jurisdictions, a defendant's sanity would turn on the "trier of fact's perception of whether society would find that conduct violated societal morality." 348

The modified insane delusion rule proposed by this Article would operate similarly. A forensic expert would assist the trier of fact to see and understand the relevant events from the perspective of the delusional defendant. Attention would focus on the defendant's motivations and reasons for acting. The expert would testify to the defendant's perception of external circumstances, associated emotions, cognitive and emotional dysfunctions, and reasoning processes at the moment of the criminal act. When the defendant acted for delusional reasons that sound in justification or excuse, the court would instruct the trier of fact to assess

342. See supra notes $228,314-15$.

343. M'Naghten's Case, 10 Cl. \& Fin. at 211; see also supra note 229.

344. I am grateful to Chris Slobogin for offering this observation.

345. See M'Naghten's Case, $10 \mathrm{Cl}$. \& Fin. at 208 (noting that the judges were "confin[ing] their answers to the statement of that which they hold to be the law upon the abstract questions proposed by [the House of Lords]").

346. Henry Montagu Randall Pope, A Treatise on the Law and Practice of Lunacy 385 (2d ed. 1890); see Anthony Platt \& Bernard L. Diamond, The Origins of the "Right and Wrong" Test of Criminal Responsibility and Its Subsequent Development in the United States: An Historical Survey, 54 CALIF. L. REV. 1227, 1233-37, 1247-48 (1966) (tracing the history of "knowledge of right and wrong" prior to M'Naghten and concluding that, "during the early nineteenth century, the phrases 'good and evil' and 'right and wrong' were used interchangeably and synonymously”); People v. Schmidt, 110 N.E. 945, 946-47 (N.Y. 1915).

347. Bloch \& Gould, supra note 235, at 934.

348. Id. at 935 . 
wrongfulness from a "generalized societal vantage point" informed by the underlying principles or thrust of the criminal code, as opposed to its particulars. Particularly important would be whether (and why) the defendant believed the act was necessary. The ultimate focus should be whether the delusions so affected the defendant's decision-making and the moral quality of her act that she should be excused from moral censure.

The benefits of assessing a delusional defendant's objectives by societal views of morality (or a looser view of legality) rather than strict legality - both in the context of the insane delusion rule and the general moral incapacity test-are substantial. First, such a standard would allow consideration of the moral nature of the defendant's action within her particular psychological context. ${ }^{349}$ Second, while factoring in "the baneful effects of various forms of mental illness on the cognitive capacity of the human mind," 350 this standard would be sufficiently objective, as it would reflect the trier of fact's understanding of generally accepted standards of morality as opposed to a defendant's personal moral code. ${ }^{351}$ Third, it avoids the perplexing and likely disturbing task of holding a psychotic defendant to typical standards of rationality and thus may resolve possible issues of jury confusion. ${ }^{352}$ Finally, a moral (or broader legal) standard avoids probing the complexities of a delusion and the imagination of the delusional defendant to determine if all preconditions of a legal defense would have been satisfied had the delusion been real. ${ }^{353}$ Additionally, juries inevitably "exercise a moral judgment as to the sanity of the accused," 354 so such a standard makes both theoretical and pragmatic sense.

However, subjecting a defendant's delusional reasoning to a broader legal wrong standard - perhaps especially in the case of misperceived threats ${ }^{355}$ - is not immune

349. See People v. Serravo, 823 P.2d 128, 135-36 (Colo. 1992) (en banc) (“[W]e are of the view that limiting the definition of 'wrong' to 'legal wrong' results in stripping legal insanity of a significant part of its psychological components."); AM. BAR Ass'N, supra note 32, at 344 ("Use of the term criminality suggests to triers of fact that they ignore even the most florid effects of delusions and hallucinations in any case in which a defendant's conduct would still be criminal had the delusions been true or the hallucinations real.").

350. Serravo, 823 P.2d at 137.

351. See id. at 138.

352. See Fred Cohen, Insanity and the Law: Toward a Rational Development of Criminal Responsibility, 39 DICTA 325, 333 (1962) (discussing the plight of a juror who "decried the lack of dignity in the proceedings, the communication barriers, and the jury's inability to reach a rational decision"); supra note 326 and accompanying text.

353. See Glanville Williams, Criminal Law: The General Part 502 (2d ed. 1961) ("Only an exceptionally clear-headed lunatic would be able to furnish all these details of his delusion.”).

354. Sauer v. United States, 241 F.2d 640, 649 (9th Cir. 1957), overruled in part by Wade v. United States, 426 F.2d 64 (9th Cir. 1970); see Holloway v. United States, 148 F.2d 665, 666-67 (D.C. Cir. 1945) ("The application of these tests [of insanity] . . . to a borderline case can be nothing more than a moral judgment that it is just or unjust to blame the defendant for what he did.").

355. See People v. Leeds, 192 Cal. Rptr. 3d 906, 914 (Ct. App. 2015) (holding that "[w]hatever may be the standard for knowing an act is morally compelled is of no moment" because the defendant's "conduct was based on the legal doctrine of self-defense"), as modified on denial of reh'g (Oct. 27, 2015). 
from objections. ${ }^{356}$ One serious objection to permitting exculpation when a delusional defendant believed she acted in accord with the general thrust of a legal defense is that no consensus exists on what a "general thrust" would mean, ${ }^{357}$ so such a stance would be akin to endorsing a personal standard of morality. ${ }^{358}$ This could imperil the "certainty, objectivity or security for evaluation by the courts or society at large." 359 Sanctioning a personal code of morality could undercut the normative function of the law and reduce its deterrent force. For instance, the California Supreme Court found that a "schizophrenic and paranoid" defendant's genuine belief that he was justified "according to defendant's personal, prison-influenced standards" in killing a fellow inmate who threatened a future attack did not require a finding of moral incapacity. ${ }^{360}$ The court explained, "This is necessarily so if organized society is to formulate standards of conduct and responsibility deemed essential to its preservation or welfare, and to require compliance, within tolerances, with those standards." $" 361$

Consequently, states have struggled to balance deference to the jury's assessment of generally accepted standards of morality with a desire to tether misperceived harm allegations to external, objective standards. California provides a good example. The state allows a delusion's strict conformance to a legal justification to establish a defendant's inability to understand wrongfulness in the context of an insane delusion case. ${ }^{362}$ However, when the perceived facts of a delusion would not have provided a defense, a mental disease may still support a finding of moral insanity so long as the defendant adduces additional evidence of (a) actual belief that her actions were morally justified according to her perception of generally accepted ethical or moral principles derived from an external source, ${ }^{363}$ or (b) an inability (i.e., a lack of the

356. Others may argue no principled reason exists to privilege delusions of justification or excuse; rather, irresponsibility should turn on "the 'intensity of the psychotic experience,' meaning the degree to which psychosis detaches the individual from reality" or "the ability to correct factual premises." Slobogin, A Defense, supra note 320, at 535-36 (describing Richard Bonnie's objection to Slobogin's Integrationist Test and the position of Stephen Morse and Morris Hoffman). However, unlike Slobogin's Integrationist Test, the proposal offered here is not to limit mental-disorder-related exculpation to delusional "reasons that sound in justification or duress." Slobogin, An End to Insanity, supra note 320, at 1246 (also recognizing exculpation when mental disorder negates mens rea). Rather, this Article recognizes an irresponsibility framework that includes an insane delusion rule, both because that rule may hold value and because, regardless of its value, courts actively employ the rule. See Johnston \& Leahey, supra note 2. Its argument is that one way to apply the rule justly may be to factor a delusional defendant's reasoning impairments into the rule by dislodging its tethering to strict illegality in favor of a broader sense of social morality.

357. Cohen, supra note 33, at 52-54.

358. See State v. Hamann, 285 N.W.2d 180, 184 (Iowa 1979) (holding that "wrong” should only be considered in its legal capacity because a moral standard would be "amorphous and shifting" and "therefore invite[] the functional equivalent of jury nullification").

359. Clark, supra note 335 at 178.

360. People v. Rittger, 355 P.2d 645, 653 (Cal. 1960).

361. Id. at 653 .

362. People v. Skinner, 704 P.2d 752, 762 n.13 (Cal. 1985).

363. See People v. Coddington, 2 P.3d 1081, 1144 (Cal. 2000), as modified on denial of reh'g (Sept. 27, 2000), overruled on other grounds by Price v. Super. Ct., 25 P.3d 618 (Cal. 
cognitive abilities necessary) to understand the wrongfulness of her act. ${ }^{364}$ While morality "need not reflect the principles of a recognized religion and does not demand belief in a God or other supreme being, it does require a sincerely held belief grounded in generally accepted ethical or moral principles derived from an external source." $" 365$

Appellate court decisions show California courts' struggle to fairly apply the external source requirement in moral incapacity cases involving delusional, misperceived threats of harm. At least one court has held that, when a defendant's perceived moral justification sounds in self-defense, generally accepted moral standards equate to those of legality, necessitating that the trial court provide jury instructions on the perceived (delusional) defense so the jury can properly evaluate the moral incapacity claim. ${ }^{366}$ Other cases suggest less rigorous enforcement of the external source requirement in cases of delusional threats of harm or perceived necessity. ${ }^{367}$ Most provocatively, one appellate opinion indicates that acts taken in

2001).

364. Cf. Skinner, 704 P.2d at 762 n.13 (observing that the second delusion mentioned in M'Naghten - "that the deceased had inflicted a serious injury to his character and fortune, and he killed him in revenge for such supposed injury"- "without more, does not suggest that the defendant believes his act is lawful or morally justified" (emphasis added)). See supra Part II.A.

365. Coddington, 2 P.3d at 1144.

366. See People v. Leeds, 192 Cal. Rptr. 3d 906, 912 (Ct. App. 2015) ("Without applying the facts as [the defendant] perceived them to the law of self-defense, the jury would have no way of evaluating whether his paranoid schizophrenia rendered him incapable of appreciating the wrongfulness of his actions."), as modified on denial of reh'g (Oct. 27, 2015). Perhaps for this reason, forensic mental health professionals have opined that the narrow definition of morality in California basically eliminates the distinction between moral and legal wrongfulness. Yakush \& Wolbransky, supra note 26, at 362.

367. See People v. Nelson, A094445, 2003 WL 1958803, at *9 (Cal. Ct. App. Apr. 28, 2003) (quoting approvingly this closing argument, in a case involving perceived threat of harm from the victim's father as well as personal religious views, as consistent with the moral wrong standard: "The position of the defense expressed during closing argument was that defendant felt a 'moral responsibility' as a mother to 'protect her child,' not as a 'moral standard that reflects her distorted thinking,' but as 'one of the most commonly-understood phenomenas of human nature. It goes to the heart of our concept of morality. Her reasons for thinking the child needed protection may have been distorted, may have been delusional. But the act of protecting your baby from harm is accepted and respected by our society"); People v. Stress, 252 Cal. Rptr. 913, 923 (Ct. App. 1988) (observing that "Appellant's explanation for killing his wife was liberally sprinkled with comments indicating her death would contribute to some higher good" and thus might have qualified for insanity under a moral wrong theory); People v. Mills, No. E028485, 2002 WL 1309128, at*8 (Cal. Ct. App. June 17, 2002) (upholding jury instructions and observing: "[The jury] would have considered any moral standard, including one that approves of euthanasia, provided it viewed such a standard as 'generally accepted.' It would then have asked whether defendant knew that his conduct violated even such a standard. It evidently found that mercy killing is not a generally accepted moral standard and/or that defendant knew he was not engaged in a mercy killing"); People v. O'Rourke, No. D062132, 2013 WL 6154369, at *2-6 (Cal. Ct. App. Nov. 25, 2013) (affirming conviction and discussing the jury's apparent rejection of defendant's argument that he lacked the ability to appreciate the moral wrongfulness of his act because he killed elementary school children 
delusional, perceived self-defense or defense of others - even if the alleged facts would not clearly satisfy the legal criteria of either defense ${ }^{368}$-may warrant a finding of insanity under M'Naghten's insane delusion rule. ${ }^{369}$ Still, other cases suggest that how near a delusion comes to meeting the elements of the perceived defense contributes to the evaluation of moral incapacity. ${ }^{370}$

To the extent courts fear that explicitly endorsing a looser standard of legal wrong in the context of perceived justification or excuse could veer too close to a subjective standard, courts could opt to reject the insane delusion rule and simply employ the jurisdiction's moral incapacity test, defining “wrong" in reference to society's moral standards or leaving the term undefined. ${ }^{371}$ Indeed, appellate decisions suggest that simply not defining "wrong" for the jury — the majority approach ${ }^{372}$ — could yield the results anticipated by allowing the gist of a perceived legal defense to satisfy the insane delusion rule. ${ }^{373}$ Jurisdictions not defining "wrong" often permit a broader, more general understanding of legal defenses-particularly self-defense-to permeate insanity cases. ${ }^{374}$ In these jurisdictions, the defendant's subjective sense of justification may factor into the general right-wrong calculus without being subjected

in an effort to stop longstanding perceived persecution, including torture, threats to his life, holding him captive, and making false claims he committed rape, and stressing: "This is not a case where a defendant attacked his perceived persecutors"); see infra note 369 (discussing People v. Torres).

368. See People v. Torres, 26 Cal. Rptr. 3d 518, 521-22 (Ct. App. 2005) (reporting the defendant's belief he was the "Victim of a Medical Conspiracy" in which doctors, over the course of ten years, "had injected him with 'a deadly experiment,' possibly the AIDS virus" and were now refusing to help him).

369. In Torres, the appellate court reversed the jury's finding of sanity because the trial court's instruction required the defendant to prove his inability to distinguish both legal and moral wrong. Id. at 526. The court explained: Defendant offered evidence that he was suffering under the delusion that doctors were injecting him and others with lethal materials and that he felt morally justified in killing doctors to protect himself and others. A jury could accept this evidence as establishing that defendant could not distinguish between moral right and moral wrong. As stated in M'Naghten's Case, "[I]f under the influence of his delusion he supposes another man to be in the act of attempting to take away his life, and he kills that man, as he supposes, in self-defence, he would be exempt from punishment." Defendant had the right to have the jury make the determination whether he fell within that rubric, but the erroneous instruction denied him of that right. Id.

370. See People v. Dennis, No. B236745, 2013 WL 3853178, at *16 (Cal. Ct. App. July 24,2013 ) ("Whether appellant acted in revenge or to prevent further harm or death was a factor relevant to whether appellant knew that what she did was morally wrong, whether or not that factor was also relevant to whether she knew that what she did was legally wrong.").

371. See, e.g., Ryan v. People, 153 P. 756, 758 (Colo. 1915); Parsons v. State, 2 So. 854, 866 (Ala. 1887); Kearney v. State, 8 So. 292, 292 (Miss. 1890); Kraus v. State, 187 N.W. 895, 899 (Neb. 1922). For a discussion of possible benefits engendered by the insane delusion rule, see Johnston \& Leahey, supra note 2, at 1837-41.

372. GoldSTEIN, supra note 7, at 52; State v. Hamann, 285 N.W.2d 180, 184 (Iowa 1979).

373. See, e.g., State v. Abercrombie, 375 So. 2d 1170, 1178-79 (La. 1979); State v. Crenshaw, 659 P.2d 488, 497 (Wash. 1983) (en banc); Ivery v. State, 686 So. 2d 495, 500 (Ala. Crim. App. 1996); supra note 356356 (explaining the intent of the proposal).

374. See infra note 375. 
to an elemental analysis. ${ }^{375}$ Case law suggests that subjectively feeling justifiedwhen the facts, as believed, generally cohere with the basic thrust of the justification (even if, admittedly, quite warped)—will militate in support of the defendant's general insanity claim. Indeed, Daniel M'Naghten, whose delusions of persecution (if true) would likely not have justified using deadly defensive force, seems to have benefited from such a sentiment. ${ }^{376}$ Crucially, to achieve results similar to those that could be reached with a broader insane delusion rule, forensic practice would need to recognize the potentially exculpatory nature of a larger swath of delusions. Some forensic treatises and practice guides appear to support this practice now. ${ }^{377}$

A final benefit of expanding the insane delusion rule to recognize the exculpatory nature of delusions consistent with the gist of a legal defense- or of allowing the jury to employ their own notions of morality in this setting - may be that doing so would comport with what Norman Finkel has called "commonsense justice," the

375. See, e.g., State v. Chanthabouly, 262 P.3d 144, 162 (Wash. Ct. App. 2011) (approving the trial court's decision to permit the defendant to introduce evidence and argument that he acted under a delusional belief of self-defense without reference to the elements of that defense); State v. Dangerfield, 214 So. 3d 1001, 1018-19 (La. Ct. App. 2017) (finding that Louisiana courts, to reverse a conviction on grounds of insanity, typically require a showing that the defendant "articulated to a degree [her] belief that there was some justification" for her alleged criminal act and briefly discussing relevant cases); Moler v. State, 782 N.E.2d 454, 458-59 (Ind. Ct. App. 2003) (reluctantly affirming conviction but emphasizing the near certain "conclusion" that the defendant held a "firmly sustained' belief that [the victim] was a witch from which he needed to protect himself" without mentioning that the perceived facts, if true, would not have permitted deadly force); Dixon v. State, 668 So. 2d 65, 72 (Ala. Crim. App. 1994) (reversing a conviction for attempted murder of a police officer in part because of "evidence that the appellant was suffering from a delusion that the assault was necessary to ensure the appellant's safety"); State v. Roy, 395 So. 2d 664, 668 (La. 1981) (reversing a conviction where the defendant was "markedly preoccupied with blacks and their 'evil' nature" and felt that "he was going to war for his country" and was "executing God's will").

376. Daniel M'Naughten, in his single public statement concerning his motive, explained,

[The Tories] follow, persecute me wherever I go, and have entirely destroyed my peace of mind. . . I I cannot sleep nor get no rest from them in consequence of the course they pursue towards me ... They have accused me of crimes of which I am not guilty, they do everything in their power to harass and persecute me; in fact, they wish to murder me.

Richard Moran, Knowing Right from Wrong: The Insanity Defense of Daniel McNaughtan 10 (1981). As the Nevada Supreme Court observed, "M'Naghten was not legally insane because, even if his delusion were true and the prime minister was conspiring to kill M'Naghten, this would not entitle M'Naghten to take the law into his own hands and hunt down the prime minister." Finger v. State, 27 P.3d 66, 73 (Nev. 2001) (mistakenly attributing this conclusion to the House of Lords).

377. See Rogers \& SHUMAN, supra note 17, at 200 ("Impaired knowledge of wrongfulness is most commonly observed with instances of misperceived necessity for self-defense. We use 'self-defense' as a descriptive term to represent the defendant's general motivation and not as strictly defined affirmative defense. . . Conclusions about impaired knowledge of wrongfulness must take into account the degree of threat (e.g., death vs. slanderous letters) and its immediacy."). 
ordinary person's notions of what is blameworthy and what is not. ${ }^{378}$ Research suggests that jurors may consider delusional, general motives of self-defense or defense of others to be exculpatory. A few of the small number of studies on the effect of delusional content have found that mock jurors tend to deem action tied delusionally to a crime - regardless of the delusion's strict conformance with a legal justification ${ }^{379}$ — exculpable on grounds of mental disorder, especially if the behavior appeared relatively unplanned. ${ }^{380}$ For example, in a mock jury study involving 289 participants, psychologists Caton Roberts and Stephen Golding found that verdict distributions in a murder case were not influenced by whether delusional content involved self-defense ("in imminent danger of being "exterminated") or a belief of persecution without fear of death. ${ }^{381}$ While subjects distinguished defendants by their perceived degree of imminent danger and appreciation of wrongfulness, they found both defendants equally nonculpable because of their incapacity to act differently. ${ }^{382}$ Other studies have found "the emotion of fear (e.g., the desire to protect oneself, as in the rape and self-defense cases) generally leads to a true not guilty, whereas other strong emotions (e.g., jealousy, envy, anger, betrayal, revenge, sexual desire) typically lead to a true guilty verdict." 383

\section{CONCLUSION AND FUTURE STEPS}

This Article uses the origins of modern insanity tests and the science of delusions to argue that a broader range of cognitive and emotional impairments should factor into insanity cases. M'Naghten's Case expressly links knowledge to reasoning, so any impairment destructive of rationality should be as relevant to moral incapacity in jurisdictions requiring ignorance of an act's wrongfulness as in those focusing on inability to appreciate it. More controversially, the Article also argues that research on the cognitive and emotional impairments associated with delusions, particularly with regard to persecutory delusions, calls for a different assessment of the

378. See Norman J. Finkel, Commonsense Justice: Jurors' Notions of the LaW (1995).

379. Caton F. Roberts \& Stephen L. Golding, The Social Construction of Criminal Responsibility and Insanity, 15 LAW \& HUM. BEHAV. 349, 359-60 (1991).

380. See Caton F. Roberts, Stephen L. Golding \& Frank D. Fincham, Implicit Theories of Criminal Responsibility, 11 LaW \& Hum. Behav. 207, 225 (1987) (finding in a study of 181 undergraduates that $95 \%$ of subjects arrived at NGRI judgments when crime-relevant delusions were combined with lack of painfulness, and concluding that "the prototypic insanity acquittee acts impulsively in response to a crime-relevant delusional idea"); Roberts \& Golding, supra note 379, at 359-60 (finding, in a mixed sample of 145 undergraduates and 144 community members, that the relative probability of an NGRI verdict was $40 \%$ for planful conduct and $54 \%$ for nonplanful defendants).

381. Roberts \& Golding, supra note 379, at 359-60; see id. at 355 (describing delusional content of vignettes).

382. Id. at 358-59. The researchers concluded, "The degree of delusional involvement in the mens rea of even the non-self-defense cases led a majority of subjects to conclude that it was not just to find criminal guilt in such persons despite the degree of apparent capacity for criminal intent and appreciation evidenced by the defendant." Id. at 370 .

383. Norman J. Finkel \& Jennifer L. Groscup, Crime Prototypes, Objective Versus Subjective Culpability, and Commonsense Balance, 21 LAw \& Hum. BeHAv. 209, 225 (1997). 
defendant's state of knowledge. Currently, forensic practice guides, court decisions, and a dominant understanding of "wrong" indicate that a defendant will only be found ignorant of the wrongfulness of her delusion-fueled criminal act if the circumstances of her delusion, had they been real, would have provided a legal defense. Instead, the modern understanding of delusions militates toward considering the defendant's cognitive and emotional impairments when assessing her response to a perceived (delusional) threat. It also calls for a broader understanding of "wrong" that extends beyond illegality and could excuse actions taken in conformance with the general thrust of a perceived legal justification or excuse, so long as the trier of fact feels that the defendant's objectives cohered with societal standards of morality.

Effectuating these changes would necessitate a transformation in defense-side perceptions of moral incapacity, modifications in jury instructions, and an invigoration of the practice of defense attorneys and forensic experts. ${ }^{384}$ Legal experts have suggested that defense attorneys and forensic experts may unblinkingly accept narrow conceptions of the key functionality ("know" or even "appreciate") in insanity tests, ${ }^{385}$ and that forensic experts tend to offer conclusory opinions on sanity without much reasoning in support. ${ }^{386}$ These practices must change. Despite misconceptions about the narrow category of impairments relevant to insanity, ${ }^{387}$ courts overwhelmingly admit all mental state evidence, whether cognitive, emotional, or volitional. ${ }^{388}$ Moreover, although often not providing jury instructions on key terms such as "know," 389 when they do, courts tend to define these terms broadly. ${ }^{390}$ Defense counsel should work to educate themselves on reasoning impairments associated with psychosis, ${ }^{391}$ educate their forensic experts on the scope of impairments relevant to legal insanity, ${ }^{392}$ help develop testimony on these sources of dysfunction, ${ }^{393}$ and request jury instructions on their relevance to the legal test. ${ }^{394}$

In addition, forensic experts should expand the scope of their examinations, ${ }^{395}$ the detail provided in their sanity evaluation reports, ${ }^{396}$ and the testimony given at trial. Forensic scholars have long complained of the low standards applied by evaluators

384. Abraham Goldstein advocated for many of these reforms in 1967. See GoLDSTEIN, supra note 7, at 94 .

385. See supra notes 19-20, 25.

386. See supra notes $15-16$ and accompanying text.

387. See supra notes 19-20, 25.

388. See supra notes $115-116$ and accompanying text.

389. See supra note 114.

390. See supra notes 104-113 and accompanying text.

391. See GoldSTEIN, supra note 7, at 125-26, 134-35.

392. See supra note 20 and accompanying text.

393. See GolDSTEIN, supra note 7, at 94 ("Unless an extraordinary effort is made, lawyers will probably continue to put only conclusionary questions to experts, usually cast in the words of the insanity test itself. And experts will come to believe 'the law' is not interested in a detailed description of the defendant's mental state but only in the answers to the test questions."); supra note 17 (referring to model direct examination and expert testimony).

394. See Bonnie, supra note 328 , at 62 ; Goldstein, supra note 7 , at 105; FingaretTe, supra note 52, at 239-40.

395. See supra note 17 (referring to model direct examination and expert testimony).

396. Detailed reports are particularly important given the high percentage of cases adjudicated outside of the trial process. See supra note 13. 
in sanity evaluations. ${ }^{397}$ Training materials and practice guides provide methodologies for comprehensive assessment ${ }^{398}$ and generation of reports. ${ }^{399}$ Experts should also provide the trier of fact with more of the reasoning supporting their ultimate conclusions to allow jurors to perform their moral and legal function. ${ }^{400}$ Although the wording of insanity tests does not appear to matter to verdicts rendered, ${ }^{401}$ juror decision-making studies have found that jurors pay great care to expert testimony. ${ }^{402}$ Indeed, some evidence suggests that jurors would appreciate more of it, ${ }^{403}$ particularly from defense forensic expert witnesses. ${ }^{404}$ And history

397. See supra note 15.

398. See Amanda L. Reed \& Patricia A. Zapf, Criminal Forensic Assessment, in Handbook of Forensic Mental Health Services 79, 79-103 (Ronald Roesch \& Alana N. Cook eds., 2017); Janofsky et al., supra note 15, at S21-S26; MELTON ET AL., supra note 5, § 8.06 .

399. See Janofsky et al., supra note 15, at S26-S28.

400. See supra notes 15-16 and accompanying text.

401. See, e.g., Norman J. Finkel, Ray Shaw, Susan Bercaw \& Juliann Koch, Insanity Defenses: From the Jurors' Perspective, 9 Law \& Psych. Rev. 77, 83-84 (1985) (finding, in a study of 132 undergraduates, no overall significant differences among six instructions and tests of insanity); Ronald L. Poulson et al., Mock Jurors' Insanity Defense Verdict Selections: The Role of Evidence, Attitudes, and Verdict Options, 12 J. Soc. Behav. \& Personality 743, 752 (1997); James R.P. Ogloff, A Comparison of Insanity Defense Standards on Juror Decision Making, 15 Law \& Hum. Behav. 509, 522-23 (1991) (finding, in experiments involving 177 and 226 undergraduates, no significant effects on mock jurors' verdicts for insanity instructions (including no instructions), the assignment of burden of proof, or standard of proof).

402. See Rita M. James, Status and Competence of Jurors, 64 Am. J. Soc. 563, 566 \& tbl. 3 (1959) (finding, in a study of 240 actual jurors in a mock insanity case dominated by psychiatric expert testimony, that jurors in each educational category exhibited a very high percentage -71 to 78 percent - of accurate and pertinent comments concerning the recall of testimony); Rita M. James, Jurors' Assessment of Criminal Responsibility, 7 Soc. Probs. 58, 65 (1959) (analyzing the deliberations of ten juries in an insanity case and observing that jurors "paid careful attention to the testimony of the two [defense] experts," and, in each deliberation, discussed and expressed strong opinions about it). James is the maiden name of Rita Simon, a preeminent scholar of remarkable breadth.

403. See Rita M. James, Jurors' Evaluation of Psychiatric Testimony, 21 Oніо STATE L.J. $75,84-85$ (1960) (finding, in a sample of 816 jurors, that $44 \%$ of jurors who found the defendant NGRI, but only $29 \%$ of jurors who found the defendant guilty, wished they had been provided more information from defense psychiatric expert witnesses).

404. Id. at $84,87-88$ (finding the overwhelming majority (74\%) of sample jurors found the two defense psychiatric witnesses helpful and rating the two defense psychiatrists more important than the six other witnesses in the insanity trial, with the exception of the complaining witnesses); Ogloff, supra note 401, at 525-26 (finding that student mock jurors identified expert psychiatric testimony to be most important when determining whether to find a defendant NGRI); Karen E. Whittemore \& James R.P. Ogloff, Factors that Influence Jury Decision Making: Dispositional Instructions and Mental State at the Time of the Trial, 19 LAW \& Hum. BeHAV. 283, 295-96 \& tbl.5 (1995) (finding, in a study of 349 student mock jurors, that the two most important factors listed by participants as important in deciding the defendant's verdict were mental state prior to the offense $(n=87)$ and expert testimony $(n=72))$. However, other research indicates that accurate identification of the factors leading to decisions may be elusive. See Richard E. Nisbett \& Timothy DeCamp Wilson, Telling More 
proves that testimony of expert witnesses evincing a broader understanding of significant impairment and irresponsibility can change public conceptions of insanity, even without a change in the wording of the insanity test. ${ }^{405}$ Given the large gap between medical and some courtroom actors' legal understanding of the key functionality in moral incapacity (knowing or possibly appreciating wrongfulness $)^{406}$ - and evidence of narrow conceptions of insanity amongst the public ${ }^{407}$ - testimony on disordered reasoning, including reasoning impairments associated with delusions, is essential for the law to keep pace with evolving medical knowledge and to keep the responsibility inquiry tethered to moral blameworthiness.

Than We Can Know: Verbal Reports on Mental Processes, 84 Psych. Rev. 231 (1977).

405. See Joel Peter Eigen, Delusion in the Courtroom: The Role of Partial Insanity in Early Forensic Testimony, 35 MED. HIST. 25, 38-48 (1991) (tracing how expert medical witnesses in London insanity trials between the years 1825 and 1843 used court testimony to redefine the meaning of "know," change the content of the legal test of insanity from global to partial, and shift jurors from "an exclusively intellectualist conception of the mind to a consideration of the potency of will and emotion in human, and particularly criminal behavior"); JOEL PETER Eigen, Witnessing Insanity: Maness and Mad-Doctors in the English Court (1995) (showing how the understanding of madness changed over time, including the treatment of delusions and the increasing role of impairment of will, through a systematic investigation of medical testimony in British insanity trials from 1760 to 1843).

406. See supra notes $22,25$.

407. See Jennifer L. Skeem \& Stephen L. Golding, Describing Jurors' Personal Conceptions of Insanity and Their Relationship to Case Judgments, 7 Psych. PuB. PoL'Y \& L. 561, 581, 589-90, 601 (2001) (finding, in a series of studies with former venirepersons and students, that jurors harbor complex, multifaceted prototypes of insanity and identifying three broad prototypes for insanity that share the common characteristics of symptoms of psychosis, multiple impairments at the time of the crime, and mental states supported by expert evidence). 


\section{APPENDIX: INSANITY STANDARDS IN THE UNITED STATES 408}

\begin{tabular}{|c|c|c|c|c|c|c|c|c|c|}
\hline \multirow[b]{2}{*}{ Jurisdiction } & \multirow[b]{2}{*}{$\begin{array}{c}\text { Mental } \\
\text { disease }^{409}\end{array}$} & \multicolumn{4}{|c|}{ Cognitive Incapacity } & \multicolumn{4}{|c|}{ Moral Incapacity } \\
\hline & & $\begin{array}{c}\text { Actual } \\
\text { lack }\end{array}$ & Incapacity & $\begin{array}{c}\text { Level of } \\
\text { understanding }\end{array}$ & Nature/quality & $\begin{array}{c}\text { Actual } \\
\text { lack }\end{array}$ & Incapacity & $\begin{array}{c}\text { Level of } \\
\text { understanding }\end{array}$ & Wrongfulness \\
\hline Alabama $^{410}$ & $\begin{array}{c}\text { Severe } \\
\text { mental } \\
\text { disease or } \\
\text { defect }\end{array}$ & & Unable & Appreciate & $\begin{array}{l}\text { Nature and } \\
\text { quality of his } \\
\text { acts }\end{array}$ & & Unable & Appreciate & $\begin{array}{l}\text { Wrongfulness } \\
\text { of his acts }\end{array}$ \\
\hline Arizona $^{411}$ & $\begin{array}{c}\text { Mental } \\
\text { disease or } \\
\text { defect of } \\
\text { such severity }\end{array}$ & & & & & Did not & & Know & $\begin{array}{l}\text { Criminal act } \\
\text { was wrong }\end{array}$ \\
\hline Arkansas $^{412}$ & $\begin{array}{c}\text { Mental } \\
\text { disease or } \\
\text { defect }\end{array}$ & & & & & & $\begin{array}{l}\text { Lacked the } \\
\text { capacity }\end{array}$ & Appreciate & $\begin{array}{l}\text { Criminality of } \\
\text { his or her } \\
\text { conduct }\end{array}$ \\
\hline
\end{tabular}

408. These statutory references were compiled by the dissent in Kahler v. Kansas, $140 \mathrm{~S}$. Ct. 1021, 1051-59 (2020) (Breyer, J., dissenting). For ease of presentation, volitional components of insanity tests appear in the relevant jurisdictions' footnotes. Three unique formulations of the insanity defense exist. First, New Hampshire provides: "A defendant asserting an insanity defense must prove two elements: first, that at the time he acted, he was suffering from a mental disease or defect; and, second, that a mental disease or defect caused his actions." State v. Fichera, 903 A.2d 1030, 1034 (N.H. 2006) (citing State v. Abbott, 503 A.2d 791, 794 (N.H. 1985)). Second, in North Dakota,

[a]n individual is not criminally responsible for criminal conduct if, as a result of mental disease or defect existing at the time the conduct occurs:

a. The individual lacks substantial capacity to comprehend the harmful nature or consequences of the conduct, or the conduct is the result of a loss or serious distortion of the individual's capacity to recognize reality; and

b. It is an essential element of the crime charged that the individual act willfully.

N.D. Cent. Code $\S 12.1-04.1-01(1)$ (2012). Third, Alaska limits its affirmative defense to cognitive incapacity, see ALASKA STAT. § 12.47.010(a) (2018), and also permits mental health evidence to rebut the state of mind element of the offense, see id. §12.47.020. Finally, Idaho, Kansas, Montana, and Utah do not afford an affirmative insanity defense but allow mental health evidence to rebut the mens rea of a charged offense. See IDAHO CODE § 18-207(1), (3) (2016); Kan. Stat. AnN. § 21-5209 (Supp. 2018); Mont. Code AnN. § 46-14-102 (2019); UtAH CODE ANN. § 76-2-305 (West 2017).

409. This table does not include statutes' further specification of mental condition.

410. Ala. Code § 13A-3-1(a) (2015).

411. Ariz. Rev. Stat. AnN. § 13-502(A) (2010). Arizona has a "guilty except insane" verdict where the defendant, if successful in her affirmative defense of insanity, shall be sentenced "to a term of incarceration in the state department of corrections and ... placed under the jurisdiction of the psychiatric security review board and committed to a state mental health facility under the department of health services ... for that term." Id. § 13-502(D).

412. ArK. Code ANN. §§ 5-2-312, 5-2-301(6) (Supp. 2019). This insanity standard also includes a volitional prong, providing for acquittal when, due to a mental disease or defect, a defendant lacked the capacity at the time of the alleged offense to "[c]onform his or her 


\begin{tabular}{|c|c|c|c|c|c|c|c|c|c|}
\hline \multirow[b]{2}{*}{ Jurisdiction } & \multirow[b]{2}{*}{$\begin{array}{l}\text { Mental } \\
\text { disease }\end{array}$} & \multicolumn{4}{|c|}{ Cognitive Incapacity } & \multicolumn{4}{|c|}{ Moral Incapacity } \\
\hline & & $\begin{array}{c}\text { Actual } \\
\text { lack }\end{array}$ & Incapacity & $\begin{array}{c}\text { Level of } \\
\text { understanding }\end{array}$ & Nature/quality & $\begin{array}{c}\text { Actual } \\
\text { lack }\end{array}$ & Incapacity & $\begin{array}{c}\text { Level of } \\
\text { understanding }\end{array}$ & Wrongfulness \\
\hline California ${ }^{413}$ & & & Incapable & $\begin{array}{l}\text { Knowing or } \\
\text { understanding }\end{array}$ & $\begin{array}{c}\text { Nature and } \\
\text { quality of his or } \\
\text { her act }\end{array}$ & & Incapable & Distinguishing & $\begin{array}{l}\text { Right from } \\
\text { wrong at the } \\
\text { time of the } \\
\text { commission of } \\
\text { the offense }\end{array}$ \\
\hline Colorado ${ }^{414}$ & $\begin{array}{l}\text { So diseased } \\
\text { or defective } \\
\text { in mind }\end{array}$ & & & & & & Incapable & Distinguishing & $\begin{array}{c}\text { Right from } \\
\text { wrong with } \\
\text { respect to that } \\
\text { act }\end{array}$ \\
\hline Connecticut ${ }^{415}$ & $\begin{array}{l}\text { Mental } \\
\text { disease or } \\
\text { defect }\end{array}$ & & & & & & $\begin{array}{l}\text { Lacked } \\
\text { substantial } \\
\text { capacity }\end{array}$ & Appreciate & $\begin{array}{l}\text { Wrongfulness } \\
\text { of his conduct }\end{array}$ \\
\hline Delaware ${ }^{416}$ & $\begin{array}{c}\text { Mental } \\
\text { illness or } \\
\text { serious } \\
\text { mental } \\
\text { disorder }\end{array}$ & & & & & & $\begin{array}{l}\text { Lacked } \\
\text { substantial } \\
\text { capacity to }\end{array}$ & Appreciate & $\begin{array}{l}\text { Wrongfulness } \\
\text { of his conduct }\end{array}$ \\
\hline Florida $^{417}$ & $\begin{array}{l}\text { Mental } \\
\text { infirmity, } \\
\text { disease, or } \\
\text { defect }\end{array}$ & Did not & & Know & $\begin{array}{l}\text { What he or she } \\
\text { was doing or its } \\
\text { consequences }\end{array}$ & Did not & & Know & $\begin{array}{l}\text { What he or } \\
\text { she was doing } \\
\text { was wrong }\end{array}$ \\
\hline Georgia $^{418}$ & & & & & & & $\begin{array}{l}\text { Did not } \\
\text { have } \\
\text { mental } \\
\text { capacity }\end{array}$ & To distinguish & $\begin{array}{l}\text { Between right } \\
\text { and wrong in } \\
\text { relation to } \\
\text { such act, } \\
\text { omission, or } \\
\text { negligence }\end{array}$ \\
\hline Hawaiii ${ }^{419}$ & $\begin{array}{l}\text { Physical or } \\
\text { mental } \\
\text { disease, } \\
\text { disorder, or } \\
\text { defect }\end{array}$ & & & & & & $\begin{array}{l}\text { Lacks } \\
\text { substantial } \\
\text { capacity }\end{array}$ & To appreciate & $\begin{array}{l}\text { Wrongfulness } \\
\text { of the person's } \\
\text { conduct }\end{array}$ \\
\hline
\end{tabular}

conduct to the requirements of the law." Id. at $\S 5-2-301(6)$.

413. Cal. Penal Code $\S 25(b)$ (West 2014).

414. Colo. Rev. Stat. § 16-8-101.5(1) (2019).

415. Conn. Gen. Stat. § 53a-13(a) (2017). This insanity standard also includes a volitional prong, providing for acquittal when, due to a mental disease or defect, a defendant lacked the substantial capacity at the time of the alleged offense to "control his conduct within the requirements of the law." Id.

416. Del. Code AnN. tit. 11, § 401(a) (2015).

417. FLA. STAT. § 775.027(1) (2018).

418. GA. CODE ANN. § 16-3-2 (2019). Georgia also has a delusional compulsion statute that provides: "A person shall not be found guilty of a crime when, at the time of the act, omission, or negligence constituting the crime, the person, because of mental disease, injury, or congenital deficiency, acted as he did because of a delusional compulsion as to such act which overmastered his will to resist committing the crime." Id. § 16-3-3.

419. Haw. Rev. Stat. § 704-400(1) (2014). This insanity standard also includes a volitional prong, providing for acquittal when, due to a physical or mental disease, disorder, or defect, a defendant lacked the substantial capacity at the time of the alleged offense to 


\begin{tabular}{|c|c|c|c|c|c|c|c|c|c|}
\hline \multirow[b]{2}{*}{ Jurisdiction } & \multirow{2}{*}{$\begin{array}{l}\text { Mental } \\
\text { disease }\end{array}$} & \multicolumn{4}{|c|}{ Cognitive Incapacity } & \multicolumn{4}{|c|}{ Moral Incapacity } \\
\hline & & $\begin{array}{c}\text { Actual } \\
\text { lack }\end{array}$ & Incapacity & $\begin{array}{c}\text { Level of } \\
\text { understanding }\end{array}$ & Nature/quality & $\begin{array}{c}\text { Actual } \\
\text { lack }\end{array}$ & Incapacity & $\begin{array}{c}\text { Level of } \\
\text { understanding }\end{array}$ & Wrongfulness \\
\hline Illinois $^{420}$ & $\begin{array}{c}\text { Mental } \\
\text { disease or } \\
\text { mental } \\
\text { defect }\end{array}$ & & & & & & $\begin{array}{c}\text { Lacks } \\
\text { substantial } \\
\text { capacity }\end{array}$ & To appreciate & $\begin{array}{l}\text { Criminality of } \\
\text { his conduct }\end{array}$ \\
\hline Indiana $^{421}$ & $\begin{array}{c}\text { Mental } \\
\text { disease or } \\
\text { defect }\end{array}$ & & & & & & Unable & To appreciate & $\begin{array}{l}\text { Wrongfulness } \\
\text { of the conduct }\end{array}$ \\
\hline Iowa $^{422}$ & $\begin{array}{l}\text { Such a } \\
\text { diseased or } \\
\text { deranged } \\
\text { condition of } \\
\text { the mind }\end{array}$ & & Incapable & Know & $\begin{array}{l}\text { Nature and } \\
\text { quality of the } \\
\text { act }\end{array}$ & & Incapable & Distinguishing & $\begin{array}{l}\text { Right and } \\
\text { wrong in } \\
\text { relation to that } \\
\text { act }\end{array}$ \\
\hline Kentucky $^{423}$ & $\begin{array}{c}\text { Mental } \\
\text { illness or } \\
\text { intellectual } \\
\text { disability }\end{array}$ & & & & & & $\begin{array}{c}\text { Lacks } \\
\text { substantial } \\
\text { capacity }\end{array}$ & Appreciate & $\begin{array}{c}\text { Wrongfulness } \\
\text { of the person's } \\
\text { conduct }\end{array}$ \\
\hline Louisiana $^{424}$ & $\begin{array}{c}\text { Mental } \\
\text { disease or } \\
\text { mental } \\
\text { defect }\end{array}$ & & & & & & Incapable & Distinguishing & $\begin{array}{c}\text { Right and } \\
\text { wrong with } \\
\text { reference to } \\
\text { the conduct in } \\
\text { question }\end{array}$ \\
\hline Maine $^{425}$ & $\begin{array}{l}\text { Mental } \\
\text { disease or } \\
\text { defect }\end{array}$ & & & & & & $\begin{array}{c}\text { Lacked } \\
\text { substantial } \\
\text { capacity }\end{array}$ & Appreciate & $\begin{array}{l}\text { Wrongfulness } \\
\text { of the criminal } \\
\text { conduct }\end{array}$ \\
\hline Maryland $^{426}$ & $\begin{array}{c}\text { Mental } \\
\text { disorder or } \\
\text { mental } \\
\text { retardation }\end{array}$ & & & & & & $\begin{array}{c}\text { Lacks } \\
\text { substantial } \\
\text { capacity }\end{array}$ & To appreciate & $\begin{array}{l}\text { Criminality of } \\
\text { that conduct }\end{array}$ \\
\hline$\underset{427}{\text { Massachusetts }_{4}}$ & $\begin{array}{c}\text { Mental } \\
\text { disease or } \\
\text { defect }\end{array}$ & & & & & & $\begin{array}{c}\text { Lack } \\
\text { substantial } \\
\text { capacity }\end{array}$ & Appreciate & $\begin{array}{l}\text { Criminality of } \\
\text { his conduct }\end{array}$ \\
\hline
\end{tabular}

"conform the person's conduct to the requirements of the law." Id.

420. 720 Ill. Comp. Stat. 5/6-2(a) (2012).

421. IND. CODE $\S 35-41-3-6($ a) (2019).

422. IOWA CODE $\S 701.4$ (2016).

423. Ky. Rev. Stat. AnN. § 504.020(1) (West 2016). This insanity standard also includes a volitional prong, providing for acquittal when, due to a mental illness or intellectual disability, a defendant lacked the substantial capacity at the time of the alleged offense to "conform his conduct to the requirements of law." Id.

424. LA. STAT. ANN. § 14:14 (2016).

425. Me. Stat. tit. 17-A, § 39(1) (2006).

426. Md. Code AnN., Crim. Proc. § 3-109(a) (West 2018). This insanity standard also includes a volitional prong, providing for acquittal when, due to a mental disorder or mental retardation, a defendant lacked the substantial capacity at the time of the alleged offense to "conform that conduct to the requirements of law." Id.

427. Commonwealth v. Lawson, 62 N.E.3d 22, 28 (Mass. 2016). This insanity standard also includes a volitional prong, providing for acquittal when, after the defendant has admitted some evidence of irresponsibility, the Commonwealth fails to prove beyond a reasonable doubt that the defendant did not have a mental disease or defect at the time of the crime that caused the defendant to lack the substantial capacity to "conform his conduct to the 


\begin{tabular}{|c|c|c|c|c|c|c|c|c|c|}
\hline \multirow[b]{2}{*}{ Jurisdiction } & \multirow[b]{2}{*}{$\begin{array}{l}\text { Mental } \\
\text { disease }\end{array}$} & \multicolumn{4}{|c|}{ Cognitive Incapacity } & \multicolumn{4}{|c|}{ Moral Incapacity } \\
\hline & & $\begin{array}{c}\text { Actual } \\
\text { lack }\end{array}$ & Incapacity & $\begin{array}{c}\text { Level of } \\
\text { understanding }\end{array}$ & Nature/quality & $\begin{array}{c}\text { Actual } \\
\text { lack }\end{array}$ & Incapacity & $\begin{array}{c}\text { Level of } \\
\text { understanding }\end{array}$ & Wrongfulness \\
\hline Michigan $^{428}$ & $\begin{array}{l}\text { Mental } \\
\text { illness }\end{array}$ & & $\begin{array}{c}\text { Lacks } \\
\text { substantial } \\
\text { capacity }\end{array}$ & Appreciate & $\begin{array}{l}\text { Nature and } \\
\text { quality of his or } \\
\text { her conduct }\end{array}$ & & $\begin{array}{c}\text { Lacks } \\
\text { substantial } \\
\text { capacity }\end{array}$ & Appreciate & $\begin{array}{l}\text { Wrongfulness } \\
\text { of his or her } \\
\text { conduct }\end{array}$ \\
\hline Minnesota ${ }^{429}$ & $\begin{array}{l}\text { Laboring } \\
\text { under such a } \\
\text { defect of } \\
\text { reason, from } \\
\text { mental } \\
\text { illness or } \\
\text { cognitive } \\
\text { impairment }\end{array}$ & Not to & & Know & $\begin{array}{c}\text { Nature of the } \\
\text { act }\end{array}$ & Not to & & Know & $\begin{array}{l}\text { [The act] was } \\
\text { wrong }\end{array}$ \\
\hline Mississippi ${ }^{430}$ & $\begin{array}{l}\text { Laboring } \\
\text { under such } \\
\text { defect of } \\
\text { reason from } \\
\text { disease of } \\
\text { the mind }\end{array}$ & Not to & & Know & $\begin{array}{l}\text { Nature and } \\
\text { quality of the } \\
\text { act }\end{array}$ & Did not & & Know & $\begin{array}{c}\text { What he was } \\
\text { doing was } \\
\text { wrong }\end{array}$ \\
\hline Missouri $^{431}$ & $\begin{array}{l}\text { Mental } \\
\text { disease or } \\
\text { defect }\end{array}$ & & Incapable & $\begin{array}{l}\text { Knowing and } \\
\text { appreciating }\end{array}$ & $\begin{array}{l}\text { Nature [or] } \\
\text { quality of his or } \\
\text { her conduct }\end{array}$ & & Incapable & $\begin{array}{l}\text { Knowing and } \\
\text { appreciating }\end{array}$ & Wrongfulness \\
\hline Nebraska $^{432}$ & $\begin{array}{l}\text { Mental } \\
\text { disease or } \\
\text { defect }\end{array}$ & Did not & & $\begin{array}{l}\text { Know or } \\
\text { understand }\end{array}$ & $\begin{array}{l}\text { Nature and } \\
\text { consequences } \\
\text { of his or her } \\
\text { actions }\end{array}$ & Did not & & Know & $\begin{array}{c}\text { Difference } \\
\text { between right } \\
\text { and wrong }\end{array}$ \\
\hline Nevada ${ }^{433}$ & $\begin{array}{l}\text { A delusional } \\
\text { state }\end{array}$ & & Cannot & $\begin{array}{l}\text { Know or } \\
\text { understand }\end{array}$ & $\begin{array}{l}\text { Nature and } \\
\text { capacity of his } \\
\text { act }\end{array}$ & & Cannot & Appreciate & $\begin{array}{l}\text { Wrongfulness } \\
\text { of his act, that } \\
\text { is, that the act } \\
\text { is not } \\
\text { authorized by } \\
\text { law }\end{array}$ \\
\hline New Jersey ${ }^{434}$ & $\begin{array}{l}\text { Laboring } \\
\text { under such a } \\
\text { defect of } \\
\text { reason, from } \\
\text { disease of } \\
\text { the mind }\end{array}$ & Not & & To know & $\begin{array}{l}\text { Nature and } \\
\text { quality of the } \\
\text { act }\end{array}$ & Not & & Know & $\begin{array}{l}\text { What he was } \\
\text { doing was } \\
\text { wrong }\end{array}$ \\
\hline
\end{tabular}

requirements of law." $I d$.

428. Мich. Сомp. Laws $\S 768.21 \mathrm{a}(1)$ (2000); id. $\S 330.1400$. This insanity standard also includes a volitional prong, providing for acquittal when, due to a mental illness, a defendant lacked the substantial capacity at the time of the alleged offense to "conform his or her conduct to the requirements of the law." $I d$. $\S 768.21 \mathrm{a}(1)$.

429. Minn. Stat. § 611.026 (2019).

430. Hearn v. State, 3 So. 3d 722, 738 (Miss. 2008).

431. Mo. Rev. Stat. § 562.086(1) (2016).

432. State v. Hotz, 795 N.W.2d 645, 653 (Neb. 2011).

433. Finger v. State, 27 P.3d 66, 84-85 (Nev. 2001).

434. N.J. Stat. AnN. § 2C:4-1 (West 2015). 


\begin{tabular}{|c|c|c|c|c|c|c|c|c|c|}
\hline \multirow[b]{2}{*}{ Jurisdiction } & \multirow{2}{*}{$\begin{array}{l}\text { Mental } \\
\text { disease }\end{array}$} & \multicolumn{4}{|c|}{ Cognitive Incapacity } & \multicolumn{4}{|c|}{ Moral Incapacity } \\
\hline & & $\begin{array}{c}\text { Actual } \\
\text { lack }\end{array}$ & Incapacity & $\begin{array}{c}\text { Level of } \\
\text { understanding }\end{array}$ & Nature/quality & $\begin{array}{c}\text { Actual } \\
\text { lack }\end{array}$ & Incapacity & $\begin{array}{c}\text { Level of } \\
\text { understanding }\end{array}$ & Wrongfulness \\
\hline New Mexico ${ }^{435}$ & $\begin{array}{l}\text { Disease of } \\
\text { the mind }\end{array}$ & Did not & & Know & $\begin{array}{c}\text { Nature and } \\
\text { quality of the } \\
\text { act }\end{array}$ & Did not & & Know & $\begin{array}{l}\text { The act was } \\
\text { wrong }\end{array}$ \\
\hline New York ${ }^{436}$ & $\begin{array}{c}\text { Mental } \\
\text { disease or } \\
\text { defect }\end{array}$ & & $\begin{array}{c}\text { Lacked } \\
\text { substantial } \\
\text { capacity }\end{array}$ & $\begin{array}{l}\text { To know or } \\
\text { appreciate }\end{array}$ & $\begin{array}{c}\text { Nature and } \\
\text { consequences } \\
\text { of such conduct }\end{array}$ & & $\begin{array}{c}\text { Lacked } \\
\text { substantial } \\
\text { capacity } \\
\end{array}$ & $\begin{array}{l}\text { To know or } \\
\text { appreciate }\end{array}$ & $\begin{array}{l}\text { Such conduct } \\
\text { was wrong }\end{array}$ \\
\hline $\begin{array}{c}\text { North } \\
\text { Carolina }^{437}\end{array}$ & $\begin{array}{l}\text { Laboring } \\
\text { under such a } \\
\text { defect of } \\
\text { reason, from } \\
\text { disease of } \\
\text { the mind }\end{array}$ & & Incapable & Knowing & $\begin{array}{l}\text { Nature and } \\
\text { quality of the } \\
\text { act }\end{array}$ & & Incapable & Distinguishing & $\begin{array}{l}\text { Between right } \\
\text { and wrong in } \\
\text { relation to } \\
\text { such act }\end{array}$ \\
\hline Ohio $^{438}$ & $\begin{array}{c}\text { Severe } \\
\text { mental } \\
\text { disease or } \\
\text { defect } \\
\end{array}$ & & & & & Did not & & Know & $\begin{array}{l}\text { Wrongfulness } \\
\text { of the person's } \\
\text { acts }\end{array}$ \\
\hline \multirow[b]{2}{*}{ Oklahoma $^{439}$} & \multirow{2}{*}{$\begin{array}{l}\text { Nature } \\
\text { prong: } \\
\text { disability of } \\
\text { reason or } \\
\text { disease of } \\
\text { the mind } \\
\\
\text { Wrongful- } \\
\text { ness prong: } \\
\text { mental } \\
\text { disability }\end{array}$} & \multirow[b]{2}{*}{ Does not } & & \multirow[b]{2}{*}{ Understand } & \multirow[b]{2}{*}{$\begin{array}{l}\text { Nature or } \\
\text { consequences } \\
\text { of his acts or } \\
\text { omissions }\end{array}$} & $\begin{array}{c}\text { Does } \\
\text { not }\end{array}$ & & Know & $\begin{array}{l}\text { Acts are } \\
\text { wrong }\end{array}$ \\
\hline & & & & & & & Unable & To distinguish & $\begin{array}{l}\text { Right from } \\
\text { wrong with } \\
\text { respect to his } \\
\text { acts }\end{array}$ \\
\hline Oregon $^{440}$ & $\begin{array}{l}\text { Qualifying } \\
\text { mental } \\
\text { disorder }\end{array}$ & & & & & & $\begin{array}{c}\text { Lacks } \\
\text { substantial } \\
\text { capacity }\end{array}$ & To appreciate & $\begin{array}{l}\text { Criminality of } \\
\text { the conduct }\end{array}$ \\
\hline Pennsylvania ${ }^{441}$ & $\begin{array}{l}\text { Laboring } \\
\text { under such a } \\
\text { defect of } \\
\text { reason, from } \\
\text { disease of } \\
\text { the mind }\end{array}$ & Not & & To know & $\begin{array}{l}\text { Nature and } \\
\text { quality of the } \\
\text { act }\end{array}$ & Not & & Know & $\begin{array}{l}\text { He was doing } \\
\text { what was } \\
\text { wrong }\end{array}$ \\
\hline
\end{tabular}

435. State v. Hartley, 565 P.2d 658, 660 (N.M. 1977). "This rule prevailed in New Mexico until 1954 when this court in State v. White, 270 P.2d 727 (1954) made a careful analysis of the authorities and made a limited extension of the M'Naghten rule, adding a third ingredient. The court held that if the accused, [] as a result of disease of the mind 'was incapable of preventing himself from committing' the crime, he could be adjudged insane and thereby relieved of legal responsibility for what would otherwise be a criminal act." Id.

436. N.Y. Penal Law $\S 40.15$ (McKinney 2009).

437. State v. Thompson, 402 S.E.2d 386, 390 (N.C. 1991).

438. Ohio Rev. Code AnN. § 2901.01(A)(14) (LexisNexis 2014).

439. Cheney v. State, 909 P.2d 74, 90 (Okla. Crim. App. 1995).

440. OR. REv. STAT. § 161.295(1) (2019). This insanity standard also includes a volitional prong, providing for acquittal when, due to a mental disorder, a defendant lacked the substantial capacity at the time of the alleged offense to "conform the conduct to the requirements of law." Id.

441. 18 Pa. Cons. Stat. § 314(d) (2015); M'Naghten's Case, 8 Eng. Rep. 718, 722, $10 \mathrm{Cl}$. \& Fin. 200, 210 (1843). 


\begin{tabular}{|c|c|c|c|c|c|c|c|c|c|}
\hline \multirow[b]{2}{*}{ Jurisdiction } & \multirow[b]{2}{*}{$\begin{array}{l}\text { Mental } \\
\text { disease }\end{array}$} & \multicolumn{4}{|c|}{ Cognitive Incapacity } & \multicolumn{4}{|c|}{ Moral Incapacity } \\
\hline & & $\begin{array}{c}\text { Actual } \\
\text { lack }\end{array}$ & Incapacity & $\begin{array}{c}\text { Level of } \\
\text { understanding }\end{array}$ & Nature/quality & $\begin{array}{c}\text { Actual } \\
\text { lack }\end{array}$ & Incapacity & $\begin{array}{c}\text { Level of } \\
\text { understanding }\end{array}$ & Wrongfulness \\
\hline Rhode Island ${ }^{442}$ & $\begin{array}{l}\text { Mental } \\
\text { disease or } \\
\text { defect }\end{array}$ & & & & & & $\begin{array}{c}\text { Capacity } \\
\text { was so } \\
\text { substant- } \\
\text { ially } \\
\text { impaired } \\
\text { that he } \\
\text { cannot } \\
\text { justly be } \\
\text { held } \\
\text { responsible }\end{array}$ & To appreciate & $\begin{array}{l}\text { Wrongfulness } \\
\text { of his conduct }\end{array}$ \\
\hline \multirow{2}{*}{$\begin{array}{c}\text { South } \\
\text { Carolina }{ }^{443}\end{array}$} & \multirow{2}{*}{$\begin{array}{c}\text { Mental } \\
\text { disease or } \\
\text { defect }\end{array}$} & & & & & & $\begin{array}{l}\text { Lacked the } \\
\text { capacity }\end{array}$ & Distinguish & $\begin{array}{l}\text { Moral or legal } \\
\text { right from } \\
\text { moral or legal } \\
\text { wrong }\end{array}$ \\
\hline & & & & & & & $\begin{array}{l}\text { Lacked the } \\
\text { capacity }\end{array}$ & Recognize & $\begin{array}{l}\text { The particular } \\
\text { act charged as } \\
\text { morally or } \\
\text { legally wrong }\end{array}$ \\
\hline South Dakota ${ }^{444}$ & $\begin{array}{l}\text { The } \\
\text { condition of } \\
\text { a person } \\
\text { temporarily } \\
\text { or partially } \\
\text { deprived of } \\
\text { reason }\end{array}$ & & & & & & Incapable & Knowing & $\begin{array}{l}\text { Wrongfulness } \\
\text { of act }\end{array}$ \\
\hline Tennessee $e^{445}$ & $\begin{array}{c}\text { Severe } \\
\text { mental } \\
\text { disease or } \\
\text { defect }\end{array}$ & & Unable & To appreciate & $\begin{array}{l}\text { Nature of the } \\
\text { defendant's } \\
\text { acts }\end{array}$ & & Unable & To appreciate & $\begin{array}{l}\text { Wrongfulness } \\
\text { of the } \\
\text { defendant's } \\
\text { acts }\end{array}$ \\
\hline Texas $^{446}$ & $\begin{array}{c}\text { Severe } \\
\text { mental } \\
\text { disease or } \\
\text { defect }\end{array}$ & & & & & Did not & & Know & $\begin{array}{l}\text { His conduct } \\
\text { was wrong }\end{array}$ \\
\hline Vermont $^{447}$ & $\begin{array}{l}\text { Mental } \\
\text { disease or } \\
\text { defect }\end{array}$ & & & & & & $\begin{array}{l}\text { Lacks } \\
\text { adequate } \\
\text { capacity }\end{array}$ & To appreciate & $\begin{array}{l}\text { Criminality of } \\
\text { his or her } \\
\text { conduct }\end{array}$ \\
\hline
\end{tabular}

442. State v. Carpio, 43 A.3d 1, 12 n.10 (R.I. 2012). In addition, "[a] person is not responsible for criminal conduct if at the time of such conduct, as a result of mental disease or defect, his capacity . . . to conform his conduct to the requirements of the law [was] so substantially impaired that he cannot justly be held responsible." Id.

443. S.C. CODE ANN. § 17-24-10(A) (2014).

444. S.D. CoDIFIED LAWS $\S 22-1-2(20)$ (2017).

445. Tenn. Code AnN. § 39-11-501(a) (2018).

446. Tex. Penal Code Ann. § 8.01(a) (West 2011).

447. Vт. Stat. AnN. tit. 13, § 4801(a)(1) (2019). This insanity standard also includes a volitional prong, providing for acquittal when, due to a mental disease or defect, a defendant lacked adequate capacity at the time of the alleged offense to "conform his or her conduct to the requirements of law." Id. 


\begin{tabular}{|c|c|c|c|c|c|c|c|c|c|}
\hline \multirow[b]{2}{*}{ Jurisdiction } & \multirow[b]{2}{*}{$\begin{array}{l}\text { Mental } \\
\text { disease }\end{array}$} & \multicolumn{4}{|c|}{ Cognitive Incapacity } & \multicolumn{4}{|c|}{ Moral Incapacity } \\
\hline & & $\begin{array}{c}\text { Actual } \\
\text { lack }\end{array}$ & Incapacity & $\begin{array}{c}\text { Level of } \\
\text { understanding }\end{array}$ & Nature/quality & $\begin{array}{c}\text { Actual } \\
\text { lack }\end{array}$ & Incapacity & $\begin{array}{c}\text { Level of } \\
\text { understanding }\end{array}$ & Wrongfulness \\
\hline Virginia $^{448}$ & $\begin{array}{l}\text { Mental } \\
\text { disease or } \\
\text { defect }\end{array}$ & Did not & & Know & $\begin{array}{l}\text { Nature and } \\
\text { quality of the } \\
\text { act }\end{array}$ & Did not & & Know & $\begin{array}{c}\text { What he was } \\
\text { doing was } \\
\text { wrong }\end{array}$ \\
\hline Washington ${ }^{449}$ & $\begin{array}{l}\text { Mental } \\
\text { disease or } \\
\text { defect, the } \\
\text { mind of the } \\
\text { actor was } \\
\text { affected to } \\
\text { such an } \\
\text { extent that }\end{array}$ & & Unable & To perceive & $\begin{array}{l}\text { Nature and } \\
\text { quality of the } \\
\text { act }\end{array}$ & & Unable & To tell & $\begin{array}{l}\text { Right from } \\
\text { wrong with } \\
\text { reference to } \\
\text { the particular } \\
\text { act charged }\end{array}$ \\
\hline $\begin{array}{c}\text { West } \\
\text { Virginia }^{450}\end{array}$ & $\begin{array}{c}\text { Mental } \\
\text { disease or } \\
\text { defect }\end{array}$ & & & & & & $\begin{array}{l}\text { Lack the } \\
\text { capacity }\end{array}$ & To appreciate & $\begin{array}{l}\text { Wrongfulness } \\
\text { of his act }\end{array}$ \\
\hline Wisconsin $^{451}$ & $\begin{array}{c}\text { Mental } \\
\text { disease or } \\
\text { defect }\end{array}$ & & & & & & $\begin{array}{c}\text { Lacked } \\
\text { substantial } \\
\text { capacity }\end{array}$ & To appreciate & $\begin{array}{c}\text { Wrongfulness } \\
\text { of his or her } \\
\text { conduct }\end{array}$ \\
\hline Wyoming ${ }^{452}$ & $\begin{array}{c}\text { Mental } \\
\text { illness or } \\
\text { deficiency }\end{array}$ & & & & & & $\begin{array}{c}\text { Lacked } \\
\text { substantial } \\
\text { capacity }\end{array}$ & To appreciate & $\begin{array}{l}\text { Wrongfulness } \\
\text { of his or her } \\
\text { conduct }\end{array}$ \\
\hline Federal $^{453}$ & $\begin{array}{c}\text { Severe } \\
\text { mental } \\
\text { disease or } \\
\text { defect }\end{array}$ & & Unable & To appreciate & $\begin{array}{l}\text { Nature and } \\
\text { quality of his } \\
\text { acts }\end{array}$ & & Unable & To appreciate & $\begin{array}{l}\text { Wrongfulness } \\
\text { of his acts }\end{array}$ \\
\hline $\begin{array}{l}\text { District of } \\
\text { Columbia }^{454}\end{array}$ & $\begin{array}{c}\text { Mental } \\
\text { disease or } \\
\text { defect }\end{array}$ & & & & & & $\begin{array}{l}\text { Lacked } \\
\text { substantial } \\
\text { capacity }\end{array}$ & To recognize & $\begin{array}{l}\text { Wrongfulness } \\
\text { of his conduct }\end{array}$ \\
\hline
\end{tabular}

448. Orndorff v. Commonwealth, 691 S.E.2d 177, 179 n.5 (Va. 2010). "In addition, we have approved in appropriate cases the granting of an instruction defining an 'irresistible impulse' as a form of legal insanity. 'The irresistible impulse doctrine is applicable only to that class of cases where the accused is able to understand the nature and consequences of his act and knows it is wrong, but his mind has become so impaired by disease that he is totally deprived of the mental power to control or restrain his act." Id. (quoting Thompson v. Commonwealth, 70 S.E.2d 284, 292 (Va. 1952)).

449. WASH. REv. CODE $§ 9 A .12 .010$ (2015).

450. State v. Fleming, 784 S.E.2d 743, 751-52 (W. Va. 2016). An insanity acquittal can also be based on a lack of capacity to conform his acts to the requirements of law. Id.

451. Wis. STAT. § 971.15(1) (2016). An insanity acquittal can also be based on a lack of substantial capacity to "conform his ... conduct to the requirements of law." Id.

452. Wyo. StAT. AnN. § 7-11-304(a) (2019). An insanity acquittal can also be based on a lack of substantial capacity to "conform his conduct to the requirements of law." Id.

453. 18 U.S.C. $\S 17$.

454. Bethea v. United States, 365 A.2d 64, 79 \& n.30 (D.C. 1976). An insanity acquittal can also be based on a lack of a substantial capacity "to conform his conduct to the requirements of law." Id. 